\title{
The Role of Exercise in the Interplay between Myokines, Hepatokines, Osteokines, Adipokines, and Modulation of Inflammation for Energy Substrate Redistribution and Fat Mass Loss: A Review
}

\author{
Adrian M. Gonzalez-Gil ${ }^{1,2}$ and Leticia Elizondo-Montemayor 1,2,3,*(D) \\ 1 Tecnologico de Monterrey, Escuela de Medicina y Ciencias de la Salud, Ave. Morones Prieto 3000, \\ Monterrey N.L. 64710, Mexico; amgonzalezgil@hotmail.com \\ 2 Tecnologico de Monterrey, Center for Research in Clinical Nutrition and Obesity, Ave. Morones Prieto 300, \\ Monterrey N.L. 64710, Mexico \\ 3 Tecnologico de Monterrey, Cardiovascular and Metabolomics Research Group, Hospital Zambrano Hellion, \\ San Pedro Garza Garcia P.C. 66278, Mexico \\ * Correspondence: lelizond@tec.mx
}

Received: 26 May 2020; Accepted: 18 June 2020; Published: 26 June 2020

\begin{abstract}
Exercise is an effective strategy for preventing and treating obesity and its related cardiometabolic disorders, resulting in significant loss of body fat mass, white adipose tissue browning, redistribution of energy substrates, optimization of global energy expenditure, enhancement of hypothalamic circuits that control appetite-satiety and energy expenditure, and decreased systemic inflammation and insulin resistance. Novel exercise-inducible soluble factors, including myokines, hepatokines, and osteokines, and immune cytokines and adipokines are hypothesized to play an important role in the body's response to exercise. To our knowledge, no review has provided a comprehensive integrative overview of these novel molecular players and the mechanisms involved in the redistribution of metabolic fuel during and after exercise, the loss of weight and fat mass, and reduced inflammation. In this review, we explain the potential role of these exercise-inducible factors, namely myokines, such as irisin, IL-6, IL-15, METRNL, BAIBA, and myostatin, and hepatokines, in particular selenoprotein P, fetuin A, FGF21, ANGPTL4, and follistatin. We also describe the function of osteokines, specifically osteocalcin, and of adipokines such as leptin, adiponectin, and resistin. We also emphasize an integrative overview of the pleiotropic mechanisms, the metabolic pathways, and the inter-organ crosstalk involved in energy expenditure, fat mass loss, reduced inflammation, and healthy weight induced by exercise.
\end{abstract}

Keywords: exercise; physical activity; fat mass loss; obesity; energy substrate redistribution; myokines; hepatokines; osteokines; adipokines; inflammation

\section{Introduction}

Obesity, characterized by abdominal fat gain, is a complex multifactorial disease considered by many as a 21st century epidemic [1]. Its incidence is expected to continue given that the energy surplus results not only in increased body fat, specially abdominal fat, but also in numerous physiologic derangements and cardiometabolic complications and increased morbidity and mortality [1-9]. Currently considered a cornerstone in the management and prevention of obesity, exercise has been demonstrated to have a myriad of health benefits $[9,10]$. Of concern, less than $5 \%$ of adults from the U.S. follow the recommended guideline for physical activity of a minimum of $150 \mathrm{~min}$ per week [11].

Evidence suggests that M2 alternatively activated macrophage $(\mathrm{M} \varphi)$ infiltrates are crucial for beige and brown adipose tissue (BAT) activity and that proinflammatory cytokines impair BAT function [12]. 
In patients with obesity, BAT function is significantly impaired, partially explained by the systemic proinflammatory state and the accompanying catecholamine-resistance that ensues [13], which is driven by proinflammatory M1 M $\varphi$ and CD4+ Th1-cell infiltrates in adipose tissue (AT) [14]. Although by far more studied in rodents than in humans [15], induction of beige adipocytes by exercise or functional enhancement of existing BAT has shown to improve total energy expenditure and insulin sensitivity, contributing to fat and weight loss [16-19]. Furthermore, the hallmark systemic low-grade proinflammatory state that accompanies obesity has been described to contribute in part to insulin resistance in skeletal muscle (SkM) and in the liver, which compromises their normal metabolic functions [20]. In SkM, insulin resistance has been shown to impair glucose uptake and glycogen storage due to decreased glucose transporter 4 (GLUT4) translocation, a state that is maintained by the ectopic accumulation of lipids (lipotoxicity) that results from increased circulating free fatty acids and their impaired catabolism. These latter events are driven by reduced expression and/or function of fatty acid transporters and enzymes involved in lipid oxidation, which results in further impairment of signaling downstream of the insulin receptor [21] by DAG-induced activation of PKC and phosphorylation of serine residues in IRS proteins [20]. Of interest, exercise is known to upregulate proteins and enzymes that participate in fatty acid oxidation and to increase insulin sensitivity and glucose uptake in SkM [21], as well as to promote a generalized anti-inflammatory state [9]. In the liver, hepatic insulin resistance, among other effects, has proved to result in increased gluconeogenesis, lipogenesis, and synthesis of very-low-density lipoproteins (VLDL) [22] that carry cholesterol and triglycerides for their accretion in peripheral tissues; if this accretion is deregulated, it may lead to an atherogenic lipid profile, increased fat mass, and lipotoxicity. Additionally, if the capacity of the liver to synthesize and export lipids is overrun by excess substrate, intrahepatic lipid accumulation and steatosis eventually ensue, which have been described to exacerbate not only local, but also systemic insulin-resistance [23]. Interestingly, exercise is known to decrease hepatic steatosis [24]. Finally, obesity has also been associated with altered central regulation of energy expenditure and appetite, and it is generally agreed that exercise can positively influence central energy balance in the long term [25]. Altogether, considering the pleiotropic beneficial metabolic effects of exercise, the search for the mechanisms through which it favors fat mass loss and metabolic health has been an ongoing focus of interest. Of these, novel circulating molecules induced by exercise, such as myokines, hepatokines, osteokines, immune cytokines, and adipokines regulate metabolic pathways and inter-tissue crosstalk by means of autocrine, paracrine, and endocrine effects [2], and could thus be at least partially responsible for preventing, or even reverting, obesity and the obesity-associated metabolic dysfunction in target organs.

Myokines such as irisin, interleukin-6 (IL-6), interleukin-15 (IL-15), meteorin-like (METRNL), and $\beta$-aminoisobutyric acid (BAIBA) have been consistently shown to be released by SkM in response to exercise. These exert beneficial physiologic and metabolic effects not only in SkM itself but also in distant tissues such as white adipose tissue (WAT), bone, liver, the central nervous system (CNS), and cells of the immune system to drive a systemic anti-inflammatory and insulin-sensitive state, permissive for optimization of total-body energy expenditure $[5,7,26,27]$. Likewise, hepatokines such as FGF21, ANGPTL4, and follistatin, released during and after exercise, may influence WAT and SkM metabolism to favor redistribution of lipid-derived metabolic fuel towards catabolic pathways [4]. On the other hand, the detrimental hepatokines fetuin $\mathrm{A}$ and selenoprotein $\mathrm{P}$, which are increased in insulin-resistant states [23], could blunt the beneficial effects of exercise-inducible factors. The decrease of such unfavorable hepatokines and the reversal of the hepatic steatosis that frequently accompanies the obese state $[3,23]$ could be achieved with exercise interventions. Moreover, the osteokine osteocalcin $(\mathrm{OCN})$ is released by bone following bouts of exercise and cooperates with myokines to increase FFA utilization in multiple tissues [28]. The combined actions of these factors, either directly or indirectly, likely result in decreased triglyceride (TG) accretion in visceral fat depots and in increased mobilization and fatty acid oxidation (FAO) in the liver and SkM. These changes further increase available SkM bulk for glucose disposal, decreasing lipogenesis in both the liver and WAT and decreasing inflammatory mediators 
that result in insulin resistance, BAT dysfunction, and dysregulation of the hypothalamic neurons controlling energy balance. Furthermore, exercise-induced loss of visceral adipose tissue (VAT) could reestablish normal levels of the anorexigenic adipokine leptin, increase levels of the insulin-sensitizing and anti-inflammatory adipokine adiponectin, and decrease the levels of proinflammatory immune cytokines in general [6,9], thus promoting healthy weight maintenance and metabolic health. Further adding a level of complexity, exercise-inducible factors engage in intricate cross-regulation with one another and with the cytokines that determine inflammatory status, thus engaging in synergistic crosstalk while mitigating metabolic stress in target organs.

Literature on this topic is vast and has been reviewed by others but on a separate basis, by describing either individual molecules or groups of factors, proteins, hormones, or molecules [2-9,29]. However, to our knowledge, no review has yet provided a comprehensive integrative overview of these mostly novel molecular players. Hence, the aim of this review is to provide a state-of-the-art holistic view of the mechanisms through which exercise induces abdominal fat loss and maintains metabolic homeostasis and a healthy weight. Given the broad nature of this topic, for which we conducted an exhaustive literature search in the PubMed database, we sought to summarize the existing evidence in the form of a narrative review. We first describe the individual myokines, hepatokines, cytokines, osteokines, and adipokines that have been shown to be modified in response to exercise in adults and that, through either direct or indirect mechanisms, contribute to fat loss and weight loss. We then include both clinical and preclinical studies to highlight the possible mechanisms of these exercise-inducible factors. Finally, we integrate this information and propose a model of inter-organ crosstalk in which these molecules and their metabolic pathways interplay, through which exercise mediates its beneficial effects on fat loss, weight maintenance, and healthy metabolism. We also comprise a set of figures showing the intertwining pathways.

\section{Redistribution of Energy Substrates in Response to Acute and Chronic Exercise}

An acute bout of exercise brings about the activation of multiple neuroendocrine pathways that result in short-term and long-term systemic metabolic adaptations. In the short term, breakdown of ATP and phosphocreatine, leading to anaerobic glycolysis in the exercising SkM, has been described [30]. Increased metabolic demands are accomplished through mechanisms that are mostly mediated by the sympathetic nervous system (SNS), such as lipolysis in WAT dependent on the activation of hormone sensitive lipase (HSL) by catecholamines [18,30], mobilization of hepatic glycogen stores, and antagonism of the anabolic actions of insulin through the increased release of cortisol and growth hormone [31] that favors TG catabolism in WAT [32]. The net result is increased available glucose and free fatty acids (FFAs) for the exercising SkM [30].

With chronic aerobic exercise (e.g., daily training), the cellular mechanisms involved in oxidative metabolism are upregulated in SkM in a time-dependent manner but are immediately reverted to baseline following abstinence from exercise [30]. Indeed, SkM undergoes multiple adaptive mechanisms, including increased mitochondrial biogenesis, expression of fatty acid transporters, activity of oxidative enzymes and of those involved in the electron transport chain in the mitochondria, and, importantly, SkM hypertrophy [30]. Additionally, continued FAO takes place during the post-exercise early recovery period (i.e., $4 \mathrm{~h}$ ) and continues at a lesser degree (still above baseline) for as long as $24 \mathrm{~h}$ [32]. The basal metabolic rate (BMR) increases 5-10\% from baseline after exercise, but, intriguingly, this effect has been reported to last up to $48 \mathrm{~h}$ post-exercise [33]. Therefore, mechanisms other than continued FAO must also account for the increased BMR observed during the post-exercise period. Increased total energy expenditure could result from a reestablished hypothalamic setpoint in control of energy expenditure, increased excess nutrient disposal, and thermogenesis by BAT [34]. Metabolic energy demands may also be met through redistribution of energy substrates due to increased SkM mass with oxidative metabolic adaptations that allow for enhanced consumption of glucose or glycogen storage in the resting state. This, together with the potent insulin-sensitizing effect of exercise [35], limits the amount of substrate available for lipogenesis in WAT and in the liver. In the latter, TGs are transported 
into the circulation and eventually accreted in WAT [36]. Indeed, considering that SkM represents approximately half of the total body mass, that it accounts for nearly $80 \%$ of insulin-stimulated glucose uptake, and that it is a major determinant of the basal metabolic rate, even small increases in the energy demand in SkM can have significant effects on total-body energy expenditure [37], even in the basal state. Thus, exercise can favor the redistribution of energetic substrates to SkM, where they are expended, instead of to WAT, where they are stored, thus maintaining physiologic levels of fat mass. As discussed later, exercise factors may be involved in many of these processes and may therefore influence fat mass. Regardless of the mechanism, the post-exercise period appears to be crucial for the observed VAT loss that accompanies exercise.

The mechanisms through which "exercise-inducible factors" may have a global effect on metabolism by influencing any of the processes outlined above are described in the following sections and summarized in Tables 1-4. Some of these factors are not exclusively synthesized by a specific type of tissue. Hence, they are classified based on their most important source following bouts of exercise.

\section{The Role of Myokines in Metabolic Pathways during Exercise}

Myokines are a broad group of muscle-secreted proteins, peptides, and metabolites that have been reported to hold endocrine activity, most of which are secreted in response to SkM contraction, bouts of physical activity, and other endocrine signals. Well-studied myokines [38] are summarized in Table 1, where brief overview on their physiologic role, regulation, and changes in levels or activity in response to exercise is provided. 
Table 1. Myokines summary. Exercise modality evaluated in clinical studies is aerobic and conducted in adult populations unless specified otherwise. $\downarrow$ : Decreased; $\uparrow:$ Increased; $\leftrightarrow$ : Unchanged; ?: Controversial; *: Possible mechanism (based on indirect evidence); -: Data not available; ${ }^{\circ}$ : Depending on the specific context, may be either pro- or anti-inflammatory; +: Indicates reviews or meta-analyses; AE: Acute exercise; CE: Chronic exercise; Ob: Obesity; Ow: Overweight; T2DM: Type 2 diabetes mellitus. Other abbreviations are given throughout the text.

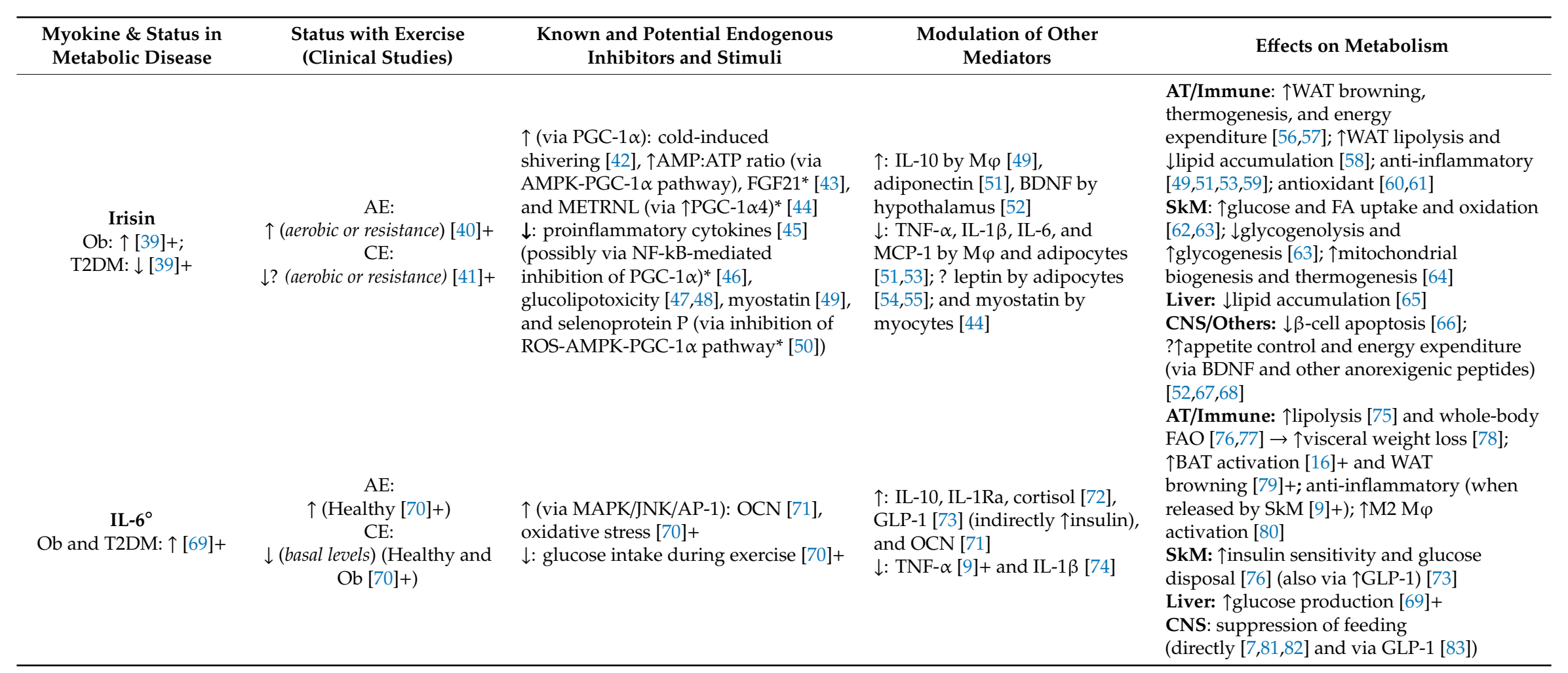


Table 1. Cont.

\begin{tabular}{|c|c|c|c|c|}
\hline $\begin{array}{l}\text { Myokine \& Status in } \\
\text { Metabolic Disease }\end{array}$ & $\begin{array}{l}\text { Status with Exercise } \\
\text { (Clinical Studies) }\end{array}$ & $\begin{array}{l}\text { Known and Potential Endogenous } \\
\text { Inhibitors and Stimuli }\end{array}$ & $\begin{array}{l}\text { Modulation of Other } \\
\text { Mediators }\end{array}$ & Effects on Metabolism \\
\hline $\begin{array}{c}\text { BAIBA } \\
\text { Ow/Ob: } \\
? \downarrow \\
\text { (trends only) }[104,105]\end{array}$ & $\begin{array}{c}\text { AE: } ? \uparrow \leftrightarrow,(\text { Healthy, Ob, and } \\
\text { T2DM [84]+) } \\
\text { CE: ? }(\text { Healthy [85]); ? } \leftrightarrow \\
\text { (Ob and T2DM [84]+; possibly } \\
\text { due to increased sIL-15Ra) }\end{array}$ & $\begin{array}{c}\uparrow(\text { via PGC- } 1 \alpha 4 \text { [98]): cold exposure } \\
\text { (in WAT) } \\
\downarrow \text { : elevated FFAs [100] }\end{array}$ & $\begin{array}{l}\uparrow: \text { IL-4 and IL-13 by Eos [98], } \\
\text { irisin, and BAIBA (via } \\
\uparrow P G C-1 \alpha)^{*}[100] \\
\downarrow: \text { TNF- } \alpha, \text { MCP-1, and IL-6 [100] }\end{array}$ & 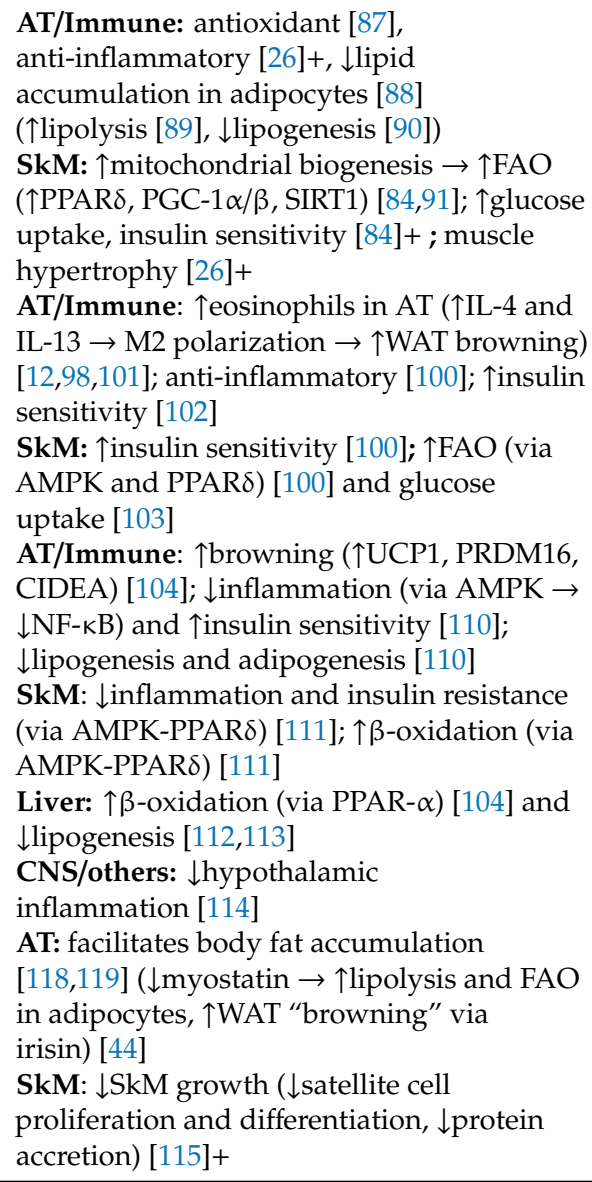 \\
\hline
\end{tabular}




\subsection{Irisin}

Irisin is released primarily from SkM after physical exercise, and to a lesser extent by WAT, from its precursor fibronectin type III domain-containing protein 5 (FNDC5), its cleavage probably involving ADAM family proteases [120]. When originally described, it was found to exert browning of WAT, increase energy expenditure, improve insulin sensitivity, and induce weight loss, through upregulation of UCP1 in exercised mice overexpressing PGC-1 $\alpha$ [57]. Irisin concentrations have been found to be increased in obesity in humans [39]. Irisin was described to stimulate lipolysis via HSL and to inhibit lipid accumulation in adipocytes [58,64]. In SkM, after physical activity, irisin induced downstream activation of glucose and FFA uptake and oxidation [62]. It has favored not only M2 M $\varphi$ polarization, but also reversion of an already established M1-polarized proinflammatory state [59]. Irisin induces VAT loss as well. After an 8-week endurance training in healthy adults, increased circulating irisin levels were positively correlated with the amount of visceral fat loss measured by DEXA scan [121]. The anti-inflammatory effect of irisin in VAT might potentiate its browning properties while sensitizing white adipocytes in situ to the action of catecholamines, further contributing to a decrease in VAT mass. Released FFAs from VAT could then be redistributed to metabolically active tissues, given that irisin directly promotes expression of genes involved in FFA uptake and oxidation and stimulates hypertrophy [44], thus increasing available SkM mass for FAO and glucose disposal, which further decreases available substrates for lipogenesis. Moreover, the antioxidative and anti-inflammatory effects of irisin have also been described in hepatocytes, which may help decrease hepatic steatosis [65] and favor a healthy hepatokine profile which also contributes to decreased fat mass [23]. Although still controversial [56], it is generally agreed that irisin levels increase transiently following acute bouts of aerobic and resistance exercise [40], which could contribute to loss of fat mass. Data on chronic exercise are less conclusive. A meta-analysis has described a decrease in irisin levels with resistance training and a tendency to decrease with endurance training [41]. These results could be attributed to decreased metabolic stress and inflammation that follows exercise-associated fat loss, rather than as a consequence of exercise per se, and to the inclusion of studies that did not measure irisin levels immediately following exercise bouts, considering its proposed short life in circulation [40].

\subsection{IL-6}

Increased concentration of IL-6, secreted by adipocytes and monocytes and activated through the TLR4-NF- $\mathrm{kB}$ pathway, has been classically associated with proinflammatory responses and insulin resistance in obesity. However, when released by SkM during exercise bouts and secreted in response to activation of the MAPK/JNK/AP-1 pathway, IL-6 has been shown to exert an anti-inflammatory and insulin-sensitizing action [122]. IL-6 serum levels have been shown to increase following bouts of aerobic exercise, with exercise duration as the main determinant of the increase (e.g., 5 -fold following $30 \mathrm{~min}$ of running at $75 \%$ maximal oxygen consumption $\left(\mathrm{VO}_{2} \mathrm{max}\right)$ to 100 -fold during marathon running) $[8,70]$. Obese adults receiving tocilizumab, subjected to 12 weeks of endurance exercise, showed a blunted exercise-induced loss of visceral fat mass compared with controls, as measured by DEXA [78]. Thus, IL-6 appears to be crucial in exercise-induced loss of VAT. It has been shown to directly increase GLP-1 in mice [73] and to stimulate SNS, increasing WAT lipolysis and "browning" and BAT thermogenesis [19]. By directly promoting lipolysis and mediating metabolic adaptation to exercise in SkM [75], IL-6 favors glucose disposal, which ultimately results in SkM effectively utilizing FFAs derived from VAT lipolysis and decreased available lipogenic substrate.

\section{3. $I L-15$}

IL-15 is produced by SkM in response to exercise [123], acting by autocrine means. IL-15 augments glucose uptake in SkM by increasing transcription [124] and membrane translocation of GLUT4 via JAK3/STAT3 signaling [125], and augments PPAR $\delta$ and PGC- $1 \alpha$ activity, favoring mitochondrial biogenesis and FAO $[84,91,126]$. It decreases fat mass by promoting influx of energetic substrates 
to SkM, which limits FFA deposits in VAT and in adipocytes [127]. The global effect of IL-15 on fat mass appears to be significant, as exemplified in a murine model overexpressing IL-15 in which the percentage of visceral fat mass, measured by DEXA, was approximately half when compared with controls [88]. Most of the studies in both healthy and obese adults have found increased circulating IL-15 immediately following acute bouts of aerobic exercise (e.g., running or cycling at $55-75 \%$ of age-predicted maximum heart rate for 30-120 $\mathrm{min}$ ) [128-130]. IL-15 concentrations in SkM biopsies are markedly increased despite no apparent increase in the circulation following exercise [85]. IL-15 promotes SkM hypertrophy, facilitating utilization of FFAs that would otherwise be reincorporated to VAT. In obese/T2DM subjects, soluble IL-15R $\alpha$ is released in greater amounts, impairing upregulation of SkM oxidative metabolism or lipolysis in WAT [84].

\subsection{Meteorin-Like (METRNL)}

In SkM, METRNL is upregulated by activation of the PGC- $1 \alpha 4$ isoform. It has been shown to induce PPAR $\gamma$ activity in WAT to increase preadipocyte differentiation and insulin sensitivity [102]. It was found to promote $\mathrm{M} 2 \mathrm{M} \varphi$ polarization [98], enhance oxidative metabolism in SkM and WAT "browning" [100], stimulate FAO, and suppress FFA-induced inflammation and insulin resistance in SkM via activation of AMPK and PPAR $\delta$. A recent study found a positive correlation between METRNL and irisin levels in patients with T2DM [92]. Regulation of METRNL by exercise in humans has been scarcely evaluated. Increased METRNL gene expression at 1 and $4 \mathrm{~h}$ following an acute bout of combined resistance and endurance exercise in healthy young adult males was described [98]. METRNL mRNA expression was also found upregulated in SkM biopsies taken $3 \mathrm{~h}$ into the recovery period compared with the immediate post-exercise period both before and after 20 days of standardized high-intensity interval training (HIIT; $5 \times 4$-min bouts at $80 \%$ pre-training peak power output) in healthy young males [97]. A recent study identified a significant inverse association between visceral fat area, evaluated with DEXA, and circulating levels of METRNL in adults with T2DM [131], advocating its possible involvement in fat mass regulation. Overall, the scant evidence suggests that METRNL may play a role in exercise-induced loss of fat mass. It could also initiate a cascade of myokines that synergistically increase energy expenditure, through increased glucose and FFA disposal, and thermogenesis in BAT, possibly attenuating insulin resistance, which indirectly results in loss of fat mass.

\section{5. $\beta$-Aminoisobutyric Acid (BAIBA)}

$\beta$-Aminoisobutyric acid (BAIBA), released from contracting SkM, was originally identified in culture supernatant of murine skeletal myocytes and in the circulation of both chronically exercised mice and those overexpressing PGC- $1 \alpha$, promoting WAT "browning" and increasing hepatic $\beta$-oxidation through PPAR $\alpha$-dependent mechanisms. Fat mass loss associated with increased total energy expenditure was also observed [104]. BAIBA promoted reversal of weight gain and adiposity in HFD-induced severely obese mice [114], attributed to restored hypothalamic neuronal function and possibly sensitivity to anorexigenic hormones. BAIBA promotes increased VAT lipolysis, increased FFA oxidation, and glucose uptake in SkM [110-112]. In the liver, a simultaneous decrease in de novo lipogenesis and increased FAO [112,113] could also reduce accretion of diet-derived TGs and excess carbohydrates in VAT. However, BAIBA remains understudied in humans. A study showed negative correlations between BAIBA levels and percentage of body fat, total fat mass, subcutaneous adipose tissue (scAT), and VAT, and a positive association with lean mass in obese vs. healthy adults [105]. Regarding exercise interventions, two studies have reported increased circulating levels of BAIBA following aerobic exercise, e.g., cycling for $1 \mathrm{~h}$ at $40 \%$ maximal power output [106] or after 20 weeks of 30-50 min cycling sessions at 55-75\% $\mathrm{VO}_{2} \max$ [104] in healthy young men. A trend toward a negative correlation between BAIBA and BMI [104] was shown, while another study reported no increase [107]. Thus, the relationship between exercise-induced BAIBA and anthropometric markers warrants further study. 


\subsection{Myostatin}

Myostatin was the first identified muscle-secreted factor and is known to promote SkM atrophy [115]. It is the only myokine known to be downregulated by acute and chronic enduranceand resistance-type exercise in both rodents and humans [115]. Its expression is increased in human obesity and strongly associated with insulin resistance by downregulating GLUT4 expression and by decreasing phosphorylation of IRS1 [26]. On the contrary, inhibition of myostatin upregulates oxidative metabolism in SkM [115]. Its absence in Mstn ${ }^{-/-}$mice results in increased gene expression of enzymes and transcription factors involved in lipolysis, mitochondrial FAO, and WAT browning, as well as decreased VAT mass [132]. It contributes to the induction of PGC-1 $\alpha$, FNDC5, and irisin in SkM $[27,49,133]$. The possibility of an inter-myokine axis with irisin $[44,49]$ and crosstalk with follistatin could represent a mechanism through which myostatin is decreased by exercise. In brief, exercise-induced inhibition of myostatin promotes SkM hypertrophy and oxidative metabolism, VAT lipolysis, and WAT browning, which may redistribute FFAs from lipogenesis to their utilization as metabolic fuel.

\section{The Role of Hepatokines in Metabolic Pathways during Exercise}

Hepatokines are novel hormone-like factors released from the liver. Clinical studies have suggested that exercise modulates the levels and the activity of FGF21, follistatin, ANGPTL4, and fetuin A, whose combined effect could decrease fat mass levels, as summarized in Table 2. In addition, selenoprotein $\mathrm{P}$, although not directly modulated by exercise, may blunt the SkM adaptive response to exercise. Additionally, hepatokines may modulate the actions of other exercise-inducible factors, thus inhibiting fat accumulation; this favors SkM adaptation to exercise and an anti-inflammatory pro-browning environment that promotes loss of fat mass, attenuation of hepatic steatosis, and decreased insulin resistance. 
Table 2. Hepatokines summary. Exercise modality, evaluated in clinical studies, is aerobic and was conducted in adult populations, unless specified otherwise. $\downarrow$ : Decreased; $\uparrow:$ Increased; $\leftrightarrow$ : Unchanged; ?: Controversial; *: Possible mechanism (based on indirect evidence); -: Data not available; +: Indicates reviews or meta-analyses; AE: Acute exercise; CE: Chronic exercise; MS: Metabolic syndrome; NAFLD: Non-alcoholic fatty liver disease; Ob: Obesity; Ow: Overweight; T2DM: Type 2 diabetes mellitus. Other abbreviations are given throughout the text.

\begin{tabular}{|c|c|c|c|c|}
\hline $\begin{array}{l}\text { Hepatokine and Status in } \\
\text { Metabolic Disease }\end{array}$ & $\begin{array}{c}\text { Status with Exercise (Clinical } \\
\text { Studies) }\end{array}$ & $\begin{array}{l}\text { Known and Potential Endogenous } \\
\text { Inhibitors and Stimuli }\end{array}$ & $\begin{array}{l}\text { Modulation of Other } \\
\text { Mediators }\end{array}$ & Effects on Metabolism \\
\hline $\begin{array}{c}\text { Selenoprotein } \mathbf{P} \\
\text { Ob, NAFLD, T2DM: } \\
\uparrow[23]+\end{array}$ & $\begin{array}{c}\mathrm{AE}: \leftrightarrow[50,134] \\
\mathrm{CE}: \leftrightarrow[50]\end{array}$ & $\begin{array}{l}\uparrow: \text { hepatic steatosis [23]+ } \\
\downarrow \text { : adiponectin [135] }\end{array}$ & $\begin{array}{l}\downarrow: \text { adiponectin [136], IL-6 and } \\
\text { PGC- } 1 \alpha \text { dependent myokines } \\
\text { irisin, METRNL, BAIBA (by } \\
\text { decreasing ROS*) [50] }\end{array}$ & $\begin{array}{l}\text { SkM: antioxidant [50]; deficiency } \\
\text { facilitates SkM adaptation to exercise } \\
\text { via LRP1 ( } \downarrow \text { antioxidant SeP } \rightarrow \uparrow R O S \\
\rightarrow \uparrow A M P K \text { and PGC- } 1 \alpha \rightarrow \\
\uparrow \text { mitochondrial biogenesis and } \\
\text { metabolic adaptation to exercise) [50]; } \\
\uparrow \text { insulin resistance (possibly indirect } \\
\text { via } \downarrow \text { adiponectin) [23]+ } \\
\text { Liver: } \uparrow \text { insulin resistance [23]+ }\end{array}$ \\
\hline $\begin{array}{c}\text { Fetuin A } \\
\text { Ob, MS, NAFLD, T2DM: } \\
\uparrow[137]+\end{array}$ & $\begin{array}{c}\text { AE: } \leftrightarrow \text { (Healthy and Ow/Ob) } \\
{[134]} \\
\text { CE: } \downarrow \text { (Healthy }[138]+\text { and Ow } \\
[139,140]) ; \\
? \downarrow[141-143] \leftrightarrow[138]+(\mathrm{Ob} \\
\text { w/NAFLD or T2DM) }\end{array}$ & $\begin{array}{l}\uparrow: \text { excess glucose (via ERK1/2) [144] } \\
\text { or FFAs (via NF-KB) [145]; hepatic } \\
\text { steatosis [23]+ } \\
\downarrow \text { : adiponectin (via AMPK) [146], } \\
\text { irisin (by decreasing hepatic } \\
\text { lipogenesis*) [147] }\end{array}$ & $\begin{array}{l}\uparrow: \text { proinflammatory cytokines } \\
\text { TNF- } \alpha, \text { IL-6 [148] by adipocytes } \\
\text { and monocytes (via TLR-4) [149] } \\
\downarrow: \text { adiponectin [148] }\end{array}$ & $\begin{array}{l}\text { AT/Immune: } \uparrow \text { inflammation } \\
{[140,150] ; \uparrow \text { insulin resistance; } \uparrow F F A} \\
\text { uptake and lipogenesis [151] } \\
\text { SkM: } \uparrow \text { insulin resistance [23]+ } \\
\text { Liver: } \uparrow \text { insulin resistance [23]+ } \\
\text { Others: } \uparrow \beta \text {-cell lipotoxicity and } \\
\text { apoptosis [152] } \rightarrow \downarrow \text { insulin secretion }\end{array}$ \\
\hline $\begin{array}{c}\text { FGF21 } \\
\text { Ob, NAFLD and T2DM: } \uparrow \\
{[23,153,154]+}\end{array}$ & $\begin{array}{c}\text { AE: } \uparrow(\text { Healthy [155]); } \leftrightarrow(\mathrm{Ob} \\
\text { [156] and T2DM [157]) } \\
\text { CE: } \uparrow(\text { T2DM; aerobic or } \\
\text { resistance) [143] }\end{array}$ & $\begin{array}{l}\uparrow: \text { glucagon-to-insulin ratio (in } \\
\text { liver) [158,159]; FFAs (via PPAR- } \alpha \\
\text { in liver) [159-161]; T3 (in liver) } \\
\text { [162]; cold exposure (in BAT) [154]+ } \\
\downarrow \text { : insulin [158]; T3 (in AT) [162] }\end{array}$ & $\begin{array}{l}\uparrow: \text { catecholamines [163], } \\
\text { glucocorticoids [164], irisin (via } \\
\text { PGC- } 1 \alpha \text { in adipocytes)* [43], } \\
\text { adiponectin [165] }\end{array}$ & $\begin{array}{l}\text { AT/Immune: } \uparrow \text { SNS-induced BAT } \\
\text { energy expenditure [163,165]; } \\
\uparrow \text { PGC- } 1 \alpha \text { and WAT browning [43]; } \\
\uparrow W A T \text { lipolysis [166] } \\
\text { Liver: } \uparrow \text { hepatic FAO [160]; } \\
\downarrow \text { lipogenesis ( } \downarrow \text { SREBP-1c) [167] } \rightarrow \\
\downarrow \text { hepatic steatosis; } \uparrow \text { insulin sensitivity } \\
\text { (with adiponectin) [154] } \\
\text { CNS: } \downarrow \text { sugary food intake [168] }\end{array}$ \\
\hline
\end{tabular}


Table 2. Cont.

\begin{tabular}{|c|c|c|c|c|}
\hline $\begin{array}{l}\text { Hepatokine and Status in } \\
\text { Metabolic Disease }\end{array}$ & $\begin{array}{c}\text { Status with Exercise (Clinical } \\
\text { Studies) }\end{array}$ & $\begin{array}{l}\text { Known and Potential Endogenous } \\
\text { Inhibitors and Stimuli }\end{array}$ & $\begin{array}{l}\text { Modulation of Other } \\
\text { Mediators }\end{array}$ & Effects on Metabolism \\
\hline 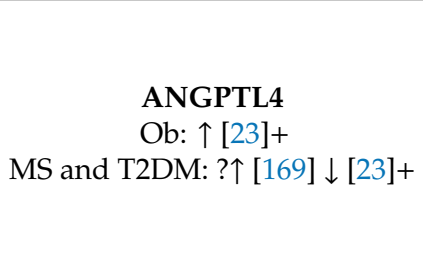 & $\begin{array}{c}\text { AE: } \uparrow \text { (Healthy }[6,170,171] \text { and } \\
\text { Ow }[171] ; \text { aerobic or resistance) } \\
\text { CE: } ? \leftrightarrow[6,172] \uparrow(\text { marathon run) } \\
{[173]}\end{array}$ & $\begin{array}{l}\uparrow: \text { glucagon-to-insulin ratio (in } \\
\text { liver) [170]; catecholamines } \rightarrow \text { FFAs } \\
\text { (via PPARs in liver and SkM) [174]; } \\
\text { cortisol [175]; TLR stimulation (in } \\
\text { M } \varphi \text { ) [169] } \\
\downarrow: \text { glucose load ( } \text { insulin } \rightarrow \\
\downarrow \text { lipolysis } \rightarrow \downarrow \text { FFAs) [174] }\end{array}$ & - & $\begin{array}{l}\text { AT: } \uparrow \text { WAT lipolysis [176,177], } \downarrow \text { LPL } \\
\text { activity [178], } \rightarrow \downarrow \text { fat mass [23]+ } \\
\text { Others: } \downarrow \text { pancreatic lipase [179] }\end{array}$ \\
\hline $\begin{array}{c}\text { Follistatin } \\
\text { NAFLD, T2DM: } \uparrow[180]\end{array}$ & $\begin{array}{c}\text { AE: } \uparrow \text { (Healthy }[117,181,182] \\
\text { HIIT, aerobic, or resistance); } \leftrightarrow \\
\text { (T2DM [157]) } \\
\text { CE: - }\end{array}$ & $\begin{array}{l}\uparrow: \text { glucagon-to-insulin ratio [183] } \\
\downarrow:-\end{array}$ & $\begin{array}{l}\downarrow: \text { myostatin [184] and glucagon } \\
{[183]}\end{array}$ & $\begin{array}{l}\text { AT: } \uparrow \text { WAT browning [185] } \\
\text { SkM: } \uparrow \text { hypertrophy ( } \uparrow \text { satellite cell } \\
\text { activation due to } \downarrow \text { myostatin) [184] } \\
\text { Others: protection of } \beta \text {-cells from } \\
\text { apoptosis [183] }\end{array}$ \\
\hline
\end{tabular}




\subsection{Selenoprotein $P$}

Excessive levels of selenoprotein P (SeP) have been shown in humans with metabolic diseases and are positively correlated with insulin resistance, which is consistent with its insulin-desensitizing effects observed in animal and in vitro models [23]. While its levels appear not to be regulated by exercise, perhaps due to insufficient exercise intensity or duration [4,50,134], SeP has been implicated in the "exercise resistance" phenomenon, which postulates that not all individuals derive the same beneficial effects from exercise. In animal models, obese SeP-deficient mice presented increased aerobic exercise capacity concomitant with enhanced mitochondrial biogenesis and function in SkM, an effect linked to increased ROS and activation of AMPK and to increased activity of PGC-1 $\alpha$ [50]. In humans, high pre-training levels of SeP were predictive of decreased aerobic exercise capacity, measured as $\mathrm{VO}_{2}$ max [50], suggesting that FFAs released by VAT lipolysis during and after exercise are less efficiently utilized by SkM and are instead preferentially reincorporated into VAT via VLDL. A potential decrease in irisin, METRNL, and BAIBA further blunts the exercise-induced loss of fat mass. These mechanisms could partially explain why obese individuals, who have higher basal levels of SeP, appear to require a longer duration of exercise for efficient weight reduction compared with healthy controls [186].

\subsection{Fetuin $A$}

Fetuin A engages TLR-4 in adipocytes and $\mathrm{M} \varphi$ to promote proinflammatory activation, in conjunction with FFAs $[187,188]$. Fetuin A has been shown to directly induce insulin resistance [189], suppress production of adiponectin by adipocytes [148], and induce pancreatic $\beta$-cell toxicity [152]. Notably, its levels have been found increased in obesity, especially associated with NAFLD [137], and are predictive for the development of T2DM [190]. Concordantly, increasing levels of fetuin A were associated with increasing VAT mass in elderly adults over a 5-year follow-up [191]. Regarding exercise, a recent meta-analysis found decreased fetuin A levels following completion of aerobic exercise regimes of varying frequency and duration (e.g., 1-12 weeks, 3-5 sessions per week of 40-70 min each) and intensity (e.g., 60-85\% maximum heart rate), except in patients with T2DM, suggesting that modulation of fetuin A by exercise partially depends on the pre-existing metabolic status [138]. Another 12-week aerobic exercise training intervention, consisting of treadmill walking at $85 \%$ maximum heart rate for 60 min per session, decreased fetuin A levels in obese, insulin-resistant subjects, leading to decreased hepatic insulin resistance, total body fat, and fasting insulin levels [139]. Thus, decreased fetuin A levels induced by exercise could reduce VAT directly by decreasing FFA availability for uptake and TG accretion by WAT, while reducing VAT indirectly by reducing insulin resistance. Furthermore, decreased fetuin A may counteract VAT accumulation in part due to decreased activation of resident proinflammatory $\mathrm{M} 1 \mathrm{M} \varphi$ that impair catecholamine-induced lipolysis and BAT function.

\subsection{Fibroblast Growth Factor 21 (FGF21)}

Exercise intensity is a determinant of the magnitude of FGF21 release from the liver; its levels have been found to be significantly higher in the recovery period than immediately post-exercise. Higher FGF21 levels were observed $1 \mathrm{~h}$ following treadmill running for $30 \mathrm{~min}$ at $80 \% \mathrm{VO}_{2}$ max versus $50 \% \mathrm{VO}_{2}$ max in healthy sedentary adults [155]. In the liver, FGF21 upregulates $\beta$-oxidation [160] and downregulates lipogenesis [167]. In WAT, it induces lipolysis [166] and browning [43], likely via upregulation of PGC-1 $\alpha$ [192]. In the CNS, FGF21 stimulates the SNS, increasing BAT activity. Weight loss likely occurs $[163,165]$ at the expense of VAT, as evidenced by a $15 \%$ mean decrease in abdominal fat content, measured by DEXA, in obese monkeys [165]. Interestingly, a recent study suggests that FGF21 may be involved in regulating preference for specific foods; specifically, it acts to reduce craving for sugary foods [168]. In summary, exercise-induced FGF21 could promote visceral fat mass loss by increasing lipolysis and thermogenesis in WAT (thereby redistributing energetic substrate to SkM), by decreasing sugary food intake (limiting de novo lipogenesis in the liver), and by reducing VLDL-mediated fat accretion in WAT. Paradoxically, FGF21 levels increase in patients with 
obesity [153], which might represent a state of FGF21 resistance [154]. Furthermore, patients with obesity-related insulin resistance have an impaired FGF21 upregulation after exercise [156,157]. Thus, increased frequency or duration of exercise may be needed to restore physiological regulation of FGF21 and thus its ability to decrease adiposity in obese subjects.

\subsection{Angiopoietin-Like 4 (ANGPTL4)}

Angiopoietin-like 4 (ANGPTL4) secretion by the liver has been primarily regulated during exercise bouts, following $3 \mathrm{~h}$ of ergometer cycling at 50\% $\mathrm{VO}_{2}$ max, in response to increased glucagon-to-insulin ratio [170], and therefore its endocrine role is hypothesized [3]. In WAT, it was shown to stimulate lipolysis via induction of adipose triglyceride lipase $[176,193]$ and to decrease the activity of LPL $[178,194]$. It has also been shown to inhibit pancreatic lipase, decreasing dietary fat absorption [179]. Anptl4-/- mice presented higher levels of visceral fat mass, visceral LPL activity, and WAT inflammation [195], highlighting the role of ANGPTL4 in the redistribution of lipoprotein-derived FFAs [4]. Although it is upregulated by SkM after aerobic or resistance exercise $[171,172,196]$, surprisingly, an even greater degree of ANGPTL4 mRNA expression was found in the portion of SkM that remained inactive during the bout of exercise compared with the active SkM $[172,196]$, representing a mechanism to redistribute FFA delivery from unexercised to exercised SkM. An autocrine role has also been proposed, given that ANGPTL4 is necessary for PPAR- $\delta$-dependent expression of HSL [176]. In exercised SkM, oxidative capacity is increased, but in unexercised SkM, protection against lipotoxicity is possible. ANGPTL4 could selectively inhibit LPL in WAT to redirect FFAs for catabolism in SkM, rather than to their storage in WAT [197]. In summary, in the context of exercise, ANGPTL4 could redistribute FFA-derived metabolic fuel to SkM away from WAT, thus potentially inhibiting lipid accumulation in VAT.

\subsection{Follistatin}

In humans, circulating follistatin is primarily derived from the liver and, similar to FGF21 and ANGPTL4, increases in response to an augmented glucagon-to-insulin ratio in conditions such as fasting and exercise, including HIIT, continuous aerobic, and resistance modalities $[182,198]$. Studies in humans have identified follistatin as an exercise-inducible hepatokine that increases transitorily in the recovery period after a bout of exercise $[117,134,183]$. Expectedly, like FGF21, patients with obesity-related insulin resistance present increased basal levels of follistatin $[157,180]$, but its exercise-induced release by the liver is blunted [157]. Follistatin might enhance SkM hypertrophy due to its ability to bind and neutralize myostatin [184,199], increasing the mass of SkM available for glucose and FFA uptake and oxidation. Additionally, it has been shown to induce thermogenic genes in murine adipocytes [185]. Follistatin-overexpressing mice showed strong insulin resistance in WAT, increased hepatic glucose production, and glucose intolerance [200], which is in line with the higher levels observed in patients with T2DM. However, higher transient levels of follistatin during and after exercise may actually be beneficial as a whole, favoring continued glucose uptake by SkM and continued WAT lipolysis and FFA uptake by SkM during exercise and post-exercise [4]. Hence, follistatin could persist beyond the acute exercise bout and thus eventually limit TG accretion in WAT by decreasing FFA availability. Nonetheless, this is speculative and should be addressed in future studies.

\section{The Role of Osteokines in Metabolic Pathways during Exercise}

\section{Osteocalcin}

Osteocalcin $(\mathrm{OCN})$ is a bone-derived hormone that is synthesized and secreted by osteoblasts and then activated by osteoclasts during the process of bone resorption [28]. Its importance in metabolism is summarized in Table 3. Ocn $/-$ mice presented increased total body fat and hepatic and AT inflammation, along with decreased insulin sensitivity and total energy expenditure [201]. Meta-analyses of clinical studies showed inverse correlations between OCN levels and BMI [202], insulin resistance [203], 
the inflammatory marker CRP [204], body fat mass [205], and specifically, visceral fat mass, determined with radiologic imaging studies [206-208]. Importantly, OCN was independently associated with visceral fat area [206], implying an involvement in the regulation of VAT. OCN promoted the survival and function of pancreatic $\beta$-cells and increased insulin secretion [209], while insulin itself induced the release of OCN [210]. OCN may also mediate its beneficial effects by stimulating the synthesis of adiponectin [201,211] and IL-10, by decreasing TNF- $\alpha$ in adipocytes [211] and by upregulating thermogenic genes in AT [212] and mitochondrial biogenesis in SkM [213].

Importantly, OCN is known to increase with acute bouts of exercise, such as $4 \times 4$-min cycling at $95 \%$ maximum heart rate HIIT $[28,214]$. It directly promotes glucose and FFA uptake by SkM and establishes a positive feedback loop with IL-6, which also results in increased glucose and FFA utilization by SkM and the release of bioactive OCN by bone [71]. Altogether, by stimulating efficient consumption of glucose and FFAs by SkM, as well as by enhancing insulin action directly and via IL-6, OCN decreases available substrates for lipogenesis and at the same time promotes an anti-inflammatory environment that is permissive for thermogenic energy expenditure in AT. These events could indirectly contribute to decreased visceral fat mass, especially considering the strong negative associations between OCN and VAT reported in clinical studies. Further well-designed longitudinal studies that evaluate VAT content in response to changes in OCN levels with long-term exercise interventions are needed. 
Table 3. Osteokines and adipokines summary. Exercise modality, evaluated in clinical studies, is aerobic and was conducted in adult populations unless specified otherwise. $\downarrow$ : Decreased; $\uparrow:$ Increased; $\leftrightarrow$ : Unchanged; ?: Controversial; *: Possible mechanism (based on indirect evidence); -: Data not available; +: Indicates reviews or meta-analyses; AE: Acute exercise; CE: Chronic exercise; MS: Metabolic syndrome; Ob: Obesity; Ow: Overweight; T2DM: Type 2 diabetes mellitus. Other abbreviations are given throughout the text.

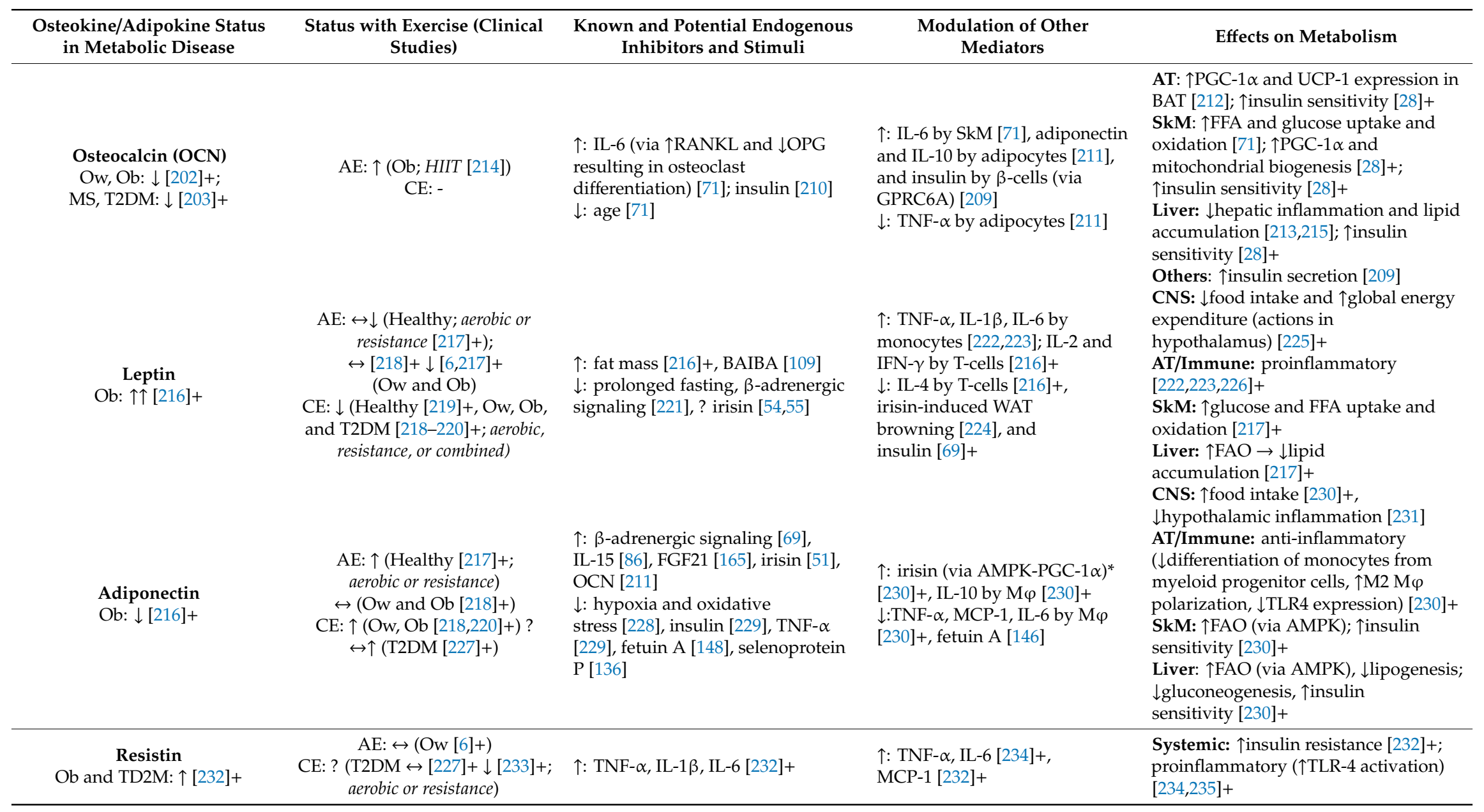




\section{The Role of Adipokines in Metabolic Pathways during Exercise}

The classic adipokines leptin, adiponectin, and resistin have been extensively reviewed, and their role in the pathogenesis of obesity-related disorders has been concisely outlined. We briefly summarize the physiologic role of each adipokine to highlight their importance in weight and fat mass loss and their maintenance (Table 3). Adipokine levels change in response to chronic exercise rather than to acute bouts of exercise, especially when changes in body composition occur, consistent with the observation that exercise reduces VAT independently of weight loss [6]. Hence, exercise bouts trigger transient changes in other exercise-inducible factors that might mediate metabolic changes and result in decreased WAT mass, shifting the adipokine profile.

\subsection{Leptin}

Leptin is preferentially expressed in subcutaneous WAT and released by adipocytes [69]. As an endocrine signal, leptin suppresses appetite and promotes energy expenditure by activating pro-opiomelanocortin (POMC)-expressing neurons and inhibiting neuropeptide Y (NPY) and agouti-related protein (AgRP) in the hypothalamus. It also enhances SNS outflow to induce thermogenesis [225]. Increased leptin levels have been found in the obese population, inducing a leptin-resistance state, accompanied by increased ROS, TNF- $\alpha$, IL- 6 and chemokine ligands. Additionally, it augments Th1 cytokines IL-2 and IFN- $\gamma$ while suppressing Th 2 cytokine IL-4 [216]. Thus, the hyperleptinemia that accompanies obesity contributes to the establishment of a proinflammatory Th1 cytokine profile and to the persistent $\mathrm{M} 1 \mathrm{M} \varphi$ infiltration in obese WAT.

Acute decreases in leptin concentrations in response to acute bouts of aerobic and resistance exercise have been described [217] but, in the presence of an altered hypothalamic set point in obesity, theoretically lead to compensatory overeating and decreased metabolic rate, impairing weight loss $[219,236,237]$. It appears that in order to restore the physiologic actions of leptin, chronic exercise is needed. Meta-analyses have revealed that chronic aerobic, resistance, and combined exercise resulted in reduced fat mass accompanied by lower leptin concentrations $[6,217,219,220]$. Improved leptin sensitivity through lower LepR feedback inhibitors, exercise-induced systemic anti-inflammatory environment $[9,238]$, and reduced hypothalamic oxidative stress [220] have been demonstrated. Besides its traditional effect in increasing SNS drive to induce global energy expenditure, restored leptin sensitivity in peripheral organs could also favor maintenance of reduced body fat, as leptin is also known to increase glucose and FFA uptake and oxidation by SkM and to decrease intrahepatic lipid content by promoting FAO [217]. Thus, leptin could also be involved in the redistribution of nutrients away from WAT, which is consistent with its function as an "adipostat" that tightly regulates adipocyte size in physiologic conditions.

\subsection{Adiponectin}

Adiponectin is an adipokine that is almost exclusively expressed by adipocytes in both WAT and BAT [69] and has insulin-sensitizing, anti-inflammatory, and anti-atherogenic properties. When adiponectin binds its receptor ADIPOR1 or 2, downstream activation of AMPK and PPAR $\alpha$ ensues, leading to decreased hepatic gluconeogenesis and lipogenesis, increased FAO in the liver and SkM, and increased glucose uptake in SkM and WAT. It directly suppresses the secretion of TNF- $\alpha$, MCP-1, and IL-6, while increasing IL-10 and the polarization to M2 and reducing $\beta$-cell apoptosis [230]. In obesity, adiponectin levels are found to be reduced [216], given that its expression is inhibited by hypoxia, oxidative stress [228], insulin resistance [229], TNF- $\alpha$, IL-6 [229], "catecholamine resistance" [239], fetuin A [148], and SeP [136].

Regarding exercise, some studies have identified increased adiponectin concentrations during the recovery period following acute aerobic and resistance exercise bouts [217] dependent on exercise intensity [6]. Upregulation by other factors that increase acutely during or shortly after exercise and that have demonstrated in preclinical studies to stimulate the release of adiponectin, such as 
irisin, IL-15, FGF21, and OCN, must be considered. Regarding chronic exercise, meta-analyses have found that adiponectin levels increase, especially with aerobic long-term interventions in adults across the entire spectrum of BMI, from those with overweight [218] up to those with full-blown T2DM [220]. The increased adiponectin levels induced by exercise are most likely the result of decreased visceral fat mass, improved WAT metabolic status, and a systemic anti-inflammatory environment. In turn, restored levels of adiponectin serve to maintain fat mass in check by contributing to an anti-inflammatory environment permissive for lipolysis, thermogenesis, and its own production, and by increasing oxidative metabolism in SkM and the liver, thereby effectively utilizing excess biofuel.

\subsection{Resistin}

Resistin, although originally identified as an adipocyte-derived adipokine in rodents, is mostly released by monocytes and $\mathrm{M} \varphi$ in humans [232]. Although its precise mechanisms remain obscure, it is generally agreed upon that its expression is induced by proinflammatory stimuli and that it in turn perpetuates the proinflammatory response and insulin resistance by interacting with TLR4 [69].

Controversy exists as to the role of exercise in its regulation in patients with obesity. Some have either shown a reduction in resistin levels [233] or no change [227] following aerobic or resistance exercise interventions. Some authors have recently proposed that the exercise-induced reduction of resistin levels in patients with T2DM might be due to the anti-inflammatory milieu that exercise elicits, rather than the change in BMI [233]. However, the systemic anti-inflammatory environment may be attributed to decreased adiposity [9], which cannot always be appreciated with a change in BMI without exploring other adiposity parameters.

\section{An Integrative Overview of Exercise-Induced Factors Influencing Appetite Regulation, Mechanisms for Energy Expenditure, Fat Mass Loss, and Healthy Weight}

Physiologic responses persist beyond an acute exercise bout and during the recovery period. For instance, after the immediate increase, lipolysis in WAT stabilizes but remains higher than the baseline rate for up to $24 \mathrm{~h}$ post-exercise $[18,240]$, while the increased BMR may persist for up to $48 \mathrm{~h}$ [33]. The effects during the post-exercise period are likely to be mediated by changes in the levels and/or activity of many exercise-inducible factors.

\subsection{Influence of Exercise on the Central Control of Energy Expenditure and Appetite}

The physiological effects induced by exercise may counter central neuroendocrine adaptive responses that favor weight regain [241,242]. Through diverse mechanisms, exercise-inducible factors may directly or indirectly modulate appetite regulation and energy expenditure in the CNS (Figure 1; to facilitate sequence flow, the steps appear numbered as they are introduced in the main text in italics). Importantly, appetite homeostasis is known to be altered in obesity due at least in part to hypothalamic inflammation and reactive gliosis that results in functional impairment of anorexigenic neurons and central leptin and insulin resistance $[243,244]$. Animal studies have shown that endurance exercise increases the phosphorylation of hypothalamic JAK2, STAT3, Akt, and Erk involved in the leptin signaling pathway [245], which could be directly mediated by organokines [7]. These mechanisms contribute to loss of fat mass and, in time, to its maintenance. First, exercise-induced BAIBA has been recently shown to directly inhibit hypothalamic inflammatory reactions in mice fed a high-fat diet [114], which could indirectly increase central sensitivity to anorexigenic hormones [243] (1a) and could also be a complementary mechanism to its own ability to stimulate leptin production by adipocytes [109] (1b). Second, IL-6 released by SkM, directly (2a) or indirectly via GLP-1 (2b), may also have central anorexigenic properties by modulating the activity of hypothalamic neurons involved in appetite regulation [7,122]. Moreover, IL-6 increases production of OCN by osteoblasts [71] (2c), which itself stimulates transient pancreatic secretion of the anorexic hormone insulin and triggers a positive feed-forward mechanism that results in increased OCN and thus more insulin $[28,209,210]$ (2d). Third, exercise-induced irisin may promote brain-derived neurotrophic factor (BDNF) synthesis 
in the CNS $[7,67,68]$; BDNF is a peptide known to possess central anorexigenic effects and to promote increased energy expenditure by increasing sympathetic outflow [246] (3). Fourth, production of lactate by SkM during high-intensity exercise may inhibit production of ghrelin, further contributing to decreased hunger [247] (4). Finally, increased levels of the hepatokine FGF21, although not influencing appetite per se, have been linked to decreased intake of obesogenic sugary foods [168] (5). Overall, reduced hypothalamic inflammation, release of osteokines and myokines, and increased sensitivity to anorexigenic hormones induced by exercise lead to reduced caloric intake and loss of fat mass. In the long term, reduced circulating leptin associated with decreased fat mass and an anti-inflammatory environment may help restore hypothalamic leptin (and insulin) sensitivity, thus restoring the balance between energy expenditure and food intake.

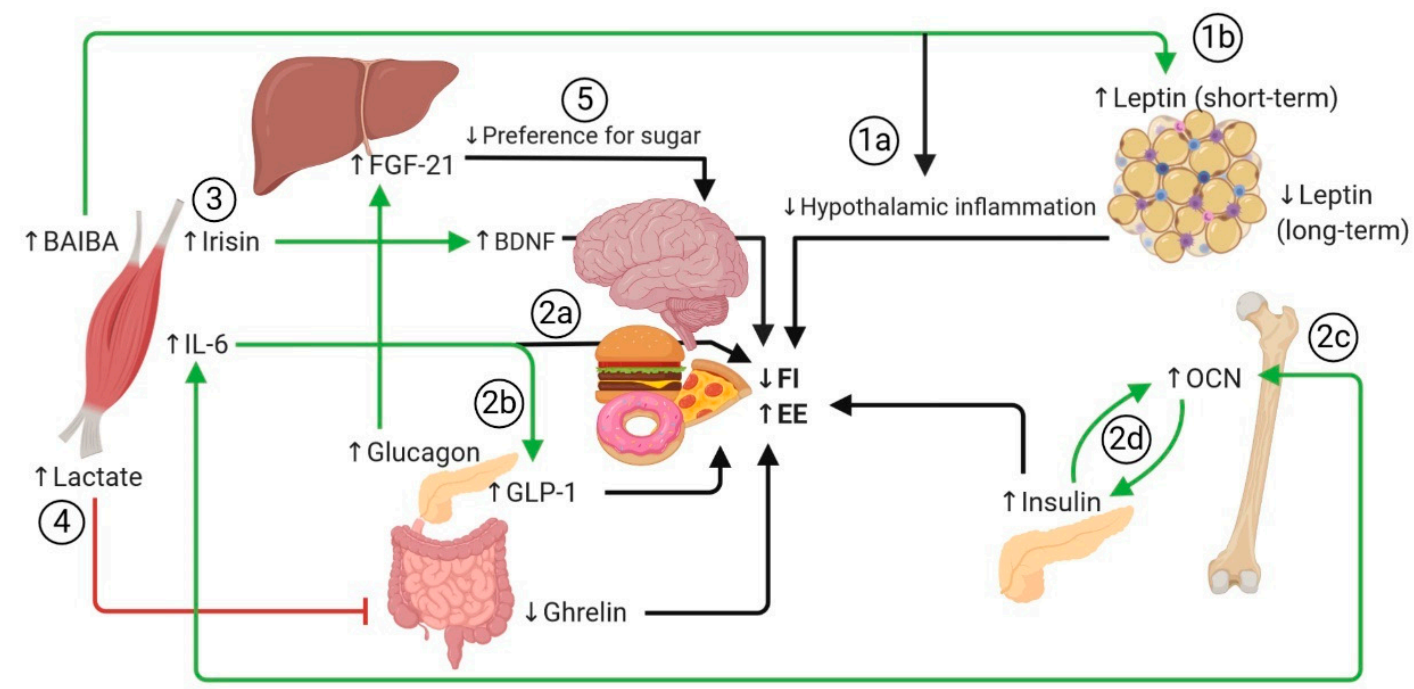

Figure 1. Effects of exercise-inducible factors on appetite control. Details in text. Abbreviations: BAIBA: $\beta$-Aminoisobutyric acid; EE: Energy expenditure; FGF21: Fibroblast-growth factor 21; FI: Food intake; GLP-1: Glucagon-like peptide 1; IL-6: Interleukin-6; OCN: Osteocalcin. Green arrows represent a stimulatory effect over another mediator; red inhibitor lines represent an inhibitory effect over another mediator; black arrows or inhibitor lines indicate the final physiologic effect of any given mediator, either stimulatory or inhibitory, respectively. Custom image created with Biorender.

7.2. Mechanisms Through which Exercise-Induced Factors Exert Anti-Inflammatory Effects and the Influence of These Effects on Insulin Sensitivity and Loss of Fat Mass

In obesity, especially in visceral adipose tissue (VAT), the initial adipocyte hypertrophy triggers adipocyte hypoxia and mechanical stress, which further results in adipocyte necrosis, all of which elicit a proinflammatory response mediated by damage-associated molecular patterns (DAMPs). The release of MCP-1 by stressed adipocytes has been shown to trigger WAT infiltration of monocytes that polarize to the classically activated M1 phenotype. M1 macrophages secrete TNF- $\alpha$, IL-1 $\beta$, IL-6, and chemokines that promote the influx of activated CD4+ Th1 cells $[14,20,239,248]$. This response is accompanied by local insulin resistance due to activation of kinases that phosphorylate serine residues of IRS1 and by excessive generation of ROS. A chronic systemic inflammatory state ensues, which in the presence of insulin resistance, promotes ectopic accumulation of lipids in the liver and SkM that exacerbates the inflammatory response, while at the same time promoting a state of "catecholamine resistance" in WAT. Proinflammatory cytokines such as TNF- $\alpha$ and IL-1 $\beta$ exacerbate insulin resistance [20], while anti-inflammatory cytokines such as IL-4 and IL-10 promote insulin sensitivity [248]. Exercise likely plays a role in the maintenance of an anti-inflammatory microenvironment and may help reverse WAT abnormalities observed in obesity. Although acute exercise was found to trigger a transient increase in oxidative stress and proinflammatory cytokines, chronic exercise was shown to induce a systemic anti-inflammatory response not only in the recovery period but also in the long term, an 
effect hypothesized to partially mediate its health benefits $[9,238]$. In healthy individuals subjected to aerobic exercise interventions, systematic reviews and meta-analyses have found decreased circulating levels of TNF- $\alpha$, IL-6, and CRP [249], as well as increased levels of the anti-inflammatory cytokine IL-10 [250]. A meta-analysis focusing specifically on individuals with T2DM has also described decreased levels of IL-6 and CRP with aerobic exercise interventions [227], which emphasizes that the anti-inflammatory properties of exercise are strong regardless of preexisting metabolic status. The systemic anti-inflammatory milieu in individuals who exercise regularly is also evidenced by decreased circulating inflammatory monocytes, which also show decreased expression of TLRs on their surface, increased IL-10-producing circulating regulatory T-cells ( $\mathrm{T}^{\text {regs }}$ ), and a shift in WAT immune cell infiltrates favoring a higher M2:M1 $\mathrm{M} \varphi$ ratio [9]. Physical activity likely plays a determinant role in the release of many factors that synergize to evoke a systemic anti-inflammatory response, both in the short and long term (Figure 2). A summary of the immune cytokines affected by exercise is given in Table 4. By generating an anti-inflammatory microenvironment in VAT, catecholamineand exercise-factor-induced sensitivity to lipolysis could be restored. Thus, released FFAs from this depot could be effectively redistributed to the SkM (which has undergone structural and biochemical adaptation for their utilization), which at the same time decreases availability of FFAs that can eventually be re-esterified and reincorporated into VAT [251]. Furthermore, considering that BAT function is dependent on an anti-inflammatory environment [12], this could also restore its thermogenic capacity, leading to enhanced energy expenditure and, consequently, loss of fat mass. These end-effects could be of particular relevance in humans given that VAT adipocytes have higher expression of $\beta 3$ adrenergic receptors than those in scAT [252].

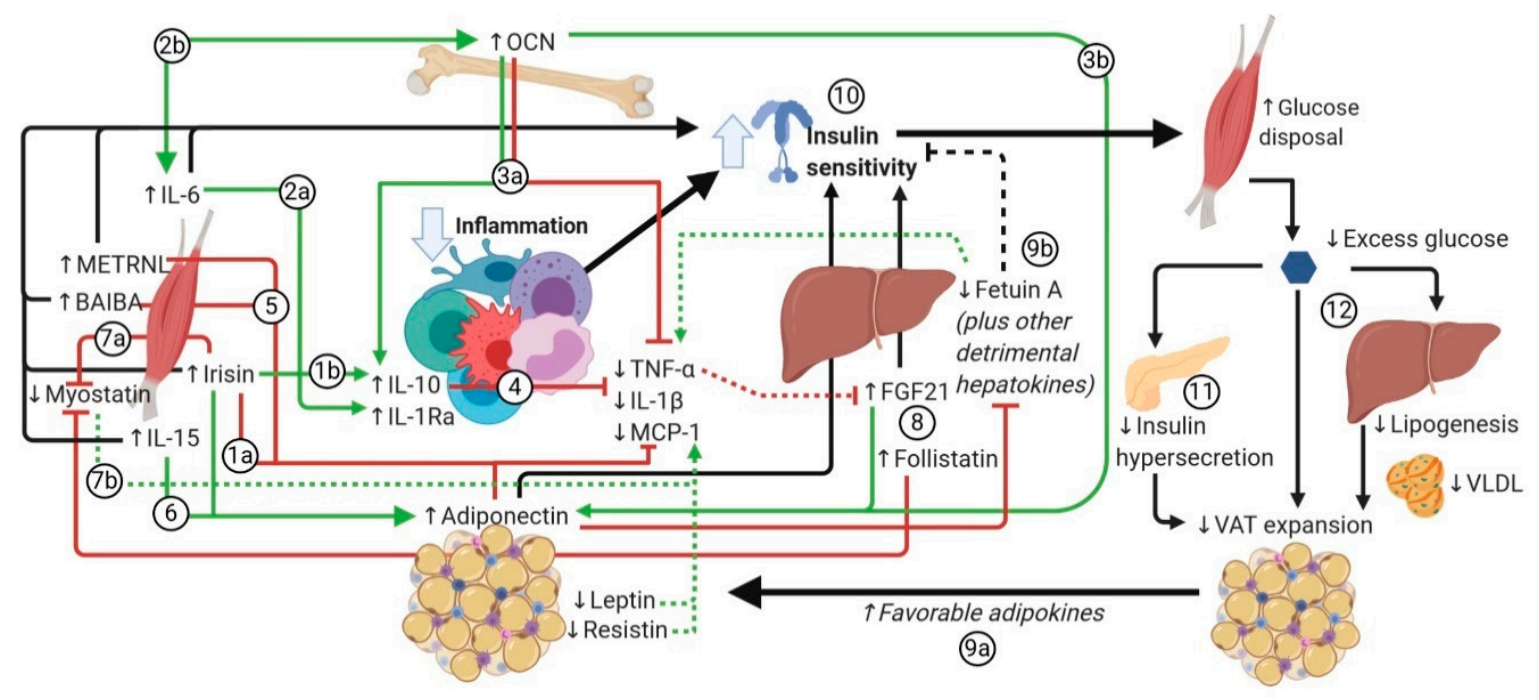

Figure 2. Effects of exercise-inducible factors on the systemic inflammatory milieu and insulin sensitivity. Details in text. Abbreviations: BAIBA: $\beta$-Aminoisobutyric acid; FGF21: Fibroblast growth factor 21; IL-1Ra: Interleukin-1 receptor antagonist; IL-1 $\beta$ : Interleukin-1 $\beta$; IL-6: Interleukin-6; IL-10: Interleukin-10; IL-15: Interleukin-15 MCP-1: Monocyte chemoattractant protein-1; METRNL: Meteorin-like; OCN: Osteocalcin; TNF- $\alpha$ : Tumor necrosis factor-alpha. Green arrows represent a stimulatory effect over another mediator; red inhibitor lines represent an inhibitory effect over another mediator; black arrows or inhibitor lines indicate the final physiologic effect of any given mediator, either stimulatory or inhibitory, respectively; dotted lines indicate absence of an expected effect, either stimulatory or inhibitory. Custom image created with Biorender. 
Table 4. Immune cytokines summary. Exercise modality, evaluated in clinical studies, is aerobic and was conducted in adult populations unless otherwise specified. $\downarrow$ : Decreased; $\uparrow:$ Increased; $\leftrightarrow$ : Unchanged; ?: Controversial; *: Possible mechanism (based on indirect evidence); -: Data not available; ${ }^{\circ}$ : Depending on the specific context, may be either pro- or anti-inflammatory; +: Indicates reviews or meta-analyses; AE: Acute exercise; CE: Chronic exercise; Ob: Obesity; Ow: Overweight; T2DM: Type 2 diabetes mellitus. Other abbreviations are given throughout the text.

\begin{tabular}{|c|c|c|c|c|}
\hline $\begin{array}{c}\text { Cytokine Status in Metabolic } \\
\text { Disease }\end{array}$ & $\begin{array}{c}\text { Status with Exercise (Clinical } \\
\text { Studies) }\end{array}$ & $\begin{array}{l}\text { Known and Potential Endogenous } \\
\text { Inhibitors and Stimuli }\end{array}$ & $\begin{array}{l}\text { Modulation of Other } \\
\text { Mediators }\end{array}$ & Effects on Metabolism \\
\hline $\begin{array}{c}\text { TNF- } \alpha \\
\text { Ob and T2DM: } \uparrow[239]+\end{array}$ & $\begin{array}{l}\text { AE: } \leftrightarrow \downarrow[6,8]+\uparrow \text { (if intensive } \\
\text { enough to cause SkM damage [6]+) } \\
\text { CE: } \downarrow \text { (Healthy [249]+), } \downarrow \\
\text { (T2DM; combined aerobic and } \\
\text { resistance [253]+) }\end{array}$ & $\begin{array}{l}\uparrow: \text { IFN- } \gamma \text { [216]+; FFAs } \\
\text { (via TLR4-NF-KB) [239]+; leptin } \\
\text { [222,223]; oxidative stress [238]+ } \\
\downarrow: \text { IL-6 [74], IL-10 [8]+; adiponectin } \\
\text { [230]+; irisin [51,53,60] }\end{array}$ & $\begin{array}{l}\uparrow: \text { leptin [254], resistin [255] } \\
\downarrow: \text { FGF21 action in AT } \\
\text { (via } \downarrow \beta \text {-klotho) [256], } \\
\text { adiponectin [229] }\end{array}$ & 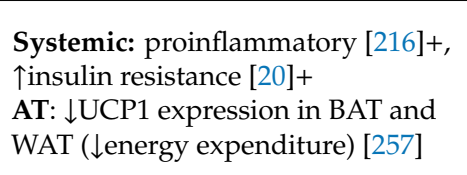 \\
\hline $\begin{array}{c}\text { IL-1 } \beta \\
\text { Ob and T2DM: } \uparrow[239]+\end{array}$ & $\begin{array}{l}\mathrm{AE}: \leftrightarrow \downarrow[8]+[238]+ \\
\mathrm{CE}: \downarrow(\mathrm{T} 2 \mathrm{DM} ; \text { aerobic, resistance, } \\
\text { and combined [253]+) }\end{array}$ & $\begin{array}{l}\uparrow: \text { oxidative stress [238]+; DAMPs } \\
\text { (via NLRs-NALP3 } \\
\text { inflammasome) [239]+ } \\
\downarrow: \text { IL-6 [74]; IL-1Ra [8]+ }\end{array}$ & $\uparrow:$ TNF- $\alpha$, IL-1 $\beta$, IL-6 [14]+ & $\begin{array}{l}\text { Systemic: proinflammatory, } \uparrow \text { insulin } \\
\text { resistance }[239]+ \\
\text { AT: } \downarrow \text { UCP1 expression in BAT and } \\
\text { WAT ( } \downarrow \text { energy expenditure) [258] } \\
\text { Others: pancreatic } \beta \text {-cell } \\
\text { damage [8]+ }\end{array}$ \\
\hline $\begin{array}{c}\text { MCP-1 } \\
\text { Ob: } \uparrow[216]+\end{array}$ & $\begin{array}{l}\mathrm{AE}: \uparrow(\text { Healthy, Ob, T2DM; } \\
\text { aerobic or resistance [6]+) } \\
\mathrm{CE}: ? \leftrightarrow \downarrow \text { (Healthy and Ob; } \\
\text { resistance [6]+); } \downarrow \text { (Ob; combined } \\
\text { aerobic and resistance [259]) }\end{array}$ & $\begin{array}{l}\uparrow: \text { adipocyte hypertrophy, hypoxia, } \\
\text { mechanical stress, FFAs, DAMPs, } \\
\text { proinflammatory cytokines (via } \\
\text { NF-KB signaling) [239]+ } \\
\downarrow: \text { irisin [51,53]; adiponectin [230]+ }\end{array}$ & - & $\begin{array}{l}\text { AT/Immune: } \uparrow \text { monocyte infiltration } \\
\text { in WAT and } \mathrm{M} 1 \mathrm{M} \varphi \\
\text { polarization [239]+ }\end{array}$ \\
\hline IL-4 & $\begin{array}{l}\text { AE: - } \\
\text { CE: } \leftrightarrow(\text { Healthy [249]+); } \uparrow(\mathrm{Ow} \\
\text { adolescents [260]; T2DM, aerobic, } \\
\text { resistance, and combined [253]+) }\end{array}$ & $\begin{array}{l}\uparrow: \text { IL-13 [12]+ } \\
\downarrow: \text { leptin [216]+ }\end{array}$ & $\begin{array}{l}\uparrow: \text { IL-10 [248]+, IL-1Ra [261]+ } \\
\downarrow: \text { TNF- } \alpha, \text { IL-1, IL-6 [261]+ }\end{array}$ & $\begin{array}{l}\text { AT/Immune: } \uparrow \text { M2 polarization } \rightarrow \\
\uparrow \text { insulin sensitivity; } \uparrow \text { Catecholamine } \\
\text { production? [12,101]+; } \\
\text { ( } \uparrow \text { thermogenic gene expression, FA } \\
\text { mobilization, energy } \\
\text { expenditure) [262] }\end{array}$ \\
\hline
\end{tabular}


Table 4. Cont

\begin{tabular}{|c|c|c|c|c|}
\hline $\begin{array}{c}\text { Cytokine Status in Metabolic } \\
\text { Disease }\end{array}$ & $\begin{array}{l}\text { Status with Exercise (Clinical } \\
\text { Studies) }\end{array}$ & $\begin{array}{c}\text { Known and Potential } \\
\text { Endogenous Inhibitors and } \\
\text { Stimuli }\end{array}$ & $\begin{array}{l}\text { Modulation of Other } \\
\text { Mediators }\end{array}$ & Effects on Metabolism \\
\hline $\begin{array}{c}\text { IL-6 }^{\circ} \\
\text { Ob and T2DM: } \uparrow[69]+\end{array}$ & $\begin{array}{l}\text { AE: produced by SkM } \\
\text { (see "myokines" above) } \\
\text { CE (immune/adipose-derived): } \\
\downarrow \text { (Healthy [249]+ and T2DM; } \\
\text { aerobic, resistance, and } \\
\text { combined [253]+) }\end{array}$ & $\begin{array}{l}\uparrow: \text { adipocyte lipolysis, } \\
\text { proinflammatory cytokines } \\
{[69]+; \text { leptin [216]+ }} \\
\downarrow: \text { adiponectin }[230]+\end{array}$ & $\uparrow:$ TNF- $\alpha$ and IL-1 $\beta$ [80] & $\begin{array}{l}\text { Systemic: } \uparrow \text { insulin resistance } \\
\text { (when released by activated } \\
\text { immune cells) [122]+ }\end{array}$ \\
\hline $\begin{array}{c}\text { IL-10 } \\
\text { Ob: } \downarrow[9]+\end{array}$ & $\begin{array}{l}\text { AE: } \uparrow \text { (Healthy; aerobic or HIIT, } \\
\text { duration-dependent [250]+) } \\
\text { CE: } \uparrow \\
\text { (T2DM; aerobic, resistance, and } \\
\text { combined [253]+) }\end{array}$ & $\uparrow:$ IL-6 [74], adiponectin [230]+ & $\begin{array}{l}\downarrow: \text { TNF- } \alpha \text { and IL-1 } \beta[9,238]+; \\
\text { IL-6 and IL-8 }[261]+\end{array}$ & $\begin{array}{l}\text { Systemic: anti-inflammatory } \\
\text { ( IFN- } \gamma \text { by Th1, } \downarrow \text { TNF- } \alpha \text { by M1 } \\
\text { M } \varphi, \uparrow I L-10 \text { by Tregs) [14]+; } \\
\uparrow i n s u l i n \text { sensitivity [9]+ }\end{array}$ \\
\hline IL-13 & $\begin{array}{l}\text { AE: - } \\
\text { CE: } \uparrow(\text { Ow adolescents; } \\
\text { HIIT [260]) }\end{array}$ & $\uparrow:$ IL-33 [12]+ & $\begin{array}{l}\uparrow: \text { IL-10 [12]+ } \\
\downarrow: \text { TNF- } \alpha, \text { IL-1, IL-8 [261]+ }\end{array}$ & $\begin{array}{l}\text { AT/Immune: } \uparrow \mathrm{M} 2 \text { polarization } \\
\text { ( } \uparrow \text { insulin sensitivity, } \\
\uparrow \text { catecholamine production ?) } \\
{[12,101]+}\end{array}$ \\
\hline $\begin{array}{c}\text { IL-33 } \\
\text { Ob: } \uparrow[263]+(\text { impaired action })\end{array}$ & $\begin{array}{l}\text { AE: - } \\
\mathrm{CE}: \uparrow(\mathrm{T} 2 \mathrm{DM}, \text { combined aerobic } \\
\text { and resistance) [264] }\end{array}$ & - & $\begin{array}{l}\uparrow: \text { IL- } 4 \text { and IL-13 (indirect, by } \\
\text { increasing recruitment and } \\
\text { activation of Eos) [12]+; IL-10 } \\
\text { (T-reg expansion) [263]+ }\end{array}$ & $\begin{array}{l}\text { AT/Immune: anti-inflammatory } \\
\text { (maintenance of ILC2 cells } \rightarrow \\
\uparrow I L-5 \text { and IL-13 } \rightarrow \uparrow I L-4 \text { and } \\
\text { IL-13 production by Eos } \rightarrow \text { M2 } \\
\text { polarization and T-regs } \rightarrow \\
\uparrow I L-10 \rightarrow \uparrow \text { WAT browning, } \\
\text { insulin sensitivity) [12]+ }\end{array}$ \\
\hline
\end{tabular}


As also shown in Figure 2 (to facilitate sequence flow, the steps appear numbered as they are introduced in the main text in italics), in the short term, irisin might directly favor a shift from $\mathrm{M} 1 \mathrm{M} \varphi$ to a M2 phenotype [49,59], as well as decrease the expression of TLR4, TNF- $\alpha$, IL-1 $\beta$, MCP-1, and IL-6 by adipocytes and M $\varphi$ [51,53,59] (1a), while increasing IL-10 [59] (1b) and antioxidant cellular mechanisms [60]. On the other hand, IL-6 has been shown to inhibit the transcription of IL-1 and TNF- $\alpha$ [74] while stimulating the release of IL-1Ra, IL-10, and cortisol in human mononuclear cells [72] (2a). Additionally, it has been found to upregulate the secretion of OCN by bone [71] (2b), which reduces the expression of TNF- $\alpha$ and increases that of IL-10 (3a) and adiponectin in adipocytes [211] (3b). IL-10, in turn, was found to inhibit the expression of proinflammatory cytokines [9], while IL-1Ra was shown to antagonize the actions of IL-1 $\beta$ [8] (4). Similarly, the myokines METRNL [100] and BAIBA [110] have proven to suppress TNF- $\alpha$ and other proinflammatory cytokines both in vitro and in vivo (5). In addition, METRNL was able to indirectly stimulate $\mathrm{M} 2 \mathrm{M} \varphi$ polarization by inducing eosinophils to secrete IL-4 and IL-13 [98]. Meanwhile, IL-15 was noted to antagonize the detrimental actions of TNF- $\alpha$, considering its antioxidant properties [26,87] and its ability to stimulate adiponectin release [86] (6). Likewise, exercise-induced reduction of myostatin by irisin [44] (7a) was described to reduce availability of myostatin to engage in proinflammatory responses [116] (7b). Moreover, the hepatokines FGF21 and follistatin, which are induced acutely by exercise, were found to contribute as well. FGF21 was determined to increase glucocorticoid action [164] and the secretion of adiponectin [165], while follistatin was found to bind and inactivate myostatin [184] (8), further inhibiting its proinflammatory effects. In the long term, reduced WAT depots by exercise favor a shift in the adipokine profile [218-220] (9a), and possibly the hepatokine profile $(9 b)$, due to the reduction of hepatic steatosis that occurs concomitantly with weight loss [23]. Altogether, increased adiponectin and decreased leptin from WAT, as well as decreased proinflammatory hepatokines fetuin A and SeP, among others, may help maintain the anti-inflammatory state and thus insulin sensitivity (10).

Enhanced insulin sensitivity could help inhibit fat mass expansion by two mechanisms. The first mechanism is by decreasing the compensatory hyperinsulinemic response that occurs with insulin resistance (11). In this regard, hyperinsulinemia has been proposed to be an early crucial driver in the progression of adiposity [265-268]. Insulin has been shown to activate genetic programs involved in adipogenesis in genetically modified mice [266]. In another study, mice with partial insulin deficiency were found not to develop hyperinsulinemia following exposure to a high-fat diet (HFD), while displaying resistance to weight gain and adiposity, compared with wild-type littermates [269]. Moreover, WAT-specific insulin receptor deficiency was shown to protect mice from obesity, independently of food intake [270,271]. In humans, the relevance of this concept is supported by the observation that hyperinsulinemia following weight loss is predictive of weight regain [272]. Regarding exercise interventions, clinical studies have found decreased fasting levels of insulin not only in healthy individuals who engage in supervised exercise interventions [35], but also in patients with established T2DM at the other end of the spectrum [273]. As the second mechanism, enhanced insulin sensitivity can inhibit the further expansion of VAT by redirecting excess glucose into the increased exercise-adapted SkM mass (where it can be consumed as metabolic fuel or stored as glycogen in the resting state) and away from hepatic lipogenesis (and thus, eventual TG accretion in WAT through VLDLs) (12). This is particularly relevant when considering that insulin resistance may occur to a greater degree in the liver than in WAT in metabolic disease [268], thus perpetuating hepatic lipogenesis, hypertriglyceridemia, and excessive fat deposition in WAT, exacerbated by exaggerated LPL activity induced by hyperinsulinemia. Importantly, some exercise-induced factors have also been shown to have direct insulin-sensitizing effects in target tissues, independently of their effect on inflammation, such as irisin [56], IL-6 [122], IL-15 [84], METRNL [274], BAIBA [112], and FGF21 [154] (10). Concurrently, other exercise-induced factors, such as irisin [66], follistatin [183], and OCN [209], directly protect $\beta$-cells from damage, further potentiating their beneficial metabolic properties. Altogether, decreased insulin resistance and concomitant decreased $\beta$-cell stress elicited by exercise-induced factors could result in mitigation of hyperinsulinemia and decreased availability of lipogenic substrate, hence reducing 
lipogenesis in susceptible WAT depots and thus reducing WAT expansion (Figure 2). In summary, it could be agreed that repeated exercise bouts result in an accumulative effect on inflammation and metabolism, while chronic exercise maintains the resulting basal anti-inflammatory, insulin-sensitive state that favors physiologic fat mass maintenance.

\subsection{Mechanisms of Exercise-Induced Factors on WAT Browning in Health and in Obesity}

Exercise itself increases total-body thermogenic activity and energy expenditure, highlighting the counterintuitive impression that exercise could mediate WAT browning in a situation where preservation of energy would be an expected compensatory response. This is known as the "exercise-induced browning paradox". This apparently paradoxical response may be a defense mechanism against ectopic accumulation of lipids. During exercise, lipolysis leads to increased circulating FFAs, which, if not expended as metabolic fuel in the liver or SkM, would be stored in tissues, leading to lipotoxicity with its associated detrimental consequences, such as oxidative stress, inflammation, and insulin resistance. Thus, by inducing WAT browning, exercise increases the total-body capacity to oxidize FFAs, thereby counteracting ectopic lipid accumulation [79]. A second hypothesis posits that exercise reduces body insulation by decreasing adipocyte size and lipid content in scAT and thus activates thermogenic processes to increase body temperature as a compensatory mechanism [16,79]. Increased WAT browning would be expected to increase BMR, a plausible mechanism through which exercise induces fat loss and weight loss.

Preclinical studies, mostly in rodents, have shown that WAT browning can be generated by various exercise-inducible factors, as shown in Figure 3 (to facilitate sequence flow, the steps appear numbered as they are introduced in the main text in italics). The myokines irisin [57] and BAIBA [104] have been described to directly induce WAT "browning" both in vitro and in vivo, by upregulating genes involved in mitochondrial biogenesis, FAO, oxidative phosphorylation, and thermogenesis (1). In addition, IL-15 was found to enhance the activity of BAT in rodents [275] (2). SkM-derived IL-6 was described to stimulate the release of GLP-1 [73] (3a), enhancing SNS output [19] (3b), and to promote the release of OCN [71] (3c), which in turn upregulates PGC- $1 \alpha$ and UCP-1 in adipocytes [212]. Importantly, as stated above, some of these myokines also possess anti-inflammatory properties $(4 a)$, which is of relevance given that an anti-inflammatory environment is optimal for differentiation and activity of BAT [12], as exemplified by METRNL, which has been found to indirectly promote WAT browning by favoring $\mathrm{M} 2$ polarization of $\mathrm{M} \varphi$ [98] (4b). Additionally, the exercise-induced hepatokines FGF21 [43] and follistatin [185], both upregulated by glucagon (5), have also been described to induce WAT browning directly (6). FGF21 further augments BAT function indirectly, by increasing SNS output $[163,165](7)$, and possibly mediates an hepatokine-myokine crosstalk via activation of PGC-1 $\alpha$ [43], which is known to upregulate the WAT browning myokines FNDC5-irisin [57], METRNL [274], and BAIBA [104]. In the long term, exercise-induced loss of fat mass may favor a permissive environment for WAT browning and BAT function by decreasing the expression of proinflammatory adipokines and increasing that of adiponectin [6] (8), thus maintaining a beneficial feed-forward cycle that promotes redistribution and consumption of excess hydrocarbon biofuel. This is consistent with the fact that BAT can indeed participate in the uptake and metabolism of circulating glucose and FFAs [17]. Hence, excess diet-derived glucose or FFAs could also be transported for their disposal to these specialized adipose depots along with exercise-adapted SkM, thus decreasing available substrates for lipogenesis in the liver and WAT expansion. In fact, the greatest benefits of BAT have been suggested to result from the redistribution of nutrient disposal rather than from thermogenesis per se [34]. BAT has the particular property that, although FFAs from stored TGs are oxidized, the presence of UCP1 uncouples the electron transport chain from ATP synthesis, thus decreasing available ATP for anabolic processes (e.g., re-esterification of FFAs into TGs, which may occur in WAT) and instead dissipating chemical energy as heat. Thus, BAT catabolizes metabolic substrates in "futile cycles", resulting in increased energy expenditure and net loss of fat mass. 


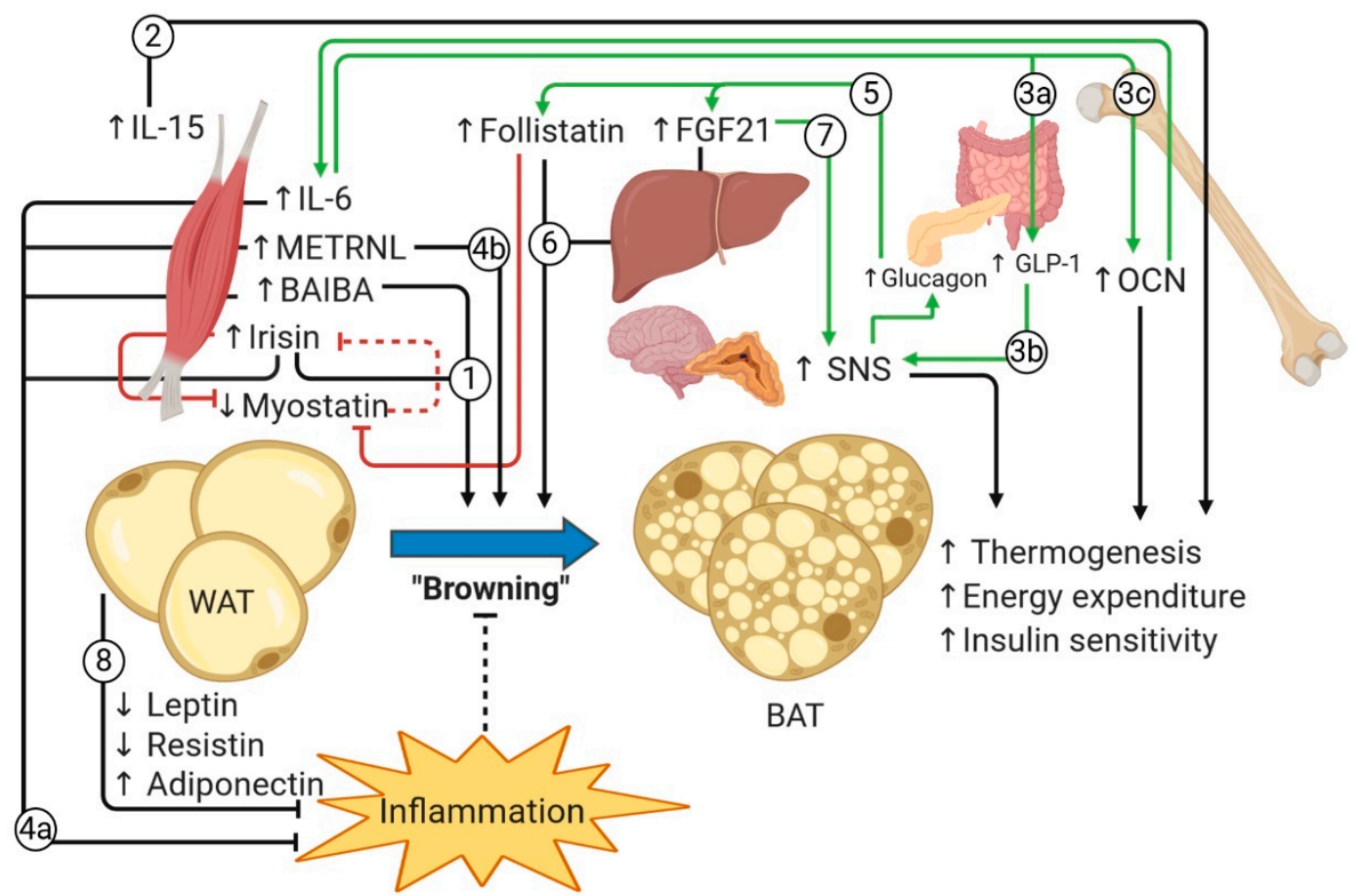

Figure 3. Effects of exercise-inducible factors on WAT "browning". Details in text. Abbreviations: BAIBA: $\beta$-Aminoisobutyric acid; BAT: Brown (and beige) adipose tissue; FGF21: Fibroblast growth factor 21; GLP-1: Glucagon-like peptide 1; IL-6: Interleukin-6; IL-15: Interleukin-15; METRNL: Meteorin-like; OCN: Osteocalcin; SNS: Sympathetic nervous system; WAT: White adipose tissue. Green arrows represent a stimulatory effect over another mediator; red inhibitor lines represent an inhibitory effect over another mediator; black arrows or inhibitor lines indicate the final physiologic effect of any given mediator, either stimulatory or inhibitory, respectively; dotted lines indicate absence of an expected effect, either stimulatory or inhibitory. Custom image created with Biorender.

Although well-validated in rodents, exercise-induced WAT browning remains controversial in humans [16]. Most studies have not found evidence of WAT browning when applying various types and durations of exercise interventions [79]. Nonetheless, increased expression of BAT genes in scAT of adults (across a wide BMI range) subjected to an aerobic exercise program has recently been demonstrated [276]. Two hypotheses have been formulated based on differences in WAT physiology between mice and humans. First, exercise-induced browning might occur in different WAT depots in humans than those in mice. Most studies in humans have evaluated the browning response in scAT biopsies, which at a first glance seems appropriate, given that it is the main AT depot subject to browning in mice [79]. However, a recent study has determined that humans express more BAT-related genes in VAT, while mice express these genes in scAT to a greater degree [277]. Second, the relatively low levels of $\beta$-adrenergic receptor expression in human scAT compared with those in VAT [252] could account for the lack of exercise-induced browning. Thus, the lack of browning in humans might be due to research not being focused in the appropriate location. If indeed BAT is induced to a greater degree in VAT in humans, then this could represent a potential mechanism for the decreased VAT mass observed with exercise.

Another interesting possibility is that the lack of observable browning in obese populations might represent a pathophysiological phenomenon, rather than a lack of such an effect [13], given that browning in VAT has not been studied in this population and that any detectable effect is likely dampened by the proinflammatory milieu in obesity. Supporting this hypothesis, "catecholamine resistance" is known to occur in individuals with long-standing obesity. Particularly, lipolysis and activation of transcription factors that result in WAT browning require signaling through the $\beta 3$-adrenergic receptor. Its downstream signaling pathway may be attenuated in obesity by chronic 
exposure to TNF- $\alpha$ through NF-KB-mediated upregulation of IKK $\varepsilon$ and TBK1, which inhibit cAMP signaling via phosphodiesterase 3B [239]. Furthermore, $\mathrm{M} 2$ anti-inflammatory $\mathrm{M} \varphi$, mostly absent in obese WAT, appear to be crucial in the process of WAT browning [12], via as of yet unclear mechanisms. In addition, $\mathrm{M} 1$ proinflammatory $\mathrm{M} \varphi$, abundant in obese WAT, seem to inhibit beige adipogenesis. In line with this, an inflammatory WAT microenvironment was shown to impair beige adipogenesis through contact-dependent interactions between M1 M $\varphi$ and adipocytes in a murine model. TNF- $\alpha$ was shown to upregulate VCAM-1 in adipocytes, which induced direct adhesion to M1 M $\varphi$ via $\alpha_{4}$ integrin. Additionally, TNF- $\alpha$ decreased UCP1 expression in adipocytes by an Erk-dependent mechanism when cultured in the presence of browning agents NE and T3. A similar mechanism was found in human adipocytes as well [278]. This highlights the possibility that chronic exposure to an overwhelming inflammatory milieu could impair browning in humans. If indeed exercise-induced WAT browning were to occur in the visceral compartment to a greater degree in humans, this would theoretically dampen the loss of visceral fat mass. If this were the case, then it could help explain why obese subjects have suboptimal results in achieving weight loss when the only adopted lifestyle modification is exercise [279].

Alternatively, impaired endocrine regulation of exercise-induced factors involved in WAT browning could represent yet another possibility in the context of obesity. Clinical studies in patients with insulin resistant conditions have described dampened upregulation of exercise-induced factors, such as FGF21 and follistatin, most likely due to an altered glucagon-to-insulin ratio $[156,157,280]$, and possibly irisin, which is known to be downregulated by glucotoxic, lipotoxic $[47,48]$, and inflammatory conditions [45]. The opposite may occur for fetuin A, whose lack of exercise-induced decrease might be explained by its upregulation in the context of insulin resistance [144,145]. Concomitantly, resistance to release of exercise-inducible factors might also be involved, potentially elucidating, at least in part, why FGF21, follistatin, irisin, and METRNL are frequently increased in patients with obesity and T2DM, even in basal conditions.

\subsection{Effects of Exercise-Induced Factors on Lipolysis, Fatty Acid Oxidation (FAO), Reduced Lipogenesis, and the Redistribution of Fatty-Acid-Derived Energy Fuel}

The total-body FAO rate is determined not only by AT but also by metabolic activity in the SkM and in the liver. Glucose and FFAs have been shown as metabolic substrates for the SkM when an individual is engaged in aerobic exercise [30], but FFAs become the main substrate in the post-exercise recovery period [32], depending on both the SkM enzymatic oxidative capacity and substrate availability supplied largely by WAT and the liver. Following bouts of aerobic exercise, circulating FFAs and the SkM FAO remain significantly elevated depending on exercise intensity and duration [32]. Aerobic exercise influences these processes, at least in part, through the action of exercise-inducible factors, as summarized next and illustrated in Figure 4 (to facilitate sequence flow, the steps appear numbered as they are introduced in the main text in italics). 


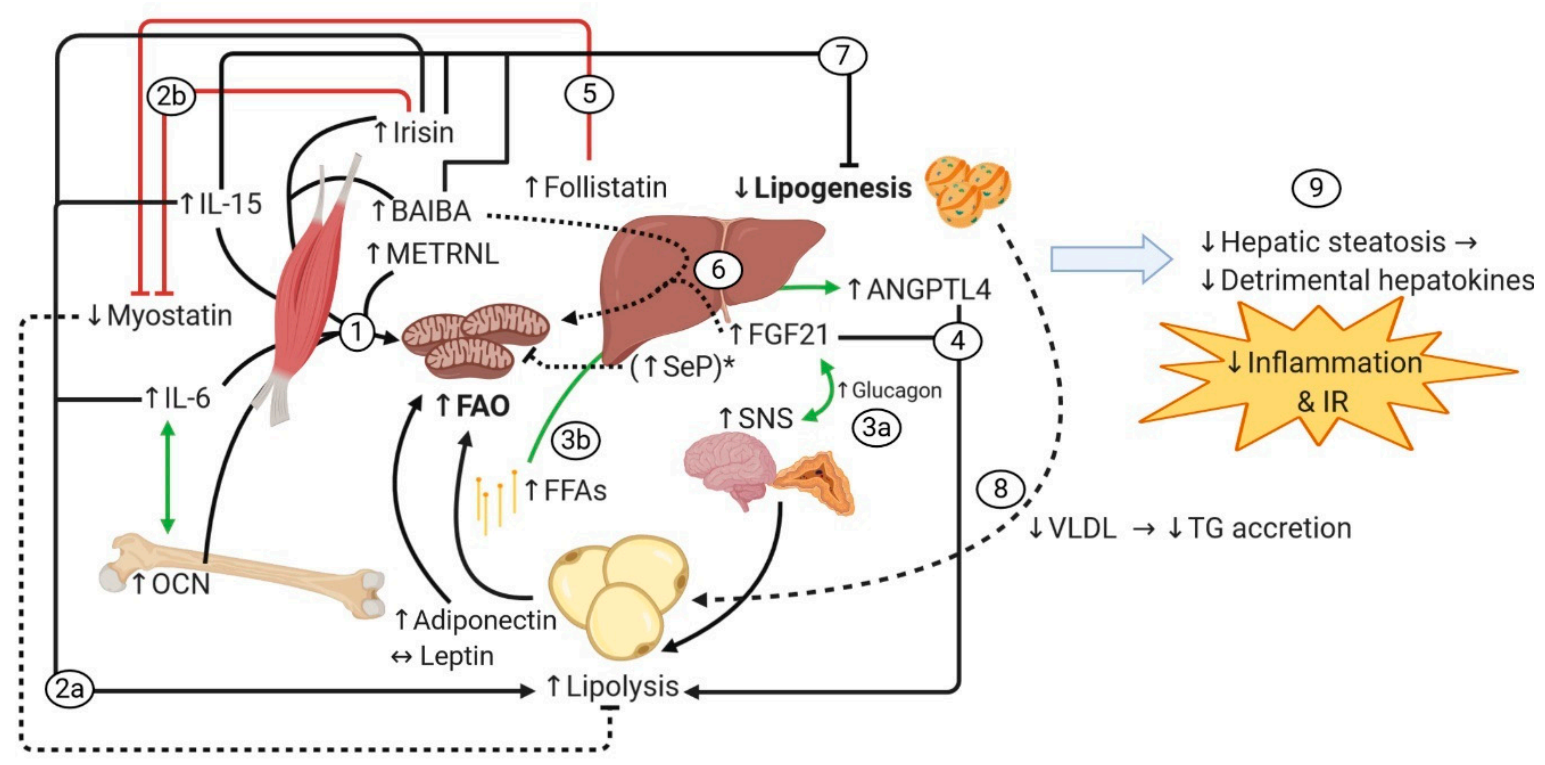

Figure 4. Effects of exercise-inducible factors on hepatic and SkM FAO, WAT lipolysis, and hepatic lipogenesis. Details in text. *Although SeP is not regulated by exercise, its high concentrations in obesity might impair SkM adaptation to oxidative metabolism. Abbreviations: ANPTL4: Angiopoietin-like 4; BAIBA: $\beta$-Aminoisobutyric acid; FAO: Fatty acid oxidation; FFAs: Free fatty acids; FGF21: Fibroblast growth factor 21; IL-6: Interleukin-6; IL-15: Interleukin-15; IR: Insulin resistance; METRNL: Meteorin-like; OCN: Osteocalcin; SeP: Selenoprotein P; TG: Triglycerides; VLDL: Very-low-density lipoprotein. Green arrows represent a stimulatory effect over another mediator; red inhibitor lines represent an inhibitory effect over another mediator; black arrows or inhibitor lines indicate the final physiologic effect of any given mediator, either stimulatory or inhibitory, respectively; dotted lines indicate absence of an expected effect, either stimulatory or inhibitory. Custom image created with Biorender.

Figure 4 shows the effects of exercise-inducible factors on hepatic and SkM FAO, WAT lipolysis, and hepatic lipogenesis. Exercise-inducible myokines, such as irisin [62,63], IL-6 [76,77], IL-15 [91,126], BAIBA [111], and METRNL [100], as well as the osteokine OCN [71] have been shown to directly stimulate oxidative metabolism in autocrine and endocrine ways, respectively (1). These mechanisms include the upregulation of transporter molecules involved in glucose and FFA uptake and of the enzymes involved in FAO, along with the stimulation of mitochondrial biogenesis, which enhances the oxidative capacity of the SkM. Furthermore, some myokines could contribute to the WAT lipolysis in an endocrine fashion. For instance, irisin [58], IL-15 [89], and IL-6 [75] have shown to directly induce lipolysis in adipocytes (2a), while irisin exerts a dual effect by also inhibiting myostatin [44] $(2 b)$, reducing myostatin-mediated inhibition of WAT lipolysis [132]. The liver also contributes by releasing hepatokines, namely FGF21, follistatin, and ANGPTL4, during exercise, with glucagon as the main prompter ( $3 a)$, as well as in the recovery period, in which circulating FFAs are the chief driver via PPAR- $\alpha[3,4](3 b)$. While both FGF21 [166] and ANGPTL4 $[176,177]$ induce WAT lipolysis (4), the latter may selectively inhibit WAT LPL to favor lipoprotein-derived FFAs by the exercising SkM [197]. Follistatin, on the other hand, by inhibiting myostatin [184] (5), might also contribute to continued lipolysis in WAT. Importantly, these exercise-inducible factors remain in circulation for hours after the exercise bouts, and thus their effects in target tissues can be expected to persist beyond the acute exercise bout. In brief, myokines and hepatokines, by stimulating oxidative metabolism concomitantly with lipolysis in the post-exercise period, increase the proportion of FFAs that are oxidized instead of being re-esterified into TGs that are eventually returned to WAT, thus limiting WAT expansion, possibly in visceral depots. 
Exercise also exerts beneficial effects by decreasing fatty accumulation in the liver. Hepatic steatosis, present in up to $70 \%$ of individuals with overweight and in $>90 \%$ of morbidly obese ones [23], has been shown to perpetuate obesity and the systemic proinflammatory and insulin-resistant state. Impaired hepatic FAO (most likely due to mitochondrial dysfunction in hepatocytes), increased circulating FFAs in the setting of basal VAT lipolysis (secondary to full-blown insulin resistance), and exaggerated lipogenesis, are considered pathogenic hallmarks of hepatic steatosis [23]. Exercise might importantly target these processes through exercise-inducible factors, which might be responsible for the beneficial effects, as supported by a recent meta-analysis that described reduced intrahepatic TG content in humans subjected to aerobic exercise interventions [24]. For instance, BAIBA [104] and FGF21 [160] have been shown to increase hepatic $\beta$-oxidation (6), while others such as irisin [65], IL-15 [90], and BAIBA [113] have been found to inhibit hepatic lipogenesis $(7)$. OCN $[28,215]$ and irisin [61,65], on the other hand, may also exert direct anti-oxidant and anti-inflammatory effects in the liver. These effects might be clinically relevant, as an inverse association between irisin concentrations and hepatic TG content in adults has been recently reported [281]. The added-up effects of the exercise-inducible factors could prevent hepatic lipid accumulation by increasing their oxidation and reducing lipogenesis, which would in turn decrease the accretion of TGs in WAT via LPL, thereby inhibiting WAT expansion (8). A synergistic effect in the SkM after exercise, mediated by ANGPTL4, might occur. In addition, this might indirectly result in a more favorable hepatokine profile (9). This is supported by clinical studies that have found that exercise interventions decrease the levels of detrimental hepatokines and increase the metabolically favorable ones, counteracting systemic inflammation and insulin resistance, as well as eliciting an increase in global energy expenditure.

In summary, through the summed metabolic effects of a favorable hepatokine profile, redistribution of hydrocarbon fuel sources is favored towards catabolism in SkM and BAT and away from anabolic pathways in the liver and eventually in WAT, thus potentially impairing WAT expansion in visceral depots. Increased circulating FFAs due to myokine- and hepatokine-induced lipolysis synergize with the lipolytic effects of catecholamines in WAT and, in conjunction with myokine- and hepatokine-induced FFA uptake and oxidation by SkM and the liver, may contribute to limit the availability of circulating FFAs for lipogenesis in WAT, thereby explaining the decreased visceral adiposity observed in preclinical models. In the long term, loss of fat mass also triggers favorable changes in the adipokine profile, augmenting adiponectin levels and further favoring FAO in SkM and the liver, as previously described.

\subsection{Considerations for Exercise-Induced Fat Mass Loss and Weight Loss in the Obese State}

Overall, most clinical evidence to date supports the concept that exercise is more effective in preventing overweight and obesity than in their reversal [279]. Nevertheless, it is important to highlight that exercise has been shown to reduce VAT depots independently of overall weight changes, and strong evidence suggests that it is more effective than hypocaloric dietetic interventions. In fact, weight loss, as a single measurement of the efficacy of an exercise intervention, is an inappropriate and misleading indicator [282], as exercise not only induces VAT loss but may also promote gain of fat-free mass [283], balancing the total weight. Thus, the importance of exercise should not be overlooked even when it does not result in net weight loss [241]. However, some physiological differences must be considered when analyzing the fat-reducing role of exercise in the context of obesity.

Obesity unleashes a self-perpetuating cascade of detrimental mechanisms that result in the maintenance of obesity itself and in the appearance of metabolic complications. Concretely, detrimental neuroendocrine positive feedback loops that are initiated and maintained in the obese state may be part of the explanation for why, once established, excess weight may prove difficult to lose if the only adopted lifestyle modification is exercise at the currently recommended levels of $150 \mathrm{~min} /$ week. In fact, evidence has shown that a higher exercise duration is needed to reverse obesity than to maintain a healthy weight [279]. Previously obese or overweight individuals were shown to require higher duration of exercise to maintain a healthy weight (200-300 $\mathrm{min} /$ week of moderate-intensity aerobic exercise) compared with those who were not previously overweight (150-250 $\mathrm{min} /$ week) [284]. This 
relative difficulty in attaining weight loss with preexisting obesity may be related to the combination of several mechanisms, such as an overwhelming proinflammatory milieu resulting in a persistently altered hypothalamic sensitivity to appetite hormones, imbalanced energy expenditure, increased insulin resistance, hyperinsulinemia leading to enhanced adipogenesis, and impaired WAT "browning". In addition, resistance or impaired synthesis of exercise-inducible factors in the obese population could be contributors to weight-loss-resistance, requiring higher intensity, frequency, and/or duration of exercise than what is commonly prescribed in order to be released to an extent significant enough to reduce fat mass. Indeed, an intensity-dependent increase in the levels of FGF21 and follistatin in healthy untrained adults subjected to a 45-min treadmill challenge has been recently described [285]. Furthermore, clinical trials with a synthetic FGF21 analog effectively reduced weight and increased insulin sensitivity in obese individuals [286]. Thus, increased concentrations of these exercise-inducible factors could hypothetically overcome the already established resistance to the favorable effects of these factors in obesity. Resistance to the effects of exercise-inducible factors on lipid mobilization and redistribution of hydrocarbon fuel away from WAT and its effect on visceral fat mass is an appealing area of study and warrants further investigation.

\subsection{Exercise Promotes Decreased Fat Mass, Healthy Weight, and Balanced Energy Metabolism by Exercise-Induced Factors: Putting it All Together}

Figure 5 shows an integrated view of the role of exercise training on pathways associated with energy expenditure, fat mass loss, redistribution of energy substrates, adipose tissue reserves, and immunometabolic health. Altogether, accumulative bouts of aerobic exercise promote the release of exercise-inducible factors that interact with one another (Table 5), convey direct insulin-sensitizing and anti-inflammatory properties, and favor metabolic adaptations that increase oxidative metabolism, jointly resulting in decreased body fat mass. The end effects of the main organokines are summarized and compared in Table 6. Decreased fat mass is accompanied by favorable changes in the adipocytokine, hepatokine, and myokine profiles. These, in turn, further maintain a systemic anti-inflammatory environment, subsequently promoting insulin sensitivity and a rebalanced total energy expenditure. This is accomplished by reversal of BAT dysfunction and a finer regulation of the hypothalamic circuitry controlling energy expenditure and food intake. Additionally, the decreased fat mass and insulin sensitivity associated with exercise, along with the direct actions on the liver of the exercise-inducible factors, lead to resolution of fatty liver, which in turn could help restore a healthy hepatokine profile that further enhances immunometabolic health. Although these proposed mechanisms are indeed interesting and important, more research is needed to corroborate these hypotheses, which are summarized in Figure 5. 


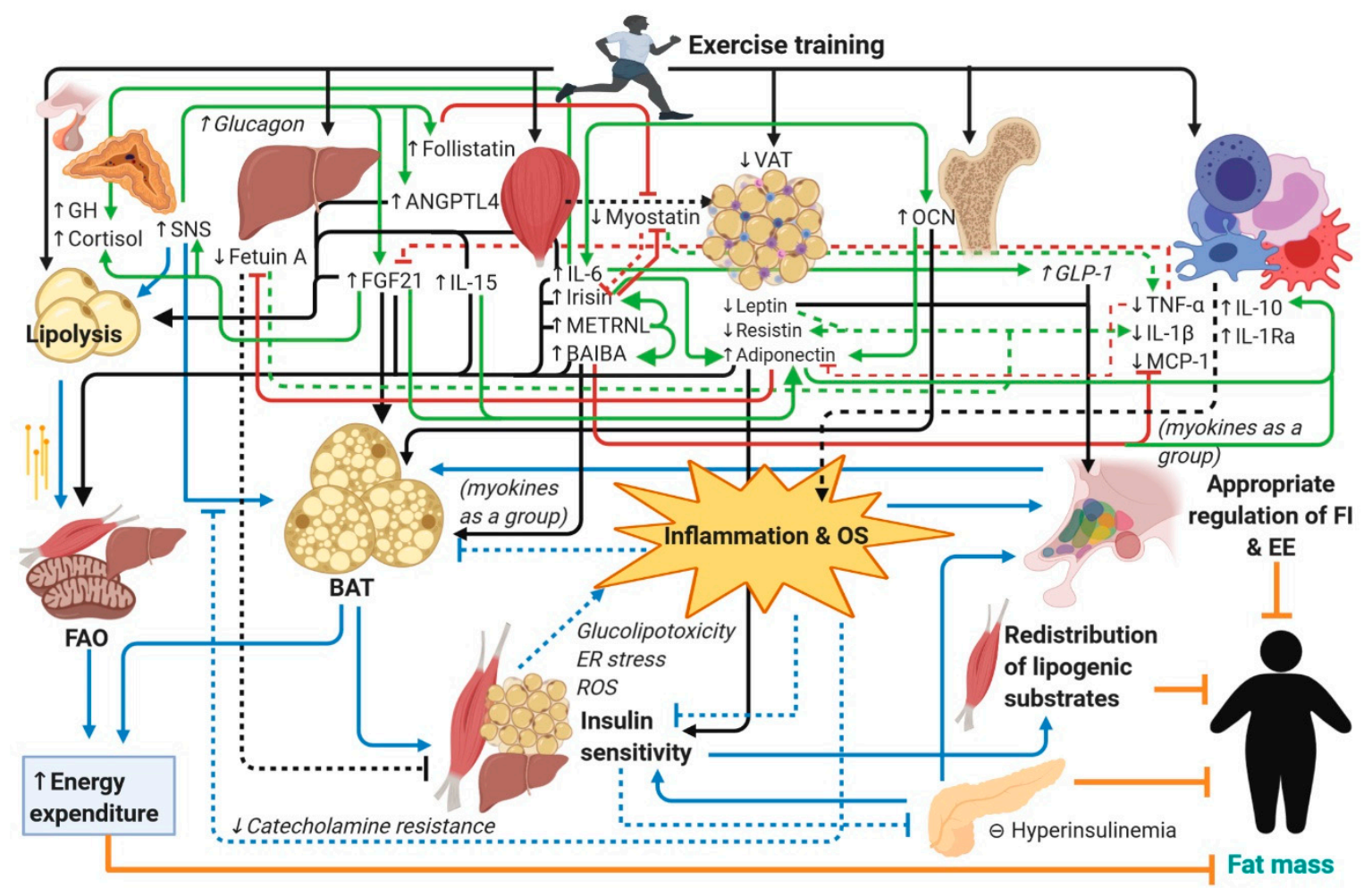

Figure 5. An integrated view of the role of exercise training on pathways associated with energy expenditure, fat mass loss, redistribution of energy substrates, adipose tissue reserves, and immunometabolic health: integrated neuroendocrine pathways associated with exercise training that affect global AT reserves and function. Interdependence between the processes of central control of energy balance, WAT browning, inflammation, and insulin sensitivity is highlighted. AT: adipose tissue, ANGPTL4: Angiopoietin-like 4; BAIBA: $\beta$-Aminoisobutyric acid; BAT: Brown (and beige) adipose tissue; EE: Energy expenditure; ER: Endoplasmic reticulum; FAO: Fatty acid oxidation; FI: Food intake; FGF21: Fibroblast growth factor 21; GH: Growth hormone; GLP-1: Glucagon-like peptide 1; IL-1Ra: Interleukin-1 receptor antagonist; IL-1 $\beta$ : Interleukin-1 $\beta$; IL-6: Interleukin-6; IL-10: Interleukin-10 IL-15: Interleukin-15; MCP-1: Monocyte chemoattractant protein-1; METRNL: Meteorin-like; OCN: Osteocalcin; OS: Oxidative stress; ROS: Reactive oxygen species; SNS: Sympathetic nervous system; TNF- $\alpha$ : Tumor necrosis factor alpha; VAT: Visceral adipose tissue. Green arrows represent a stimulatory effect over another mediator; red inhibitor lines represent an inhibitory effect over another mediator; black arrows or inhibitor lines indicate the final physiologic effect of any given mediator, either stimulatory or inhibitory, respectively; blue arrow or inhibitor lines indicate the consequence of a process as a whole, either stimulatory or inhibitory, respectively; orange inhibitor lines indicate the final processes in the control of fat mass; dotted lines indicate absence of an expected effect, either stimulatory or inhibitory. Custom image created with Biorender. 
Table 5. Crosstalk between exercise-inducible factors. $\leftrightarrow$ : Denotes a feedback loop. -: No data available. *: Indicates a possible, unconfirmed mechanism based on the activated signaling pathway.

\begin{tabular}{|c|c|c|c|c|c|c|}
\hline & Myokines & Hepatokines & Adipokines & Immune Cytokines & Osteokines & Other Hormones \\
\hline Myokines & 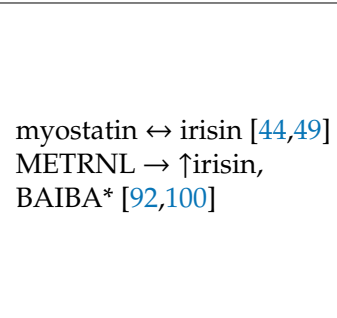 & $\begin{array}{l}\text { FGF21 } \rightarrow \text { 个irisin* }[43] \\
\text { follistatin } \rightarrow \downarrow \text { myostatin } \\
{[184]} \\
\text { SeP } \rightarrow \downarrow \text { adiponectin [136], } \\
\downarrow \text { irisin, BAIBA, METRNL } \\
(\text { via } \downarrow \text { PGC-1 } \alpha \text { due to } \\
\downarrow \text { OS)* }[50]\end{array}$ & $\begin{array}{l}\text { irisin } \rightarrow \text { } \uparrow \text { adiponectin } \\
\text { [51], ? } \downarrow \text { leptin [54,55] } \\
\text { IL-15 } \rightarrow \text { } \text { adiponectin [86] } \\
\text { BAIBA } \rightarrow \text { } \text { leptin [109] }\end{array}$ & $\begin{array}{l}\text { irisin } \rightarrow \downarrow \text { TNF- } \alpha, \text { IL-1 } \beta, \text { IL-6, } \\
\text { MCP- } 1, \uparrow I L-10[49,51,53] \\
\text { IL-6 } \rightarrow \downarrow \text { TNF- } \alpha \text { and IL-1 } \beta \text { [74] } \\
\uparrow I L-10 \text { and IL-1Ra [72] } \\
\text { BAIBA } \rightarrow \downarrow \text { TNF- } \alpha \text { and } \\
\text { MCP-1[110] } \\
\text { METRNL } \rightarrow \uparrow I L-4 \text { and } \\
\text { IL-13[98] } \downarrow \text { TNF- } \alpha, \text { MCP-1, IL-6 } \\
{[100]}\end{array}$ & $\begin{array}{l}\uparrow \mathrm{OCN} \leftrightarrow \uparrow \text { IL-6 [71] } \\
\text { BAIBA } \rightarrow \uparrow \text { OCN } \\
{[108]}\end{array}$ & $\begin{array}{l}\text { IL-6 } \rightarrow \uparrow \text { GLP-1 [73], } \\
\text { cortisol [72] } \\
\text { lactate } \rightarrow \downarrow \text { ghrelin [247] }\end{array}$ \\
\hline Hepatokines & & $\begin{array}{l}\downarrow \text { fetuin } \mathrm{A} \rightarrow \uparrow \text { FGF21, } \\
\text { follistatin, ANGPTL4 (by } \\
\text { decreasing hepatic } \\
\text { insulin resistance)* }\end{array}$ & $\begin{array}{l}\downarrow \text { adiponectin [148] } \leftrightarrow \\
\downarrow \text { fetuin A [146], SeP [135] } \\
\text { FGF21 } \rightarrow \text { } \text { adiponectin } \\
{[287]}\end{array}$ & $\begin{array}{l}\text { TNF- } \alpha \rightarrow \downarrow \text { FGF-21 (induces } \\
\text { resistance via } \downarrow \beta \text {-klotho) [256] } \\
\text { fetuin A } \rightarrow \uparrow \text { TNF- } \alpha \text {, IL-6 [148] }\end{array}$ & - & $\begin{array}{l}\text { FGF21 } \rightarrow \uparrow \text { cortisol [164] } \\
\text { glucagon } \rightarrow \uparrow F G F 21 \\
{[158,159], \text { follistatin [183], }} \\
\text { ANGPTL4 [170], } \\
\text { cortisol } \rightarrow \uparrow \text { ANGPTL4 } \\
{[175]}\end{array}$ \\
\hline Adipokines & & & - & $\begin{array}{l}\text { leptin } \rightarrow \uparrow \text { TNF- } \alpha, \text { IL-1 } \beta, \text { IL-6 } \\
{[222,223]} \\
\text { adiponectin } \rightarrow \downarrow \text { TNF- } \alpha, \text { IL-6, } \\
\uparrow I L-10[230] \\
\text { resistin } \rightarrow \uparrow T N F-\alpha, \text { IL-6 [234] } \\
\text { TNF- } \alpha \rightarrow \downarrow \text { adiponectin [229], } \\
\uparrow \text { resistin [255] and leptin [254] } \\
\text { IL-10 } \rightarrow \downarrow \text { TNF- } \alpha, \text { IL-1 } \beta[248]\end{array}$ & $\begin{array}{l}\text { OCN } \rightarrow \uparrow \text { adiponectin } \\
\text { [211] }\end{array}$ & $\begin{array}{l}\text { adiponectin } \rightarrow \text { insulin } \\
\text { sensitivity [230] } \\
\text { insulin } \rightarrow \uparrow \text { leptin [19] } \\
\text { leptin } \rightarrow \downarrow \text { insulin [69] } \\
\text { catecholamines } \rightarrow \\
\text { †adiponectin, } \downarrow \text { leptin [69] }\end{array}$ \\
\hline $\begin{array}{l}\text { Immune } \\
\text { cytokines }\end{array}$ & & & & $\begin{array}{l}\mathrm{IL}-1 \mathrm{Ra} \rightarrow \downarrow \mathrm{IL}-1 \beta[8] \\
\mathrm{IL}-33 \rightarrow \uparrow \mathrm{IL}-4 \text { and IL-13 } \rightarrow \\
\uparrow \mathrm{IL}-10 \text { [12] }\end{array}$ & $\begin{array}{l}\text { OCN } \rightarrow \uparrow I L-10, \\
\downarrow T N F-\alpha[211]\end{array}$ & 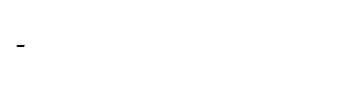 \\
\hline $\begin{array}{c}\text { Osteokines } \\
\text { Other } \\
\text { hormones }\end{array}$ & & & & & - & $\begin{array}{l}\text { OCN } \rightarrow \text { insulin [209] } \\
\text { glucagon } \leftrightarrow \text { insulin } \\
\text { catecholamines, cortisol, } \\
\text { GH } \rightarrow \downarrow \text { insulin } \\
\text { (antagonistic effect) }\end{array}$ \\
\hline
\end{tabular}


Table 6. Summary of the role of the organokines in metabolism and energy balance. Details and references in text and in Tables 1-4. $\uparrow$ : Increased; $\downarrow$ : Decreased; ?: Controversial or inconclusive; -: No effect or no data available.

\begin{tabular}{|c|c|c|c|c|c|}
\hline Organokines & $\begin{array}{l}\text { Central Energy } \\
\text { Expenditure }\end{array}$ & Meta-Inflammation & Insulin Sensitivity & Active BAT & $\begin{array}{l}\text { Role in Metabolic Pathway } \\
\text { Regulation for Fat } \\
\text { Redistribution and Loss }\end{array}$ \\
\hline \multicolumn{6}{|l|}{ Myokines } \\
\hline Irisin & $\uparrow($ via BDNF) ? & $\downarrow$ & $\begin{array}{l}\uparrow \text { (also protects } \\
\beta \text {-cells) }\end{array}$ & $\uparrow$ & 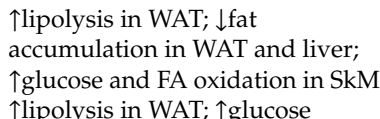 \\
\hline IL-6 & $\uparrow$ (also via GLP-1) & context-dependent & $\uparrow$ & $\uparrow$ & $\begin{array}{l}\text { export by liver; } \uparrow \text { glucose and FA } \\
\text { oxidation in SkM }\end{array}$ \\
\hline IL-15 & - & $\downarrow$ & $\uparrow$ & - & $\begin{array}{l}\text { } \text { lipolysis and } \downarrow \text { lipogenesis in } \\
\text { WAT; } \uparrow F A O \text { in SkM and } \\
\text { hypertrophy ( } \uparrow \text { global EE) }\end{array}$ \\
\hline METRNL & - & $\downarrow$ & $\uparrow$ & $\uparrow$ & Tglucose and FA oxidation in SkM \\
\hline BAIBA & $\uparrow$ & $\downarrow$ & $\uparrow$ & $\uparrow$ & $\begin{array}{l}\downarrow \text { lipogenesis in WAT and liver; } \\
\uparrow F A O \text { in SkM and liver }\end{array}$ \\
\hline Myostatin & - & $\uparrow$ & $\downarrow$ & $\downarrow$ & $\begin{array}{l}\downarrow \text { lipolysis and FAO in WAT, SkM } \\
\text { atrophy ( } \downarrow \text { global EE) }\end{array}$ \\
\hline \multicolumn{6}{|l|}{ Hepatokines } \\
\hline Selenoprotein $\mathrm{P}$ & - & - & $\downarrow$ & - & - \\
\hline Fetuin A & - & $\uparrow$ & $\begin{array}{l}\downarrow \text { (also detrimental } \\
\text { for } \beta \text {-cells) }\end{array}$ & - & lipogenesis in WAT and liver \\
\hline FGF21 & $\uparrow$ & - & $\uparrow$ & $\uparrow$ & $\begin{array}{l}\text { } \text { lipolysis in WAT; } \uparrow F A O \text { and } \\
\downarrow l \text { lipogenesis in liver }\end{array}$ \\
\hline ANGPTL4 & - & - & - & - & $\begin{array}{l}\text { Tlipolysis and } \downarrow \text { lipid accretion in } \\
\text { WAT; } \downarrow \text { dietary fat absorption }\end{array}$ \\
\hline $\begin{array}{l}\text { Follistatin } \\
\text { Osteokine }\end{array}$ & - & - & - (protects $\beta$-cells) & $\uparrow$ & $\uparrow$ SkM hypertrophy ( $($ global EE) \\
\hline $\mathrm{OCN}$ & $\uparrow($ via insulin) ? & $\downarrow$ & $\begin{array}{l}\uparrow \text { (also promotes } \\
\text { secretion) }\end{array}$ & $\uparrow$ & $\begin{array}{l}\text { Tglucose and FA oxidation in } \\
\text { SkM; } \downarrow \text { lipid accumulation in liver }\end{array}$ \\
\hline \multicolumn{6}{|l|}{ Adipokines } \\
\hline Leptin & $\uparrow$ & $\uparrow$ & - & - & $\begin{array}{l}\text { } \text { glucose and FA oxidation in } \\
\text { SkM; } \uparrow F A O \text { in liver }\end{array}$ \\
\hline Adiponectin & $\downarrow$ & $\downarrow$ & $\uparrow$ & $\uparrow$ & $\begin{array}{l}\uparrow \text { FAO in SkM and liver; } \\
\downarrow \text { lipogenesis in liver }\end{array}$ \\
\hline Resistin & - & $\uparrow$ & $\uparrow$ & - & - \\
\hline
\end{tabular}

\section{Conclusions and Future Directions}

Exercise unleashes a complex network of endocrine interactions in which circulating factors, released in response to exercise, interplay through inter-organ crosstalk and physiologic changes. Exercise influences a favorable organokine profile that, per se, mediates many of its beneficial health effects. In summary, acute exercise bouts appear to modulate the release of myokines, hepatokines, osteokines, and immune cytokines, while chronic exercise training correlates with changes in basal circulating adipokines and immune cytokines, possibly in association with weight loss itself. In conjunction, organokines act in an orchestrated manner to modulate systemic metabolic processes. Their concentrations and effects change in response to the intensity, duration, and frequency of exercise to directly or indirectly control WAT reserves. Beneficial organokines induced by exercise include irisin, IL-6, IL-15, METRNL, BAIBA, FGF21, ANGPTL4, follistatin, osteocalcin, and adiponectin, which jointly mediate the mechanisms and effects. These include the following: (1) SkM adaptation to exercise, including hypertrophy and induction of catabolic enzymes, thus promoting efficient glucose and FFA utilization that precludes these energetic fuels from entering anabolic pathways in the liver and WAT; (2) browning of WAT, which, in addition to SkM, dissipates the energy coming from the excess of nutrients in the form of heat; (3) induction of an anti-inflammatory and insulin-sensitive state that is permissive for physiologic lipolysis induced by catecholamines or other exercise-inducible factors in response to exercise and BAT activity; (4) redistribution of energy fuel away from WAT and available for SkM, as well glucose disposal in SkM, thus decreasing available substrate for lipogenesis; and (5) a restored control of energy balance by the CNS. Furthermore, in the long term, decreased levels of detrimental hepatokines such as selenoprotein $\mathrm{P}$ and fetuin $\mathrm{A}$, as well as normalized expression of leptin and decreased levels of resistin, further aid in maintaining healthy weight and fat mass by 
decreasing systemic inflammation and insulin resistance, thus being permissive to all of the above mechanisms. Considering the potent synergistic and pleiotropic effects of exercise-inducible factors summarized in Figure 5, it is plausible that, in addition to protecting against the development of obesity, exercise, when performed at a sufficient frequency, intensity, and duration, is a powerful tool for dissipating excess visceral fat mass that is causally involved in the pathogenesis of chronic cardiometabolic diseases.

Important areas to address in future research include the translational potential of the preclinical evidence, the identification of relevant effects of exercise-inducible factors from a clinical perspective, and, finally, the inter-individual variability of the physiologic response to exercise interventions, especially in obese populations. Specifically, considering that groups of exercise-inducible factors have been mostly studied independently, future interventional clinical studies with large sample sizes should address a comprehensive panel to evaluate the status of all groups of organokines, ideally at the tissue level (when feasible) and in circulation. This type of research ought to be carried out before and after predetermined time intervals following acute exercise bouts and chronic training regimens of different modalities, durations, and intensities, both in healthy controls and patients with obesity and associated metabolic diseases. Studies in humans are important, given that results could differ from those obtained in preclinical models, possibly aiding in the identification of the most viable therapeutic targets.

Altogether, exercise-factors are novel molecules that may, in the future, mark pathways towards new diagnostic and prognostic markers, as well as probable therapeutic strategies in obesity, especially considering that their basal levels, modulation by exercise, and functions could be blunted in this context, at least initially. Impairment of the modulation by exercise of these exercise-inducible factors or resistance to their actions in target tissues could perhaps be overcome by repeated and uninterrupted exercise training regimes, which we recognize may not always be a suitable option for patients with morbid obesity. Therefore, consideration of a pharmacologic alternative mimicking the effect of exercise-induced organokines could be an option in the future. Clinical trials have demonstrated controversial results, as exemplified by the successful results with an FGF21 analog [286] and the less-than-expected results obtained with exogenous leptin in non-hereditary obesity (in the absence of concomitant dietary energy restriction) [288]. Given the crosstalk among the organokines, a potential candidate for clinical trials would be an organokine that not only exerts direct effects on target tissues but also mediates additional favorable interactions with other humoral mediators. Irisin, for example, is a promising candidate which has been shown to mediate pleiotropic metabolic benefits and to possess anti-inflammatory properties in preclinical models. Nonetheless, many aspects of these molecules in general remain understudied or controversial in humans (e.g., circulating half-life, protein binding in circulation, degradation sites, receptors, elicited signaling pathways, effects in all target tissues), and thus their inclusion in clinical trials is still a long way off. Moreover, given the pleiotropic nature of these factors and their simultaneous regulation by exercise, exercise should be considered as an important influential means in humans to enhance metabolic health independently of weight loss, while also enhancing nutritional and psychosocial well-being, in the prevention and treatment of obesity. Specific indications for pharmacologic and surgical options for the treatment of obesity have been described and should be considered when recommended. Nevertheless, we emphasize the importance of exercise interventions for a healthy lifestyle and to prevent and aid in the treatment of obesity and its metabolic complications.

Literature Search: We performed an exhaustive PubMed database search to find published articles focused on endocrine modulation by physical exercise, using as key words "physical activity", "exercise", "obesity", "metabolic syndrome", "diabetes", "insulin resistance", "inflammation", "energy expenditure", "browning", "fat mass", "visceral fat", “organokines", "myokines", "hepatokines", “adipokines", “osteokines", "cytokines", and the specific organokines' names (e.g., "irisin", "IL-6", "IL-15", “METRNL", "BAIBA", "myostatin”, "selenoprotein $\mathrm{P}^{\prime}$, “fetuin A", "FGF21", “ANGPTL4", "follistatin", "osteocalcin”, “leptin”, "adiponectin", and "resistin"), sorted by relevance and by date. 
Author Contributions: Conceptualization, A.M.G.-G. and L.E.-M.; investigation, A.M.G.-G.; resources, L.E.-M.; writing—original draft preparation, A.M.G.-G.; writing—review and editing, A.M.G.-G. and L.E.-M.; visualization, A.M.G.-G. and L.E.-M.; supervision, L.E.-M. Both authors have read and agreed to the published version of the manuscript. All authors have read and agreed to the published version of the manuscript.

Funding: The research was funded by the Center for Research in Obesity and Clinical Nutrition. Escuela de Medicina. Tecnologico de Monterrey. Grant number 123

Conflicts of Interest: The authors declare no conflict of interest.

\section{Abbreviations}

\begin{tabular}{|c|c|}
\hline ADAM & A disintegrin and metalloproteinase \\
\hline AMPK & AMP-activated protein kinase \\
\hline $\mathrm{AE}$ & Acute exercise \\
\hline ANGPTL4 & Angiopoietin-like 4 \\
\hline $\mathrm{AP}-1$ & Activator protein-1 \\
\hline AT & Adipose tissue \\
\hline BAIBA & Beta-aminoisobutyric acid \\
\hline BAT & Brown or beige adipose tissue \\
\hline BMR & Basal metabolic rate \\
\hline CE & Chronic exercise \\
\hline CIDEA & Cell-death inducing DNA fragmentation factor-like effector A \\
\hline CNS & Central nervous system \\
\hline DEXA & Dual-energy X-ray absorptiometry \\
\hline EE & Energy expenditure \\
\hline FAO & Fatty acid oxidation \\
\hline FFA & Free fatty acid \\
\hline FGF21 & Fibroblast growth factor 21 \\
\hline FI & Food intake \\
\hline FNDC5 & Fibronectin type III domain-containing protein 5 \\
\hline GLP-1 & Glucagon-like peptide-1 \\
\hline GLUT4 & Glucose transporter type 4 \\
\hline HIIT & High-intensity interval training \\
\hline HSL & Hormone sensitive lipase \\
\hline IFN- $\gamma$ & Interferon gamma \\
\hline IL & Interleukin \\
\hline IRS-1 & Insulin receptor substrate 1 \\
\hline JNK & c-Jun N-terminal kinase \\
\hline $\mathrm{M} \varphi$ & Macrophage \\
\hline MAPK & Mitogen-activated protein kinase \\
\hline MCP-1 & Monocyte chemoattractant protein-1 \\
\hline METRNL & Meteorin-like \\
\hline MS & Metabolic syndrome \\
\hline NAFLD & Non-alcoholic fatty liver disease \\
\hline NF- $k B$ & Nuclear factor kappa B \\
\hline $\mathrm{Ob}$ & Obesity \\
\hline $\mathrm{OCN}$ & Osteocalcin \\
\hline OS & Oxidative stress \\
\hline Ow & Overweight \\
\hline PGC- $1 \alpha$ & Peroxisome proliferator-activated receptor-gamma coactivator 1-alpha \\
\hline PKC & Protein kinase C \\
\hline PPAR & Peroxisome proliferator-activated receptor \\
\hline PRDM16 & PR domain containing 16 \\
\hline ROS & Reactive oxygen species \\
\hline scAT & Subcutaneous adipose tissue \\
\hline SeP & Selenoprotein P \\
\hline SkM & Skeletal muscle \\
\hline
\end{tabular}




$\begin{array}{ll}\text { SNS } & \text { Sympathetic nervous system } \\ \text { T2DM } & \text { Type } 2 \text { diabetes mellitus } \\ \text { TG } & \text { Triglycerides } \\ \text { TLR4 } & \text { Toll-like receptor } 4 \\ \text { TNF- } \alpha & \text { Tumor necrosis factor alpha } \\ \text { UCP1 } & \text { Uncoupling protein } 1 \\ \text { VAT } & \text { Visceral adipose tissue } \\ \text { WAT } & \text { White adipose tissue }\end{array}$

\section{References}

1. González-Muniesa, P.; Mártinez-González, M.A.; Hu, F.B.; Després, J.P.; Matsuzawa, Y.; Loos, R.J.F.; Moreno, L.A.; Bray, G.A.; Martinez, J.A. Obesity. Nat. Rev. Dis. Primers 2017, 3, 17034. [CrossRef] [PubMed]

2. Priest, C.; Tontonoz, P. Inter-organ cross-talk in metabolic syndrome. Nat. Metab. 2019, 1, 1177-1188. [CrossRef]

3. Ennequin, G.; Sirvent, P.; Whitham, M. Role of exercise-induced hepatokines in metabolic disorders. Am. J. Physiol. Endocrinol. Metab. 2019, 317, E11-E24. [CrossRef] [PubMed]

4. Weigert, C.; Hoene, M.; Plomgaard, P. Hepatokines-A novel group of exercise factors. Pflug. Arch. 2019, 471, 383-396. [CrossRef]

5. Pedersen, B.K.; Febbraio, M.A. Muscles, exercise and obesity: Skeletal muscle as a secretory organ. Nat. Rev. Endocrinol. 2012, 8, 457-465. [CrossRef]

6. Görgens, S.W.; Eckardt, K.; Jensen, J.; Drevon, C.A.; Eckel, J. Exercise and regulation of adipokine and myokine production. Prog. Mol. Biol. Transl. Sci. 2015, 135, 313-336. [CrossRef]

7. Pedersen, B.K. Physical activity and muscle-brain crosstalk. Nat. Rev. Endocrinol. 2019, 15, $383-392$. [CrossRef]

8. Pedersen, B.K. Anti-inflammatory effects of exercise: Role in diabetes and cardiovascular disease. Eur. J. Clin. Investig. 2017, 47,600-611. [CrossRef]

9. Gleeson, M.; Bishop, N.C.; Stensel, D.J.; Lindley, M.R.; Mastana, S.S.; Nimmo, M.A. The anti-inflammatory effects of exercise: Mechanisms and implications for the prevention and treatment of disease. Nat. Rev. Immunol. 2011, 11, 607-615. [CrossRef]

10. Benatti, F.B.; Pedersen, B.K. Exercise as an anti-inflammatory therapy for rheumatic diseases-Myokine regulation. Nat. Rev. Rheumatol. 2014, 11, 86. [CrossRef]

11. Troiano, R.P.; Berrigan, D.; Dodd, K.W.; Mâsse, L.C.; Tilert, T.; McDowell, M. Physical activity in the United States measured by accelerometer. Med. Sci. Sports Exerc. 2008, 40, 181-188. [CrossRef] [PubMed]

12. Villarroya, F.; Cereijo, R.; Villarroya, J.; Gavaldà-Navarro, A.; Giralt, M. Toward an understanding of how immune cells control brown and beige adipobiology. Cell Metab. 2018, 27, 954-961. [CrossRef] [PubMed]

13. Alcalá, M.; Calderon-Dominguez, M.; Serra, D.; Herrero, L.; Viana, M. Mechanisms of impaired brown adipose tissue recruitment in obesity. Front. Physiol. 2019, 10, 94. [CrossRef]

14. Chawla, A.; Nguyen, K.D.; Goh, Y.P.S. Macrophage-mediated inflammation in metabolic disease. Nat. Rev. Immunol. 2011, 11, 738. [CrossRef]

15. Chondronikola, M.; Volpi, E.; Børsheim, E.; Porter, C.; Annamalai, P.; Enerbäck, S.; Lidell, M.E.; Saraf, M.K.; Labbe, S.M.; Hurren, N.M.; et al. Brown adipose tissue improves whole-body glucose homeostasis and insulin sensitivity in humans. Diabetes 2014, 63, 4089-4099. [CrossRef]

16. Dewal, R.S.; Stanford, K.I. Effects of exercise on brown and beige adipocytes. Biochim. Biophys. Acta (BBA) Mol. Cell Biol. Lipids 2019, 1864, 71-78. [CrossRef]

17. Bartelt, A.; Heeren, J. Adipose tissue browning and metabolic health. Nat. Rev. Endocrinol. 2014, 10, $24-36$. [CrossRef] [PubMed]

18. Aldiss, P.; Betts, J.; Sale, C.; Pope, M.; Budge, H.; Symonds, M.E. Exercise-induced 'browning' of adipose tissues. Metabolism 2018, 81, 63-70. [CrossRef]

19. Larabee, C.M.; Neely, O.C.; Domingos, A.I. Obesity: A neuroimmunometabolic perspective. Nat. Rev. Endocrinol. 2020, 16, 30-43. [CrossRef]

20. DeFronzo, R.A.; Ferrannini, E.; Groop, L.; Henry, R.R.; Herman, W.H.; Holst, J.J.; Hu, F.B.; Kahn, C.R.; Raz, I.; Shulman, G.I.; et al. Type 2 diabetes mellitus. Nat. Rev. Dis. Primers 2015, 1, 15019. [CrossRef] 
21. Turcotte, L.P.; Fisher, J.S. Skeletal muscle insulin resistance: Roles of fatty acid metabolism and exercise. Phys. Ther. 2008, 88, 1279-1296. [CrossRef] [PubMed]

22. Santoleri, D.; Titchenell, P.M. Resolving the paradox of hepatic insulin resistance. Cell. Mol. Gastroenterol. Hepatol. 2019, 7, 447-456. [CrossRef] [PubMed]

23. Meex, R.C.R.; Watt, M.J. Hepatokines: Linking nonalcoholic fatty liver disease and insulin resistance. Nat. Rev. Endocrinol. 2017, 13, 509-520. [CrossRef] [PubMed]

24. Sargeant, J.A.; Gray, L.J.; Bodicoat, D.H.; Willis, S.A.; Stensel, D.J.; Nimmo, M.A.; Aithal, G.P.; King, J.A. The effect of exercise training on intrahepatic triglyceride and hepatic insulin sensitivity: A systematic review and meta-analysis. Obes. Rev. 2018, 19, 1446-1459. [CrossRef] [PubMed]

25. Dorling, J.; Broom, D.R.; Burns, S.F.; Clayton, D.J.; Deighton, K.; James, L.J.; King, J.A.; Miyashita, M.; Thackray, A.E.; Batterham, R.L.; et al. Acute and chronic effects of exercise on appetite, energy intake, and appetite-related hormones: The modulating effect of adiposity, sex, and habitual physical activity. Nutrients 2018, 10, 1140. [CrossRef] [PubMed]

26. Das, D.K.; Graham, Z.A.; Cardozo, C.P. Myokines in skeletal muscle physiology and metabolism: Recent advances and future perspectives. Acta Physiol. (Oxf.) 2020, 228, e13367. [CrossRef]

27. Huh, J.Y. The role of exercise-induced myokines in regulating metabolism. Arch. Pharm. Res. 2018, 41, 14-29. [CrossRef]

28. Mera, P.; Ferron, M.; Mosialou, I. Regulation of energy metabolism by bone-derived hormones. Cold Spring Harb. Perspect. Med. 2018, 8. [CrossRef]

29. Leal, L.G.; Lopes, M.A.; Batista, M.L. Physical exercise-induced myokines and muscle-adipose tissue crosstalk: A review of current knowledge and the implications for health and metabolic diseases. Front. Physiol. 2018, 9, 1307. [CrossRef]

30. Segal, S.S. Exercise physiology and sports science. In Medical Physiology: A Cellular and Molecular Approach, 2nd ed.; Saunders/Elsevier: Philadelphia, PA, USA, 2012; pp. 1249-1267.

31. Kanaley, J.A.; Weltman, J.Y.; Pieper, K.S.; Weltman, A.; Hartman, M.L. Cortisol and growth hormone responses to exercise at different times of day. J. Clin. Endocrinol. Metab. 2001, 86, 2881-2889. [CrossRef]

32. Lundsgaard, A.M.; Fritzen, A.M.; Kiens, B. The importance of fatty acids as nutrients during post-exercise recovery. Nutrients 2020, 12, 280. [CrossRef]

33. Speakman, J.R.; Selman, C. Physical activity and resting metabolic rate. Proc. Nutr. Soc. 2003, 62, 621-634. [CrossRef] [PubMed]

34. Cohen, P.; Spiegelman, B.M. Brown and beige fat: Molecular parts of a thermogenic machine. Diabetes 2015, 64, 2346-2351. [CrossRef] [PubMed]

35. Conn, V.S.; Koopman, R.J.; Ruppar, T.M.; Phillips, L.J.; Mehr, D.R.; Hafdahl, A.R. Insulin sensitivity following exercise interventions: Systematic review and meta-analysis of outcomes among healthy adults. J. Prim. Care Community Health 2014, 5, 211-222. [CrossRef] [PubMed]

36. Ferrier, D.R. The feed-fast cycle. In Lippincott's Illustrated Reviews: Biochemistry, 6th ed.; Wolters-Kluwer Health|Lippincott Williams \& Wilkins: Philadelphia, PA, USA, 2014.

37. Periasamy, M.; Herrera, J.L.; Reis, F.C.G. Skeletal muscle thermogenesis and its role in whole body energy metabolism. Diabetes Metab. J. 2017, 41, 327-336. [CrossRef] [PubMed]

38. Whitham, M.; Febbraio, M.A. The ever-expanding myokinome: Discovery challenges and therapeutic implications. Nat. Rev. Drug. Discov. 2016, 15, 719-729. [CrossRef] [PubMed]

39. Polyzos, S.A.; Anastasilakis, A.D.; Efstathiadou, Z.A.; Makras, P.; Perakakis, N.; Kountouras, J.; Mantzoros, C.S. Irisin in metabolic diseases. Endocrine 2018, 59, 260-274. [CrossRef]

40. Fox, J.; Rioux, B.V.; Goulet, E.D.B.; Johanssen, N.M.; Swift, D.L.; Bouchard, D.R.; Loewen, H.; Sénéchal, M. Effect of an acute exercise bout on immediate post-exercise irisin concentration in adults: A meta-analysis. Scand. J. Med. Sci. Sports 2018, 28, 16-28. [CrossRef]

41. Qiu, S.; Cai, X.; Sun, Z.; Schumann, U.; Zügel, M.; Steinacker, J.M. Chronic exercise training and circulating irisin in adults: A meta-analysis. Sports Med. 2015, 45, 1577-1588. [CrossRef]

42. Lee, P.; Linderman, J.D.; Smith, S.; Brychta, R.J.; Wang, J.; Idelson, C.; Perron, R.M.; Werner, C.D.; Phan, G.Q.; Kammula, U.S.; et al. Irisin and FGF21 are cold-induced endocrine activators of brown fat function in humans. Cell Metab. 2014, 19, 302-309. [CrossRef] 
43. Fisher, F.M.; Kleiner, S.; Douris, N.; Fox, E.C.; Mepani, R.J.; Verdeguer, F.; Wu, J.; Kharitonenkov, A.; Flier, J.S.; Maratos-Flier, E.; et al. FGF21 regulates PGC-1 $\alpha$ and browning of white adipose tissues in adaptive thermogenesis. Genes Dev. 2012, 26, 271-281. [CrossRef]

44. Huh, J.Y.; Dincer, F.; Mesfum, E.; Mantzoros, C.S. Irisin stimulates muscle growth-related genes and regulates adipocyte differentiation and metabolism in humans. Int. J. Obes. 2014, 38, 1538. [CrossRef]

45. Matsuo, Y.; Gleitsmann, K.; Mangner, N.; Werner, S.; Fischer, T.; Bowen, T.S.; Kricke, A.; Matsumoto, Y.; Kurabayashi, M.; Schuler, G.; et al. Fibronectin type III domain containing 5 expression in skeletal muscle in chronic heart failure-relevance of inflammatory cytokines. J. Cachexia Sarcopenia Muscle 2015, 6, 62-72. [CrossRef] [PubMed]

46. Alvarez-Guardia, D.; Palomer, X.; Coll, T.; Davidson, M.M.; Chan, T.O.; Feldman, A.M.; Laguna, J.C.; Vázquez-Carrera, M. The p65 subunit of NF-kappaB binds to PGC-1alpha, linking inflammation and metabolic disturbances in cardiac cells. Cardiovasc. Res. 2010, 87, 449-458. [CrossRef] [PubMed]

47. Moreno-Navarrete, J.M.; Ortega, F.; Serrano, M.; Guerra, E.; Pardo, G.; Tinahones, F.; Ricart, W.; Fernández-Real, J.M. Irisin is expressed and produced by human muscle and adipose tissue in association with obesity and insulin resistance. J. Clin. Endocrinol. Metab. 2013, 98, E769-E778. [CrossRef]

48. Kurdiova, T.; Balaz, M.; Vician, M.; Maderova, D.; Vlcek, M.; Valkovic, L.; Srbecky, M.; Imrich, R.; Kyselovicova, O.; Belan, V.; et al. Effects of obesity, diabetes and exercise on Fndc5 gene expression and irisin release in human skeletal muscle and adipose tissue: In vivo and in vitro studies. J. Physiol. 2013, 592, 1091-1107. [CrossRef] [PubMed]

49. Dong, J.; Dong, Y.; Chen, F.; Mitch, W.E.; Zhang, L. Inhibition of myostatin in mice improves insulin sensitivity via irisin-mediated cross talk between muscle and adipose tissues. Int. J. Obes. 2015, 40, 434. [CrossRef]

50. Misu, H.; Takayama, H.; Saito, Y.; Mita, Y.; Kikuchi, A.; Ishii, K.A.; Chikamoto, K.; Kanamori, T.; Tajima, N.; Lan, F.; et al. Deficiency of the hepatokine selenoprotein $\mathrm{P}$ increases responsiveness to exercise in mice through upregulation of reactive oxygen species and AMP-activated protein kinase in muscle. Nat. Med. 2017, 23, 508-516. [CrossRef] [PubMed]

51. Mazur-Bialy, A.I.; Bilski, J.; Pochec, E.; Brzozowski, T. New insight into the direct anti-inflammatory activity of a myokine irisin against proinflammatory activation of adipocytes. Implication for exercise in obesity. J. Physiol. Pharmacol. 2017, 68, 243-251. [PubMed]

52. Wrann, C.D.; White, J.P.; Salogiannnis, J.; Laznik-Bogoslavski, D.; Wu, J.; Ma, D.; Lin, J.D.; Greenberg, M.E.; Spiegelman, B.M. Exercise induces hippocampal BDNF through a PGC-1 $\alpha /$ FNDC5 pathway. Cell Metab. 2013, 18, 649-659. [CrossRef]

53. Mazur-Bialy, A.I.; Pocheć, E.; Zarawski, M. Anti-inflammatory properties of irisin, mediator of physical activity, are connected with TLR4/MyD88 signaling pathway activation. Int. J. Mol. Sci. 2017, 18, 701. [CrossRef]

54. Gutierrez-Repiso, C.; Garcia-Serrano, S.; Rodriguez-Pacheco, F.; Garcia-Escobar, E.; Haro-Mora, J.J.; Garcia-Arnes, J.; Valdes, S.; Gonzalo, M.; Soriguer, F.; Moreno-Ruiz, F.J.; et al. FNDC5 could be regulated by leptin in adipose tissue. Eur. J. Clin. Investig. 2014, 44, 918-925. [CrossRef]

55. Gavrieli, A.; Panagiotou, G.; Mantzoros, C.S. Leptin administration in physiological or pharmacological doses does not alter circulating irisin levels in humans. Int. J. Obes. 2016, 40, 1461. [CrossRef]

56. Perakakis, N.; Triantafyllou, G.A.; Fernández-Real, J.M.; Huh, J.Y.; Park, K.H.; Seufert, J.; Mantzoros, C.S. Physiology and role of irisin in glucose homeostasis. Nat. Rev. Endocrinol. 2017, 13, 324. [CrossRef]

57. Boström, P.; Wu, J.; Jedrychowski, M.P.; Korde, A.; Ye, L.; Lo, J.C.; Rasbach, K.A.; Boström, E.A.; Choi, J.H.; Long, J.Z.; et al. A PGC1- $\alpha$-dependent myokine that drives brown-fat-like development of white fat and thermogenesis. Nature 2012, 481, 463-468. [CrossRef]

58. Xiong, X.Q.; Chen, D.; Sun, H.J.; Ding, L.; Wang, J.J.; Chen, Q.; Li, Y.H.; Zhou, Y.B.; Han, Y.; Zhang, F.; et al. FNDC5 overexpression and irisin ameliorate glucose/lipid metabolic derangements and enhance lipolysis in obesity. Biochim. Biophys. Acta 2015, 1852, 1867-1875. [CrossRef]

59. Ye, W.; Wang, J.; Lin, D.; Ding, Z. The immunomodulatory role of irisin on osteogenesis via AMPK-mediated macrophage polarization. Int. J. Biol. Macromol. 2019, 146, 25-35. [CrossRef]

60. Mazur-Bialy, A.I.; Kozlowska, K.; Pochec, E.; Bilski, J.; Brzozowski, T. Myokine irisin-induced protection against oxidative stress in vitro. Involvement of heme oxygenase- 1 and antioxidazing enzymes superoxide dismutase-2 and glutathione peroxidase. J. Physiol. Pharmacol. 2018, 69, 117-125. [CrossRef] 
61. Batirel, S.; Bozaykut, P.; Mutlu Altundag, E.; Kartal Ozer, N.; Mantzoros, C.S. The effect of Irisin on antioxidant system in liver. Free Radic. Biol. Med. 2014, 75 (Suppl. 1), S16. [CrossRef]

62. Xin, C.; Liu, J.; Zhang, J.; Zhu, D.; Wang, H.; Xiong, L.; Lee, Y.; Ye, J.; Lian, K.; Xu, C.; et al. Irisin improves fatty acid oxidation and glucose utilization in type 2 diabetes by regulating the AMPK signaling pathway. Int. J. Obes. (Lond.) 2016, 40, 443-451. [CrossRef]

63. Huh, J.Y.; Mougios, V.; Kabasakalis, A.; Fatouros, I.; Siopi, A.; Douroudos, I.I.; Filippaios, A.; Panagiotou, G.; Park, K.H.; Mantzoros, C.S. Exercise-induced irisin secretion is independent of age or fitness level and increased irisin may directly modulate muscle metabolism through AMPK activation. J. Clin. Endocrinol. Metab. 2014, 99, E2154-E2161. [CrossRef] [PubMed]

64. Vaughan, R.A.; Gannon, N.P.; Barberena, M.A.; Garcia-Smith, R.; Bisoffi, M.; Mermier, C.M.; Conn, C.A.; Trujillo, K.A. Characterization of the metabolic effects of irisin on skeletal muscle in vitro. Diabetes Obes. Metab. 2014, 16, 711-718. [CrossRef] [PubMed]

65. Park, M.J.; Kim, D.I.; Choi, J.H.; Heo, Y.R.; Park, S.H. New role of irisin in hepatocytes: The protective effect of hepatic steatosis in vitro. Cell Signal. 2015, 27, 1831-1839. [CrossRef] [PubMed]

66. Zhang, D.; Xie, T.; Leung, P.S. Irisin ameliorates glucolipotoxicity-associated $\beta$-Cell dysfunction and apoptosis via AMPK signaling and anti-inflammatory actions. Cell. Physiol. Biochem. 2018, 51, 924-937. [CrossRef] [PubMed]

67. Ferrante, C.; Orlando, G.; Recinella, L.; Leone, S.; Chiavaroli, A.; Di Nisio, C.; Shohreh, R.; Manippa, F.; Ricciuti, A.; Vacca, M.; et al. Central inhibitory effects on feeding induced by the adipo-myokine irisin. Eur. J. Pharmacol. 2016, 791, 389-394. [CrossRef] [PubMed]

68. Natalicchio, A.; Marrano, N.; Biondi, G.; Dipaola, L.; Spagnuolo, R.; Cignarelli, A.; Perrini, S.; Laviola, L.; Giorgino, F. Irisin increases the expression of anorexigenic and neurotrophic genes in mouse brain. Diabetes Metab. Res. Rev. 2020, 36, e3238. [CrossRef]

69. Scheja, L.; Heeren, J. The endocrine function of adipose tissues in health and cardiometabolic disease. Nat. Rev. Endocrinol. 2019, 15, 507-524. [CrossRef]

70. Fischer, C.P. Interleukin-6 in acute exercise and training: What is the biological relevance? Exerc. Immunol. Rev. 2006, 12, 6-33.

71. Mera, P.; Laue, K.; Ferron, M.; Confavreux, C.; Wei, J.; Galán-Díez, M.; Lacampagne, A.; Mitchell, S.J.; Mattison, J.A.; Chen, Y.; et al. Osteocalcin signaling in myofibers is necessary and sufficient for optimum adaptation to exercise. Cell Metab. 2017, 25, 218. [CrossRef]

72. Steensberg, A.; Fischer, C.P.; Keller, C.; Møller, K.; Pedersen, B.K. IL-6 enhances plasma IL-1ra, IL-10, and cortisol in humans. Am. J. Physiol. Endocrinol. Metab. 2003, 285, E433-E437. [CrossRef]

73. Ellingsgaard, H.; Hauselmann, I.; Schuler, B.; Habib, A.M.; Baggio, L.L.; Meier, D.T.; Eppler, E.; Bouzakri, K.; Wueest, S.; Muller, Y.D.; et al. Interleukin-6 enhances insulin secretion by increasing glucagon-like peptide-1 secretion from L cells and alpha cells. Nat. Med. 2011, 17, 1481-1489. [CrossRef] [PubMed]

74. Schindler, R.; Mancilla, J.; Endres, S.; Ghorbani, R.; Clark, S.C.; Dinarello, C.A. Correlations and interactions in the production of interleukin-6 (IL-6), IL-1, and tumor necrosis factor (TNF) in human blood mononuclear cells: IL-6 suppresses IL-1 and TNF. Blood 1990, 75, 40-47. [CrossRef] [PubMed]

75. van Hall, G.; Steensberg, A.; Sacchetti, M.; Fischer, C.; Keller, C.; Schjerling, P.; Hiscock, N.; Møller, K.; Saltin, B.; Febbraio, M.A.; et al. Interleukin-6 stimulates lipolysis and fat oxidation in humans. J. Clin. Endocrinol. Metab. 2003, 88, 3005-3010. [CrossRef] [PubMed]

76. Carey, A.L.; Steinberg, G.R.; Macaulay, S.L.; Thomas, W.G.; Holmes, A.G.; Ramm, G.; Prelovsek, O.; Hohnen-Behrens, C.; Watt, M.J.; James, D.E.; et al. Interleukin-6 increases insulin-stimulated glucose disposal in humans and glucose uptake and fatty acid oxidation in vitro via AMP-activated protein kinase. Diabetes 2006, 55, 2688-2697. [CrossRef] [PubMed]

77. Wolsk, E.; Mygind, H.; Grøndahl, T.S.; Pedersen, B.K.; van Hall, G. IL-6 selectively stimulates fat metabolism in human skeletal muscle. Am. J. Physiol. Endocrinol. Metab. 2010, 299, E832-E840. [CrossRef] [PubMed]

78. Wedell-Neergaard, A.S.; Lang Lehrskov, L.; Christensen, R.H.; Legaard, G.E.; Dorph, E.; Larsen, M.K.; Launbo, N.; Fagerlind, S.R.; Seide, S.K.; Nymand, S.; et al. Exercise-induced changes in visceral adipose tissue mass are regulated by IL-6 signaling: A randomized controlled trial. Cell Metab. 2019, 29, 844-855.e843. [CrossRef]

79. Townsend, L.K.; Wright, D.C. Looking on the "brite" side exercise-induced browning of white adipose tissue. Pflug. Arch. 2019, 471, 455-465. [CrossRef] 
80. Fernando, M.R.; Reyes, J.L.; Iannuzzi, J.; Leung, G.; McKay, D.M. The pro-inflammatory cytokine, interleukin-6, enhances the polarization of alternatively activated macrophages. PLoS ONE 2014, 9, e94188. [CrossRef]

81. Señarís, R.M.; Trujillo, M.L.; Navia, B.; Comes, G.; Ferrer, B.; Giralt, M.; Hidalgo, J. Interleukin-6 regulates the expression of hypothalamic neuropeptides involved in body weight in a gender-dependent way. J. Neuroendocrinol. 2011, 23, 675-686. [CrossRef]

82. Schéle, E.; Benrick, A.; Grahnemo, L.; Egecioglu, E.; Anesten, F.; Pálsdóttir, V.; Jansson, J.O. Inter-relation between interleukin (IL)-1, IL-6 and body fat regulating circuits of the hypothalamic arcuate nucleus. J. Neuroendocrinol. 2013, 25, 580-589. [CrossRef]

83. Shirazi, R.; Palsdottir, V.; Collander, J.; Anesten, F.; Vogel, H.; Langlet, F.; Jaschke, A.; Schürmann, A.; Prévot, V.; Shao, R.; et al. Glucagon-like peptide 1 receptor induced suppression of food intake, and body weight is mediated by central IL-1 and IL-6. Proc. Natl. Acad. Sci. USA 2013, 110, 16199-16204. [CrossRef]

84. Nadeau, L.; Aguer, C. Interleukin-15 as a myokine: Mechanistic insight into its effect on skeletal muscle metabolism. Appl. Physiol. Nutr. Metab. 2019, 44, 229-238. [CrossRef] [PubMed]

85. Rinnov, A.; Yfanti, C.; Nielsen, S.; Akerström, T.C.; Peijs, L.; Zankari, A.; Fischer, C.P.; Pedersen, B.K. Endurance training enhances skeletal muscle interleukin-15 in human male subjects. Endocrine 2014, 45, 271-278. [CrossRef] [PubMed]

86. Quinn, L.S.; Strait-Bodey, L.; Anderson, B.G.; Argilés, J.M.; Havel, P.J. Interleukin-15 stimulates adiponectin secretion by 3T3-L1 adipocytes: Evidence for a skeletal muscle-to-fat signaling pathway. Cell Biol. Int. 2005, 29, 449-457. [CrossRef] [PubMed]

87. Li, F.; Li, Y.; Tang, Y.; Lin, B.; Kong, X.; Oladele, O.A.; Yin, Y. Protective effect of myokine IL-15 against $\mathrm{H}_{2} \mathrm{O}_{2}$-mediated oxidative stress in skeletal muscle cells. Mol. Biol. Rep. 2014, 41, 7715-7722. [CrossRef] [PubMed]

88. Quinn, L.S.; Anderson, B.G.; Strait-Bodey, L.; Stroud, A.M.; Argilés, J.M. Oversecretion of interleukin-15 from skeletal muscle reduces adiposity. Am. J. Physiol. Endocrinol. Metab. 2009, 296, E191-E202. [CrossRef]

89. Pierce, J.R.; Maples, J.M.; Hickner, R.C. IL-15 concentrations in skeletal muscle and subcutaneous adipose tissue in lean and obese humans: Local effects of IL-15 on adipose tissue lipolysis. Am. J. Physiol. Endocrinol. Metab. 2015, 308, E1131-E1139. [CrossRef]

90. Carbó, N.; López-Soriano, J.; Costelli, P.; Alvarez, B.; Busquets, S.; Baccino, F.M.; Quinn, L.S.; López-Soriano, F.J.; Argilés, J.M. Interleukin-15 mediates reciprocal regulation of adipose and muscle mass: A potential role in body weight control. Biochim. Biophys. Acta 2001, 1526, 17-24. [CrossRef]

91. Quinn, L.S.; Anderson, B.G.; Conner, J.D.; Wolden-Hanson, T. IL-15 overexpression promotes endurance, oxidative energy metabolism, and muscle PPAR $\delta$, SIRT1, PGC- $1 \alpha$, and PGC- $1 \beta$ expression in male mice. Endocrinology 2013, 154, 232-245. [CrossRef]

92. AlKhairi, I.; Cherian, P.; Abu-Farha, M.; Madhoun, A.A.; Nizam, R.; Melhem, M.; Jamal, M.; Al-Sabah, S.; Ali, H.; Tuomilehto, J.; et al. Increased expression of meteorin-like hormone in type 2 diabetes and obesity and its association with irisin. Cells 2019, 8, 1283. [CrossRef]

93. Chung, H.S.; Hwang, S.Y.; Choi, J.H.; Lee, H.J.; Kim, N.H.; Yoo, H.J.; Seo, J.A.; Kim, S.G.; Baik, S.H.; Choi, K.M. Implications of circulating Meteorin-like (Metrnl) level in human subjects with type 2 diabetes. Diabetes Res. Clin. Pract. 2018, 136, 100-107. [CrossRef] [PubMed]

94. Wang, C.; Pan, Y.; Song, J.; Sun, Y.; Li, H.; Chen, L.; Hou, X. Serum metrnl level is correlated with insulin resistance, but not with $\beta$-Cell function in type 2 diabetics. Med. Sci. Monit. 2019, 25, 8968-8974. [CrossRef]

95. Lee, J.H.; Kang, Y.E.; Kim, J.M.; Choung, S.; Joung, K.H.; Kim, H.J.; Ku, B.J. Serum Meteorin-like protein levels decreased in patients newly diagnosed with type 2 diabetes. Diabetes Res. Clin. Pract. 2018, 135, 7-10. [CrossRef]

96. El-Ashmawy, H.M.; Selim, F.O.; Hosny, T.A.M.; Almassry, H.N. Association of low serum Meteorin like (Metrnl) concentrations with worsening of glucose tolerance, impaired endothelial function and atherosclerosis. Diabetes Res. Clin. Pract. 2019, 150, 57-63. [CrossRef]

97. Eaton, M.; Granata, C.; Barry, J.; Safdar, A.; Bishop, D.; Little, J.P. Impact of a single bout of high-intensity interval exercise and short-term interval training on interleukin-6, FNDC5, and METRNL mRNA expression in human skeletal muscle. J. Sport Health Sci. 2018, 7, 191-196. [CrossRef] [PubMed]

98. Rao, R.R.; Long, J.Z.; White, J.P.; Svensson, K.J.; Lou, J.; Lokurkar, I.; Jedrychowski, M.P.; Ruas, J.L.; Wrann, C.D.; Lo, J.C.; et al. Meteorin-like is a hormone that regulates immune-adipose interactions to increase beige fat thermogenesis. Cell 2014, 157, 1279-1291. [CrossRef] [PubMed] 
99. Saghebjoo, M.; Einaloo, A.; Mogharnasi, M.; Ahmadabadi, F. The response of meteorin-like hormone and interleukin-4 in overweight women during exercise in temperate, warm and cold water. Horm. Mol. Biol. Clin. Investig. 2018, 36. [CrossRef]

100. Jung, T.W.; Lee, S.H.; Kim, H.C.; Bang, J.S.; Abd El-Aty, A.M.; Hacımüftüoğlu, A.; Shin, Y.K.; Jeong, J.H. METRNL attenuates lipid-induced inflammation and insulin resistance via AMPK or PPAR $\delta$-dependent pathways in skeletal muscle of mice. Exp. Mol. Med. 2018, 50, 122. [CrossRef]

101. Qiu, Y.; Nguyen, K.D.; Odegaard, J.I.; Cui, X.; Tian, X.; Locksley, R.M.; Palmiter, R.D.; Chawla, A. Eosinophils and type 2 cytokine signaling in macrophages orchestrate development of functional beige fat. Cell 2014, 157, 1292-1308. [CrossRef]

102. Li, Z.Y.; Song, J.; Zheng, S.L.; Fan, M.B.; Guan, Y.F.; Qu, Y.; Xu, J.; Wang, P.; Miao, C.Y. Adipocyte metrnl antagonizes insulin resistance through PPAR $\gamma$ signaling. Diabetes 2015, 64, 4011-4022. [CrossRef]

103. Lee, J.O.; Byun, W.S.; Kang, M.J.; Han, J.A.; Moon, J.; Shin, M.J.; Lee, H.J.; Chung, J.H.; Lee, J.S.; Son, C.G.; et al. The myokine meteorin-like (metrnl) improves glucose tolerance in both skeletal muscle cells and mice by targeting AMPK $\alpha 2$. FEBS J. 2020, 287, 2087-2104. [CrossRef] [PubMed]

104. Roberts, L.D.; Boström, P.; O'Sullivan, J.F.; Schinzel, R.T.; Lewis, G.D.; Dejam, A.; Lee, Y.K.; Palma, M.J.; Calhoun, S.; Georgiadi, A.; et al. $\beta$-Aminoisobutyric acid induces browning of white fat and hepatic $\beta$-oxidation and is inversely correlated with cardiometabolic risk factors. Cell Metab. 2014, 19, 96-108. [CrossRef] [PubMed]

105. Rietman, A.; Stanley, T.L.; Clish, C.; Mootha, V.; Mensink, M.; Grinspoon, S.K.; Makimura, H. Associations between plasma branched-chain amino acids, $\beta$-aminoisobutyric acid and body composition. J. Nutr. Sci. 2016, 5, e6. [CrossRef] [PubMed]

106. Stautemas, J.; Van Kuilenburg, A.B.P.; Stroomer, L.; Vaz, F.; Blancquaert, L.; Lefevere, F.B.D.; Everaert, I.; Derave, W. Acute aerobic exercise leads to increased plasma levels of R- and S- $\beta$-aminoisobutyric acid in humans. Front. Physiol. 2019, 10, 1240. [CrossRef] [PubMed]

107. Morales, F.E.; Forsse, J.S.; Andre, T.L.; McKinley-Barnard, S.K.; Hwang, P.S.; Anthony, I.G.; Tinsley, G.M.; Spillane, M.; Grandjean, P.W.; Ramirez, A.; et al. BAIBA does not regulate UCP-3 expression in human skeletal muscle as a response to aerobic exercise. J. Am. Coll. Nutr. 2017, 36, 200-209. [CrossRef] [PubMed]

108. Zhu, X.W.; Ding, K.; Dai, X.Y.; Ling, W.Q. $\beta$-aminoisobutyric acid accelerates the proliferation and differentiation of MC3T3-E1 cells via moderate activation of ROS signaling. J. Chin. Med. Assoc. 2018, 81, 611-618. [CrossRef] [PubMed]

109. Begriche, K.; Massart, J.; Abbey-Toby, A.; Igoudjil, A.; Lettéron, P.; Fromenty, B. Beta-aminoisobutyric acid prevents diet-induced obesity in mice with partial leptin deficiency. Obesity (Silver Spring) 2008, 16, 2053-2067. [CrossRef]

110. Jung, T.W.; Park, H.S.; Choi, G.H.; Kim, D.; Lee, T. $\beta$-aminoisobutyric acid attenuates LPS-induced inflammation and insulin resistance in adipocytes through AMPK-mediated pathway. J. Biomed. Sci. 2018, 25, 27. [CrossRef]

111. Jung, T.W.; Hwang, H.J.; Hong, H.C.; Yoo, H.J.; Baik, S.H.; Choi, K.M. BAIBA attenuates insulin resistance and inflammation induced by palmitate or a high fat diet via an AMPK-PPAR $\delta$-dependent pathway in mice. Diabetologia 2015, 58, 2096-2105. [CrossRef]

112. Tanianskii, D.A.; Jarzebska, N.; Birkenfeld, A.L.; O'Sullivan, J.F.; Rodionov, R.N. Beta-aminoisobutyric acid as a novel regulator of carbohydrate and lipid metabolism. Nutrients 2019, 11, 524. [CrossRef]

113. Shi, C.X.; Zhao, M.X.; Shu, X.D.; Xiong, X.Q.; Wang, J.J.; Gao, X.Y.; Chen, Q.; Li, Y.H.; Kang, Y.M.; Zhu, G.Q. $\beta$-aminoisobutyric acid attenuates hepatic endoplasmic reticulum stress and glucose/lipid metabolic disturbance in mice with type 2 diabetes. Sci. Rep. 2016, 6, 21924. [CrossRef]

114. Park, B.S.; Tu, T.H.; Lee, H.; Jeong, D.Y.; Yang, S.; Lee, B.J.; Kim, J.G. Beta-aminoisobutyric acid inhibits hypothalamic inflammation by reversing microglia activation. Cells 2019, 8, 1609. [CrossRef] [PubMed]

115. Allen, D.L.; Hittel, D.S.; McPherron, A.C. Expression and function of myostatin in obesity, diabetes, and exercise adaptation. Med. Sci. Sports Exerc. 2011, 43, 1828-1835. [CrossRef] [PubMed]

116. Sriram, S.; Subramanian, S.; Sathiakumar, D.; Venkatesh, R.; Salerno, M.S.; McFarlane, C.D.; Kambadur, R.; Sharma, M. Modulation of reactive oxygen species in skeletal muscle by myostatin is mediated through NF-kB. Aging Cell 2011, 10, 931-948. [CrossRef] [PubMed] 
117. Hansen, J.; Brandt, C.; Nielsen, A.R.; Hojman, P.; Whitham, M.; Febbraio, M.A.; Pedersen, B.K.; Plomgaard, P. Exercise induces a marked increase in plasma follistatin: Evidence that follistatin is a contraction-induced hepatokine. Endocrinology 2011, 152, 164-171. [CrossRef]

118. McPherron, A.C.; Lee, S.-J. Suppression of body fat accumulation in myostatin-deficient mice. J. Clin. Investig. 2002, 109, 595-601. [CrossRef]

119. Guo, T.; Jou, W.; Chanturiya, T.; Portas, J.; Gavrilova, O.; McPherron, A.C. Myostatin inhibition in muscle, but not adipose tissue, decreases fat mass and improves insulin sensitivity. PloS ONE 2009, 4, e4937. [CrossRef]

120. Yu, Q.; Kou, W.; Xu, X.; Zhou, S.; Luan, P.; Li, H.; Zhuang, J.; Wang, J.; Zhao, Y.; Xu, Y.; et al. FNDC5/Irisin inhibits pathological cardiac hypertrophy. Clin. Sci. (Lond.) 2019, 133, 611-627. [CrossRef]

121. Miyamoto-Mikami, E.; Sato, K.; Kurihara, T.; Hasegawa, N.; Fujie, S.; Fujita, S.; Sanada, K.; Hamaoka, T.; Tabata, I.; Iemitsu, M. Endurance training-induced increase in circulating irisin levels is associated with reduction of abdominal visceral fat in middle-aged and older adults. PLoS ONE 2015, 10, e0120354. [CrossRef]

122. Pal, M.; Febbraio, M.A.; Whitham, M. From cytokine to myokine: The emerging role of interleukin-6 in metabolic regulation. Immunol. Cell Biol. 2014, 92, 331-339. [CrossRef]

123. Ye, J. Beneficial metabolic activities of inflammatory cytokine interleukin 15 in obesity and type 2 diabetes. Front. Med. 2015, 9, 139-145. [CrossRef] [PubMed]

124. Sun, H.; Liu, D. Hydrodynamic delivery of interleukin 15 gene promotes resistance to high fat diet-induced obesity, fatty liver and improves glucose homeostasis. Gene Ther. 2015, 22, 341-347. [CrossRef] [PubMed]

125. Krolopp, J.E.; Thornton, S.M.; Abbott, M.J. IL-15 activates the Jak3/STAT3 signaling pathway to mediate glucose uptake in skeletal muscle cells. Front. Physiol. 2016, 7, 626. [CrossRef] [PubMed]

126. Quinn, L.S.; Anderson, B.G.; Conner, J.D.; Wolden-Hanson, T.; Marcell, T.J. IL-15 is required for postexercise induction of the pro-oxidative mediators PPAR $\delta$ and SIRT1 in male mice. Endocrinology 2014, 155, 143-155. [CrossRef]

127. Barra, N.G.; Reid, S.; MacKenzie, R.; Werstuck, G.; Trigatti, B.L.; Richards, C.; Holloway, A.C.; Ashkar, A.A. Interleukin-15 contributes to the regulation of murine adipose tissue and human adipocytes. Obesity (Silver Spring) 2010, 18, 1601-1607. [CrossRef] [PubMed]

128. Tamura, Y.; Watanabe, K.; Kantani, T.; Hayashi, J.; Ishida, N.; Kaneki, M. Upregulation of circulating IL-15 by treadmill running in healthy individuals: Is IL-15 an endocrine mediator of the beneficial effects of endurance exercise? Endocr. J. 2011, 58, 211-215. [CrossRef]

129. Crane, J.D.; MacNeil, L.G.; Lally, J.S.; Ford, R.J.; Bujak, A.L.; Brar, I.K.; Kemp, B.E.; Raha, S.; Steinberg, G.R.; Tarnopolsky, M.A. Exercise-stimulated interleukin-15 is controlled by AMPK and regulates skin metabolism and aging. Aging Cell 2015, 14, 625-634. [CrossRef]

130. Christiansen, T.; Bruun, J.M.; Paulsen, S.K.; Olholm, J.; Overgaard, K.; Pedersen, S.B.; Richelsen, B. Acute exercise increases circulating inflammatory markers in overweight and obese compared with lean subjects. Eur. J. Appl. Physiol. 2013, 113, 1635-1642. [CrossRef]

131. Du, Y.; Ye, X.; Lu, A.; Zhao, D.; Liu, J.; Cheng, J.; Yang, T. Inverse relationship between serum Metrnl levels and visceral fat obesity (VFO) in patients with type 2 diabetes. Diabetes Res. Clin. Pract. 2020, 161, 108068. [CrossRef]

132. Zhang, C.; McFarlane, C.; Lokireddy, S.; Masuda, S.; Ge, X.; Gluckman, P.D.; Sharma, M.; Kambadur, R. Inhibition of myostatin protects against diet-induced obesity by enhancing fatty acid oxidation and promoting a brown adipose phenotype in mice. Diabetologia 2012, 55, 183-193. [CrossRef]

133. Shan, T.; Liang, X.; Bi, P.; Kuang, S. Myostatin knockout drives browning of white adipose tissue through activating the AMPK-PGC1 $\alpha$-Fndc5 pathway in muscle. FASEB J. 2013, 27, 1981-1989. [CrossRef] [PubMed]

134. Sargeant, J.A.; Aithal, G.P.; Takamura, T.; Misu, H.; Takayama, H.; Douglas, J.A.; Turner, M.C.; Stensel, D.J.; Nimmo, M.A.; Webb, D.R.; et al. The influence of adiposity and acute exercise on circulating hepatokines in normal-weight and overweight/obese men. Appl. Physiol. Nutr. Metab. 2018, 43, 482-490. [CrossRef] [PubMed]

135. Jung, T.W.; Choi, H.Y.; Lee, S.Y.; Hong, H.C.; Yang, S.J.; Yoo, H.J.; Youn, B.S.; Baik, S.H.; Choi, K.M. Salsalate and adiponectin improve palmitate-induced insulin resistance via inhibition of selenoprotein $P$ through the AMPK-FOXO1 $\alpha$ pathway. PLoS ONE 2013, 8, e66529. [CrossRef] [PubMed]

136. Misu, H.; Ishikura, K.; Kurita, S.; Takeshita, Y.; Ota, T.; Saito, Y.; Takahashi, K.; Kaneko, S.; Takamura, T. Inverse correlation between serum levels of selenoprotein $\mathrm{P}$ and adiponectin in patients with type 2 diabetes. PLoS ONE 2012, 7, e34952. [CrossRef] [PubMed] 
137. Trepanowski, J.F.; Mey, J.; Varady, K.A. Fetuin-A: A novel link between obesity and related complications. Int. J. Obes. (Lond.) 2015, 39, 734-741. [CrossRef]

138. Ramírez-Vélez, R.; García-Hermoso, A.; Hackney, A.C.; Izquierdo, M. Effects of exercise training on Fetuin-a in obese, type 2 diabetes and cardiovascular disease in adults and elderly: A systematic review and Meta-analysis. Lipids Health Dis. 2019, 18, 23. [CrossRef]

139. Malin, S.K.; del Rincon, J.P.; Huang, H.; Kirwan, J.P. Exercise-induced lowering of fetuin-A may increase hepatic insulin sensitivity. Med. Sci. Sports Exerc. 2014, 46, 2085-2090. [CrossRef]

140. Lee, S.; Norheim, F.; Gulseth, H.L.; Langleite, T.M.; Kolnes, K.J.; Tangen, D.S.; Stadheim, H.K.; Gilfillan, G.D.; Holen, T.; Birkeland, K.I.; et al. Interaction between plasma fetuin-A and free fatty acids predicts changes in insulin sensitivity in response to long-term exercise. Physiol. Rep. 2017, 5. [CrossRef]

141. Malin, S.K.; Mulya, A.; Fealy, C.E.; Haus, J.M.; Pagadala, M.R.; Scelsi, A.R.; Huang, H.; Flask, C.A.; McCullough, A.J.; Kirwan, J.P. Fetuin-A is linked to improved glucose tolerance after short-term exercise training in nonalcoholic fatty liver disease. J. Appl. Physiol. (1985) 2013, 115, 988-994. [CrossRef]

142. Zhang, L.Y.; Liu, T.; Teng, Y.Q.; Yao, X.Y.; Zhao, T.T.; Lin, L.Y.; Jin, Q.S.; Jin, Y.J. Effect of a 12-week aerobic exercise training on serum fetuin-A and adipocytokine levels in type 2 diabetes. Exp. Clin. Endocrinol. Diabetes 2018, 126, 487-492. [CrossRef]

143. Keihanian, A.; Arazi, H.; Kargarfard, M. Effects of aerobic versus resistance training on serum fetuin-A, fetuin-B, and fibroblast growth factor-21 levels in male diabetic patients. Physiol. Int. 2019, 106, 70-80. [CrossRef] [PubMed]

144. Takata, H.; Ikeda, Y.; Suehiro, T.; Ishibashi, A.; Inoue, M.; Kumon, Y.; Terada, Y. High glucose induces transactivation of the alpha2-HS glycoprotein gene through the ERK1/2 signaling pathway. J. Atheroscler. Thromb. 2009, 16, 448-456. [CrossRef] [PubMed]

145. Dasgupta, S.; Bhattacharya, S.; Biswas, A.; Majumdar, S.S.; Mukhopadhyay, S.; Ray, S. NF-kappaB mediates lipid-induced fetuin-A expression in hepatocytes that impairs adipocyte function effecting insulin resistance. Biochem. J. 2010, 429, 451-462. [CrossRef] [PubMed]

146. Jung, T.W.; Youn, B.S.; Choi, H.Y.; Lee, S.Y.; Hong, H.C.; Yang, S.J.; Yoo, H.J.; Kim, B.H.; Baik, S.H.; Choi, K.M. Salsalate and adiponectin ameliorate hepatic steatosis by inhibition of the hepatokine fetuin-A. Biochem. Pharmacol. 2013, 86, 960-969. [CrossRef]

147. Tang, H.; Yu, R.; Liu, S.; Huwatibieke, B.; Li, Z.; Zhang, W. Irisin inhibits hepatic cholesterol synthesis via AMPK-SREBP2 signaling. EBioMedicine 2016, 6, 139-148. [CrossRef]

148. Hennige, A.M.; Staiger, H.; Wicke, C.; Machicao, F.; Fritsche, A.; Häring, H.U.; Stefan, N. Fetuin-A induces cytokine expression and suppresses adiponectin production. PLoS ONE 2008, 3, e1765. [CrossRef] [PubMed]

149. Mukhopadhyay, S.; Bhattacharya, S. Plasma fetuin-A triggers inflammatory changes in macrophages and adipocytes by acting as an adaptor protein between NEFA and TLR-4. Diabetologia 2016, 59, 859-860. [CrossRef] [PubMed]

150. Chatterjee, P.; Seal, S.; Mukherjee, S.; Kundu, R.; Ray, S.; Mukhopadhyay, S.; Majumdar, S.S.; Bhattacharya, S. Adipocyte fetuin-A contributes to macrophage migration into adipose tissue and polarization of macrophages. J. Biol. Chem. 2013, 288, 28324-28330. [CrossRef]

151. Strieder-Barboza, C.; Contreras, G.A. Fetuin-A modulates lipid mobilization in bovine adipose tissue by enhancing lipogenic activity of adipocytes. J. Dairy Sci. 2019, 102, 4628-4638. [CrossRef]

152. Shen, X.; Yang, L.; Yan, S.; Zheng, H.; Liang, L.; Cai, X.; Liao, M. Fetuin A promotes lipotoxicity in $\beta$ cells through the TLR4 signaling pathway and the role of pioglitazone in anti-lipotoxicity. Mol. Cell. Endocrinol. 2015, 412, 1-11. [CrossRef]

153. Dushay, J.; Chui, P.C.; Gopalakrishnan, G.S.; Varela-Rey, M.; Crawley, M.; Fisher, F.M.; Badman, M.K.; Martinez-Chantar, M.L.; Maratos-Flier, E. Increased fibroblast growth factor 21 in obesity and nonalcoholic fatty liver disease. Gastroenterology 2010, 139, 456-463. [CrossRef] [PubMed]

154. Fisher, F.M.; Maratos-Flier, E. Understanding the physiology of FGF21. Annu. Rev. Physiol. 2016, 78, $223-241$. [CrossRef]

155. Kim, K.H.; Kim, S.H.; Min, Y.K.; Yang, H.M.; Lee, J.B.; Lee, M.S. Acute exercise induces FGF21 expression in mice and in healthy humans. PLoS ONE 2013, 8, e63517. [CrossRef] [PubMed]

156. Slusher, A.L.; Whitehurst, M.; Zoeller, R.F.; Mock, J.T.; Maharaj, M.; Huang, C.J. Attenuated fibroblast growth factor 21 response to acute aerobic exercise in obese individuals. Nutr. Metab. Cardiovasc. Dis. 2015, 25, 839-845. [CrossRef] [PubMed] 
157. Hansen, J.S.; Pedersen, B.K.; Xu, G.; Lehmann, R.; Weigert, C.; Plomgaard, P. Exercise-induced secretion of FGF21 and follistatin are blocked by pancreatic clamp and impaired in type 2 diabetes. J. Clin. Endocrinol. Metab. 2016, 101, 2816-2825. [CrossRef]

158. Hansen, J.S.; Clemmesen, J.O.; Secher, N.H.; Hoene, M.; Drescher, A.; Weigert, C.; Pedersen, B.K.; Plomgaard, P. Glucagon-to-insulin ratio is pivotal for splanchnic regulation of FGF-21 in humans. Mol. Metab. 2015, 4, 551-560. [CrossRef]

159. Berglund, E.D.; Kang, L.; Lee-Young, R.S.; Hasenour, C.M.; Lustig, D.G.; Lynes, S.E.; Donahue, E.P.; Swift, L.L.; Charron, M.J.; Wasserman, D.H. Glucagon and lipid interactions in the regulation of hepatic AMPK signaling and expression of PPARalpha and FGF21 transcripts in vivo. Am. J. Physiol. Endocrinol. Metab. 2010, 299, E607-E614. [CrossRef]

160. Badman, M.K.; Pissios, P.; Kennedy, A.R.; Koukos, G.; Flier, J.S.; Maratos-Flier, E. Hepatic fibroblast growth factor 21 is regulated by PPARalpha and is a key mediator of hepatic lipid metabolism in ketotic states. Cell Metab. 2007, 5, 426-437. [CrossRef] [PubMed]

161. Mai, K.; Andres, J.; Biedasek, K.; Weicht, J.; Bobbert, T.; Sabath, M.; Meinus, S.; Reinecke, F.; Möhlig, M.; Weickert, M.O.; et al. Free fatty acids link metabolism and regulation of the insulin-sensitizing fibroblast growth factor-21. Diabetes 2009, 58, 1532-1538. [CrossRef]

162. Adams, A.C.; Astapova, I.; Fisher, F.M.; Badman, M.K.; Kurgansky, K.E.; Flier, J.S.; Hollenberg, A.N.; Maratos-Flier, E. Thyroid hormone regulates hepatic expression of fibroblast growth factor 21 in a PPARalpha-dependent manner. J. Biol. Chem. 2010, 285, 14078-14082. [CrossRef]

163. Owen, B.M.; Ding, X.; Morgan, D.A.; Coate, K.C.; Bookout, A.L.; Rahmouni, K.; Kliewer, S.A.; Mangelsdorf, D.J. FGF21 acts centrally to induce sympathetic nerve activity, energy expenditure, and weight loss. Cell Metab. 2014, 20, 670-677. [CrossRef] [PubMed]

164. Liang, Q.; Zhong, L.; Zhang, J.; Wang, Y.; Bornstein, S.R.; Triggle, C.R.; Ding, H.; Lam, K.S.; Xu, A. FGF21 maintains glucose homeostasis by mediating the cross talk between liver and brain during prolonged fasting. Diabetes 2014, 63, 4064-4075. [CrossRef] [PubMed]

165. Talukdar, S.; Zhou, Y.; Li, D.; Rossulek, M.; Dong, J.; Somayaji, V.; Weng, Y.; Clark, R.; Lanba, A.; Owen, B.M.; et al. A long-acting FGF21 molecule, PF-05231023, decreases body weight and improves lipid profile in non-human primates and type 2 diabetic subjects. Cell Metab. 2016, 23, 427-440. [CrossRef] [PubMed]

166. Inagaki, T.; Dutchak, P.; Zhao, G.; Ding, X.; Gautron, L.; Parameswara, V.; Li, Y.; Goetz, R.; Mohammadi, M.; Esser, V.; et al. Endocrine regulation of the fasting response by PPARalpha-mediated induction of fibroblast growth factor 21. Cell Metab. 2007, 5, 415-425. [CrossRef]

167. Xu, J.; Lloyd, D.J.; Hale, C.; Stanislaus, S.; Chen, M.; Sivits, G.; Vonderfecht, S.; Hecht, R.; Li, Y.S.; Lindberg, R.A.; et al. Fibroblast growth factor 21 reverses hepatic steatosis, increases energy expenditure, and improves insulin sensitivity in diet-induced obese mice. Diabetes 2009, 58, 250-259. [CrossRef]

168. von Holstein-Rathlou, S.; BonDurant, L.D.; Peltekian, L.; Naber, M.C.; Yin, T.C.; Claflin, K.E.; Urizar, A.I.; Madsen, A.N.; Ratner, C.; Holst, B.; et al. FGF21 mediates endocrine control of simple sugar intake and sweet taste preference by the liver. Cell Metab. 2016, 23, 335-343. [CrossRef]

169. Tjeerdema, N.; Georgiadi, A.; Jonker, J.T.; van Glabbeek, M.; Alizadeh Dehnavi, R.; Tamsma, J.T.; Smit, J.W.; Kersten, S.; Rensen, P.C. Inflammation increases plasma angiopoietin-like protein 4 in patients with the metabolic syndrome and type 2 diabetes. BMJ Open Diabetes Res. Care 2014, 2, e000034. [CrossRef]

170. Ingerslev, B.; Hansen, J.S.; Hoffmann, C.; Clemmesen, J.O.; Secher, N.H.; Scheler, M.; Hrabĕ de Angelis, M.; Häring, H.U.; Pedersen, B.K.; Weigert, C.; et al. Angiopoietin-like protein 4 is an exercise-induced hepatokine in humans, regulated by glucagon and cAMP. Mol. Metab. 2017, 6, 1286-1295. [CrossRef]

171. Norheim, F.; Hjorth, M.; Langleite, T.M.; Lee, S.; Holen, T.; Bindesbøll, C.; Stadheim, H.K.; Gulseth, H.L.; Birkeland, K.I.; Kielland, A.; et al. Regulation of angiopoietin-like protein 4 production during and after exercise. Physiol. Rep. 2014, 2. [CrossRef]

172. Catoire, M.; Alex, S.; Paraskevopulos, N.; Mattijssen, F.; Evers-van Gogh, I.; Schaart, G.; Jeppesen, J.; Kneppers, A.; Mensink, M.; Voshol, P.J.; et al. Fatty acid-inducible ANGPTL4 governs lipid metabolic response to exercise. Proc. Natl. Acad. Sci. USA 2014, 111, E1043-E1052. [CrossRef]

173. Górecka, M.; Krzemiński, K.; Buraczewska, M.; Kozacz, A.; Dąbrowski, J.; Ziemba, A.W. Effect of mountain ultra-marathon running on plasma angiopoietin-like protein 4 and lipid profile in healthy trained men. Eur. J. Appl. Physiol. 2020, 120, 117-125. [CrossRef] 
174. Kersten, S.; Lichtenstein, L.; Steenbergen, E.; Mudde, K.; Hendriks, H.F.; Hesselink, M.K.; Schrauwen, P.; Müller, M. Caloric restriction and exercise increase plasma ANGPTL4 levels in humans via elevated free fatty acids. Arterioscler. Thromb. Vasc. Biol. 2009, 29, 969-974. [CrossRef] [PubMed]

175. Koliwad, S.K.; Kuo, T.; Shipp, L.E.; Gray, N.E.; Backhed, F.; So, A.Y.; Farese, R.V.; Wang, J.C. Angiopoietin-like 4 (ANGPTL4, fasting-induced adipose factor) is a direct glucocorticoid receptor target and participates in glucocorticoid-regulated triglyceride metabolism. J. Biol. Chem. 2009, 284, 25593-25601. [CrossRef]

176. Staiger, H.; Haas, C.; Machann, J.; Werner, R.; Weisser, M.; Schick, F.; Machicao, F.; Stefan, N.; Fritsche, A.; Häring, H.U. Muscle-derived angiopoietin-like protein 4 is induced by fatty acids via peroxisome proliferator-activated receptor (PPAR)-delta and is of metabolic relevance in humans. Diabetes 2009, 58, 579-589. [CrossRef] [PubMed]

177. Mandard, S.; Zandbergen, F.; van Straten, E.; Wahli, W.; Kuipers, F.; Müller, M.; Kersten, S. The fasting-induced adipose factor/angiopoietin-like protein 4 is physically associated with lipoproteins and governs plasma lipid levels and adiposity. J. Biol. Chem. 2006, 281, 934-944. [CrossRef] [PubMed]

178. Dijk, W.; Ruppert, P.M.M.; Oost, L.J.; Kersten, S. Angiopoietin-like 4 promotes the intracellular cleavage of lipoprotein lipase by PCSK3/furin in adipocytes. J. Biol. Chem. 2018, 293, 14134-14145. [CrossRef]

179. Mattijssen, F.; Alex, S.; Swarts, H.J.; Groen, A.K.; van Schothorst, E.M.; Kersten, S. Angptl4 serves as an endogenous inhibitor of intestinal lipid digestion. Mol. Metab. 2014, 3, 135-144. [CrossRef] [PubMed]

180. Hansen, J.; Rinnov, A.; Krogh-Madsen, R.; Fischer, C.P.; Andreasen, A.S.; Berg, R.M.; Møller, K.; Pedersen, B.K.; Plomgaard, P. Plasma follistatin is elevated in patients with type 2 diabetes: Relationship to hyperglycemia, hyperinsulinemia, and systemic low-grade inflammation. Diabetes Metab. Res. Rev. 2013, 29, 463-472. [CrossRef] [PubMed]

181. Willis, S.A.; Sargeant, J.A.; Thackray, A.E.; Yates, T.; Stensel, D.J.; Aithal, G.P.; King, J.A. Effect of exercise intensity on circulating hepatokine concentrations in healthy men. Appl. Physiol. Nutr. Metab. 2019, 44, 1065-1072. [CrossRef]

182. Perakakis, N.; Mougios, V.; Fatouros, I.; Siopi, A.; Draganidis, D.; Peradze, N.; Ghaly, W.; Mantzoros, C.S. Physiology of activins/follistatins: Associations with metabolic and anthropometric variables and response to exercise. J. Clin. Endocrinol. Metab. 2018, 103, 3890-3899. [CrossRef]

183. Hansen, J.S.; Rutti, S.; Arous, C.; Clemmesen, J.O.; Secher, N.H.; Drescher, A.; Gonelle-Gispert, C.; Halban, P.A.; Pedersen, B.K.; Weigert, C.; et al. Circulating follistatin is liver-derived and regulated by the glucagon-to-insulin ratio. J. Clin. Endocrinol. Metab. 2016, 101, 550-560. [CrossRef] [PubMed]

184. Gilson, H.; Schakman, O.; Kalista, S.; Lause, P.; Tsuchida, K.; Thissen, J.P. Follistatin induces muscle hypertrophy through satellite cell proliferation and inhibition of both myostatin and activin. Am. J. Physiol. Endocrinol. Metab. 2009, 297, E157-E164. [CrossRef] [PubMed]

185. Braga, M.; Reddy, S.T.; Vergnes, L.; Pervin, S.; Grijalva, V.; Stout, D.; David, J.; Li, X.; Tomasian, V.; Reid, C.B.; et al. Follistatin promotes adipocyte differentiation, browning, and energy metabolism. J. Lipid Res. 2014, 55, 375-384. [CrossRef]

186. Choi, H.Y.; Hwang, S.Y.; Lee, C.H.; Hong, H.C.; Yang, S.J.; Yoo, H.J.; Seo, J.A.; Kim, S.G.; Kim, N.H.; Baik, S.H.; et al. Increased selenoprotein P levels in subjects with visceral obesity and nonalcoholic Fatty liver disease. Diabetes Metab. J. 2013, 37, 63-71. [CrossRef] [PubMed]

187. Pal, D.; Dasgupta, S.; Kundu, R.; Maitra, S.; Das, G.; Mukhopadhyay, S.; Ray, S.; Majumdar, S.S.; Bhattacharya, S. Fetuin-A acts as an endogenous ligand of TLR4 to promote lipid-induced insulin resistance. Nat. Med. 2012, 18, 1279-1285. [CrossRef] [PubMed]

188. Stefan, N.; Häring, H.U. Circulating fetuin-A and free fatty acids interact to predict insulin resistance in humans. Nat. Med. 2013, 19, 394-395. [CrossRef]

189. Goustin, A.S.; Derar, N.; Abou-Samra, A.B. Ahsg-fetuin blocks the metabolic arm of insulin action through its interaction with the 95-kD $\beta$-subunit of the insulin receptor. Cell Signal. 2013, 25, 981-988. [CrossRef]

190. Stefan, N.; Fritsche, A.; Weikert, C.; Boeing, H.; Joost, H.G.; Häring, H.U.; Schulze, M.B. Plasma fetuin-A levels and the risk of type 2 diabetes. Diabetes 2008, 57, 2762-2767. [CrossRef]

191. Ix, J.H.; Wassel, C.L.; Chertow, G.M.; Koster, A.; Johnson, K.C.; Tylavsky, F.A.; Cauley, J.A.; Cummings, S.R.; Harris, T.B.; Shlipak, M.G.; et al. Fetuin-A and change in body composition in older persons. J. Clin. Endocrinol. Metab. 2009, 94, 4492-4498. [CrossRef]

192. Cuevas-Ramos, D.; Mehta, R.; Aguilar-Salinas, C.A. Fibroblast growth factor 21 and browning of white adipose tissue. Front. Physiol. 2019, 10, 37. [CrossRef] 
193. Gray, N.E.; Lam, L.N.; Yang, K.; Zhou, A.Y.; Koliwad, S.; Wang, J.C. Angiopoietin-like 4 (Angptl4) protein is a physiological mediator of intracellular lipolysis in murine adipocytes. J. Biol. Chem. 2012, 287, 8444-8456. [CrossRef] [PubMed]

194. Lafferty, M.J.; Bradford, K.C.; Erie, D.A.; Neher, S.B. Angiopoietin-like protein 4 inhibition of lipoprotein lipase: Evidence for reversible complex formation. J. Biol. Chem. 2013, 288, 28524-28534. [CrossRef] [PubMed]

195. Janssen, A.W.F.; Katiraei, S.; Bartosinska, B.; Eberhard, D.; Willems van Dijk, K.; Kersten, S. Loss of angiopoietin-like 4 (ANGPTL4) in mice with diet-induced obesity uncouples visceral obesity from glucose intolerance partly via the gut microbiota. Diabetologia 2018, 61, 1447-1458. [CrossRef]

196. Catoire, M.; Mensink, M.; Boekschoten, M.V.; Hangelbroek, R.; Müller, M.; Schrauwen, P.; Kersten, S. Pronounced effects of acute endurance exercise on gene expression in resting and exercising human skeletal muscle. PLoS ONE 2012, 7, e51066. [CrossRef] [PubMed]

197. Cushing, E.M.; Chi, X.; Sylvers, K.L.; Shetty, S.K.; Potthoff, M.J.; Davies, B.S.J. Angiopoietin-like 4 directs uptake of dietary fat away from adipose during fasting. Mol. Metab. 2017, 6, 809-818. [CrossRef]

198. Hansen, J.S.; Plomgaard, P. Circulating follistatin in relation to energy metabolism. Mol. Cell. Endocrinol. 2016, 433, 87-93. [CrossRef]

199. Amthor, H.; Nicholas, G.; McKinnell, I.; Kemp, C.F.; Sharma, M.; Kambadur, R.; Patel, K. Follistatin complexes Myostatin and antagonises Myostatin-mediated inhibition of myogenesis. Dev. Biol. 2004, 270, 19-30. [CrossRef]

200. Tao, R.; Wang, C.; Stöhr, O.; Qiu, W.; Hu, Y.; Miao, J.; Dong, X.C.; Leng, S.; Stefater, M.; Stylopoulos, N.; et al. Inactivating hepatic follistatin alleviates hyperglycemia. Nat. Med. 2018, 24, 1058-1069. [CrossRef]

201. Lee, N.K.; Sowa, H.; Hinoi, E.; Ferron, M.; Ahn, J.D.; Confavreux, C.; Dacquin, R.; Mee, P.J.; McKee, M.D.; Jung, D.Y.; et al. Endocrine regulation of energy metabolism by the skeleton. Cell 2007, 130, 456-469. [CrossRef]

202. Kord-Varkaneh, H.; Djafarian, K.; Khorshidi, M.; Shab-Bidar, S. Association between serum osteocalcin and body mass index: A systematic review and meta-analysis. Endocrine 2017, 58, 24-32. [CrossRef]

203. Kunutsor, S.K.; Apekey, T.A.; Laukkanen, J.A. Association of serum total osteocalcin with type 2 diabetes and intermediate metabolic phenotypes: Systematic review and meta-analysis of observational evidence. Eur. J. Epidemiol. 2015, 30, 599-614. [CrossRef] [PubMed]

204. Fatahi, S.; Ghaedi, E.; Mousavi, S.M.; Bawadi, H.; Rahmani, J.; Pezeshki, M.; Varkaneh, H.K. The association between osteocalcin and C-reactive protein; A relation of bone with inflammation: A systematic review and meta-analysis. Horm. Metab. Res. 2019, 51, 353-361. [CrossRef] [PubMed]

205. Pittas, A.G.; Harris, S.S.; Eliades, M.; Stark, P.; Dawson-Hughes, B. Association between serum osteocalcin and markers of metabolic phenotype. J. Clin. Endocrinol. Metab. 2009, 94, 827-832. [CrossRef] [PubMed]

206. Bao, Y.; Ma, X.; Yang, R.; Wang, F.; Hao, Y.; Dou, J.; He, H.; Jia, W. Inverse relationship between serum osteocalcin levels and visceral fat area in Chinese men. J. Clin. Endocrinol. Metab. 2013, 98, 345-351. [CrossRef]

207. Kanazawa, I.; Yamaguchi, T.; Yamauchi, M.; Yamamoto, M.; Kurioka, S.; Yano, S.; Sugimoto, T. Serum undercarboxylated osteocalcin was inversely associated with plasma glucose level and fat mass in type 2 diabetes mellitus. Osteoporos. Int. 2011, 22, 187-194. [CrossRef] [PubMed]

208. Kim, S.H.; Lee, J.W.; Im, J.A.; Hwang, H.J. Serum osteocalcin is related to abdominal obesity in Korean obese and overweight men. Clin. Chim. Acta 2010, 411, 2054-2057. [CrossRef]

209. Sabek, O.M.; Nishimoto, S.K.; Fraga, D.; Tejpal, N.; Ricordi, C.; Gaber, A.O. Osteocalcin effect on human $\beta$-cells mass and function. Endocrinology 2015, 156, 3137-3146. [CrossRef]

210. Ferron, M.; Wei, J.; Yoshizawa, T.; Del Fattore, A.; DePinho, R.A.; Teti, A.; Ducy, P.; Karsenty, G. Insulin signaling in osteoblasts integrates bone remodeling and energy metabolism. Cell 2010, 142, 296-308. [CrossRef]

211. Hill, H.S.; Grams, J.; Walton, R.G.; Liu, J.; Moellering, D.R.; Garvey, W.T. Carboxylated and uncarboxylated forms of osteocalcin directly modulate the glucose transport system and inflammation in adipocytes. Horm. Metab. Res. 2014, 46, 341-347. [CrossRef]

212. Ferron, M.; Hinoi, E.; Karsenty, G.; Ducy, P. Osteocalcin differentially regulates beta cell and adipocyte gene expression and affects the development of metabolic diseases in wild-type mice. Proc. Natl. Acad. Sci. USA 2008, 105, 5266-5270. [CrossRef] 
213. Ferron, M.; McKee, M.D.; Levine, R.L.; Ducy, P.; Karsenty, G. Intermittent injections of osteocalcin improve glucose metabolism and prevent type 2 diabetes in mice. Bone 2012, 50, 568-575. [CrossRef] [PubMed]

214. Levinger, I.; Jerums, G.; Stepto, N.K.; Parker, L.; Serpiello, F.R.; McConell, G.K.; Anderson, M.; Hare, D.L.; Byrnes, E.; Ebeling, P.R.; et al. The effect of acute exercise on undercarboxylated osteocalcin and insulin sensitivity in obese men. J. Bone Miner. Res. 2014, 29, 2571-2576. [CrossRef] [PubMed]

215. Gupte, A.A.; Sabek, O.M.; Fraga, D.; Minze, L.J.; Nishimoto, S.K.; Liu, J.Z.; Afshar, S.; Gaber, L.; Lyon, C.J.; Gaber, A.O.; et al. Osteocalcin protects against nonalcoholic steatohepatitis in a mouse model of metabolic syndrome. Endocrinology 2014, 155, 4697-4705. [CrossRef] [PubMed]

216. Ouchi, N.; Parker, J.L.; Lugus, J.J.; Walsh, K. Adipokines in inflammation and metabolic disease. Nat. Rev. Immunol. 2011, 11, 85-97. [CrossRef]

217. Bouassida, A.; Chamari, K.; Zaouali, M.; Feki, Y.; Zbidi, A.; Tabka, Z. Review on leptin and adiponectin responses and adaptations to acute and chronic exercise. Br. J. Sports Med. 2010, 44, 620-630. [CrossRef]

218. Yu, N.; Ruan, Y.; Gao, X.; Sun, J. Systematic review and meta-analysis of randomized, controlled trials on the effect of exercise on serum leptin and adiponectin in overweight and obese individuals. Horm. Metab. Res. 2017, 49, 164-173. [CrossRef]

219. Fedewa, M.V.; Hathaway, E.D.; Ward-Ritacco, C.L.; Williams, T.D.; Dobbs, W.C. The Effect of chronic exercise training on leptin: A systematic review and meta-analysis of randomized controlled trials. Sports Med. 2018, 48, 1437-1450. [CrossRef]

220. Becic, T.; Studenik, C.; Hoffmann, G. Exercise increases adiponectin and reduces leptin levels in prediabetic and diabetic individuals: Systematic review and meta-analysis of randomized controlled trials. Med. Sci. (Basel) 2018, 6, 97. [CrossRef]

221. Mantzoros, C.S.; Qu, D.; Frederich, R.C.; Susulic, V.S.; Lowell, B.B.; Maratos-Flier, E.; Flier, J.S. Activation of beta(3) adrenergic receptors suppresses leptin expression and mediates a leptin-independent inhibition of food intake in mice. Diabetes 1996, 45, 909-914. [CrossRef]

222. Zarkesh-Esfahani, H.; Pockley, A.G.; Wu, Z.; Hellewell, P.G.; Weetman, A.P.; Ross, R.J. Leptin indirectly activates human neutrophils via induction of TNF-alpha. J. Immunol. 2004, 172, 1809-1814. [CrossRef]

223. Tsiotra, P.C.; Boutati, E.; Dimitriadis, G.; Raptis, S.A. High insulin and leptin increase resistin and inflammatory cytokine production from human mononuclear cells. Biomed. Res. Int. 2013, 2013, 487081. [CrossRef] [PubMed]

224. Rodríguez, A.; Becerril, S.; Méndez-Giménez, L.; Ramírez, B.; Sáinz, N.; Catalán, V.; Gómez-Ambrosi, J.; Frühbeck, G. Leptin administration activates irisin-induced myogenesis via nitric oxide-dependent mechanisms, but reduces its effect on subcutaneous fat browning in mice. Int. J. Obes. (Lond.) 2015, 39, 397-407. [CrossRef] [PubMed]

225. Pan, W.W.; Myers, M.G. Leptin and the maintenance of elevated body weight. Nat. Rev. Neurosci. 2018, 19, 95-105. [CrossRef] [PubMed]

226. Francisco, V.; Pino, J.; Campos-Cabaleiro, V.; Ruiz-Fernández, C.; Mera, A.; Gonzalez-Gay, M.A.; Gómez, R.; Gualillo, O. Obesity, fat mass and immune system: Role for leptin. Front. Physiol. 2018, 9, 640. [CrossRef]

227. Hayashino, Y.; Jackson, J.L.; Hirata, T.; Fukumori, N.; Nakamura, F.; Fukuhara, S.; Tsujii, S.; Ishii, H. Effects of exercise on C-reactive protein, inflammatory cytokine and adipokine in patients with type 2 diabetes: A meta-analysis of randomized controlled trials. Metabolism 2014, 63, 431-440. [CrossRef]

228. Hosogai, N.; Fukuhara, A.; Oshima, K.; Miyata, Y.; Tanaka, S.; Segawa, K.; Furukawa, S.; Tochino, Y.; Komuro, R.; Matsuda, M.; et al. Adipose tissue hypoxia in obesity and its impact on adipocytokine dysregulation. Diabetes 2007, 56, 901-911. [CrossRef]

229. Fasshauer, M.; Klein, J.; Neumann, S.; Eszlinger, M.; Paschke, R. Hormonal regulation of adiponectin gene expression in 3T3-L1 adipocytes. Biochem. Biophys. Res. Commun. 2002, 290, 1084-1089. [CrossRef]

230. Fang, H.; Judd, R.L. Adiponectin regulation and function. Compr. Physiol. 2018, 8, 1031-1063. [CrossRef]

231. Lee, H.; Tu, T.H.; Park, B.S.; Yang, S.; Kim, J.G. Adiponectin reverses the hypothalamic microglial inflammation during short-term exposure to fat-rich diet. Int. J. Mol. Sci. 2019, 20, 5738. [CrossRef]

232. Schwartz, D.R.; Lazar, M.A. Human resistin: Found in translation from mouse to man. Trends Endocrinol. Metab. 2011, 22, 259-265. [CrossRef]

233. Cobbold, C. Type 2 diabetes mellitus risk and exercise: Is resistin involved? J. Sports Med. Phys. Fit. 2019, 59, 290-297. [CrossRef] 
234. Bokarewa, M.; Nagaev, I.; Dahlberg, L.; Smith, U.; Tarkowski, A. Resistin, an adipokine with potent proinflammatory properties. J. Immunol. 2005, 174, 5789-5795. [CrossRef]

235. Tarkowski, A.; Bjersing, J.; Shestakov, A.; Bokarewa, M.I. Resistin competes with lipopolysaccharide for binding to toll-like receptor 4. J. Cell. Mol. Med. 2010, 14, 1419-1431. [CrossRef] [PubMed]

236. Thorogood, A.; Mottillo, S.; Shimony, A.; Filion, K.B.; Joseph, L.; Genest, J.; Pilote, L.; Poirier, P.; Schiffrin, E.L.; Eisenberg, M.J. Isolated aerobic exercise and weight loss: A systematic review and meta-analysis of randomized controlled trials. Am. J. Med. 2011, 124, 747-755. [CrossRef]

237. Cox, C.E. Role of physical activity for weight loss and weight maintenance. Diabetes Spectr. 2017, 30, 157-160. [CrossRef] [PubMed]

238. Sallam, N.; Laher, I. Exercise modulates oxidative stress and inflammation in aging and cardiovascular diseases. Oxid. Med. Cell. Longev. 2016, 2016, 7239639. [CrossRef]

239. Reilly, S.M.; Saltiel, A.R. Adapting to obesity with adipose tissue inflammation. Nat. Rev. Endocrinol. 2017, 13, 633. [CrossRef] [PubMed]

240. Magkos, F.; Mohammed, B.S.; Patterson, B.W.; Mittendorfer, B. Free fatty acid kinetics in the late phase of postexercise recovery: Importance of resting fatty acid metabolism and exercise-induced energy deficit. Metabolism 2009, 58, 1248-1255. [CrossRef]

241. Petridou, A.; Siopi, A.; Mougios, V. Exercise in the management of obesity. Metabolism 2019, 92, $163-169$. [CrossRef]

242. Foright, R.M.; Presby, D.M.; Sherk, V.D.; Kahn, D.; Checkley, L.A.; Giles, E.D.; Bergouignan, A.; Higgins, J.A.; Jackman, M.R.; Hill, J.O; et al. Is regular exercise an effective strategy for weight loss maintenance? Physiol. Behav. 2018, 188, 86-93. [CrossRef]

243. Dragano, N.R.; Haddad-Tovolli, R.; Velloso, L.A. Leptin, neuroinflammation and obesity. Front. Horm. Res. 2017, 48, 84-96. [CrossRef] [PubMed]

244. Kalin, S.; Heppner, F.L.; Bechmann, I.; Prinz, M.; Tschop, M.H.; Yi, C.X. Hypothalamic innate immune reaction in obesity. Nat. Rev. Endocrinol. 2015, 11, 339-351. [CrossRef] [PubMed]

245. Zhao, J.; Tian, Y.; Xu, J.; Liu, D.; Wang, X.; Zhao, B. Endurance exercise is a leptin signaling mimetic in hypothalamus of Wistar rats. Lipids Health Dis. 2011, 10, 225. [CrossRef]

246. Xu, B.; Xie, X. Neurotrophic factor control of satiety and body weight. Nat. Rev. Neurosci. 2016, 17, $282-292$. [CrossRef] [PubMed]

247. Islam, H.; Townsend, L.K.; McKie, G.L.; Medeiros, P.J.; Gurd, B.J.; Hazell, T.J. Potential involvement of lactate and interleukin-6 in the appetite-regulatory hormonal response to an acute exercise bout. J. Appl. Physiol. (1985) 2017, 123, 614-623. [CrossRef] [PubMed]

248. Odegaard, J.I.; Chawla, A. Pleiotropic actions of insulin resistance and inflammation in metabolic homeostasis. Science 2013, 339, 172-177. [CrossRef] [PubMed]

249. Zheng, G.; Qiu, P.; Xia, R.; Lin, H.; Ye, B.; Tao, J.; Chen, L. Effect of aerobic exercise on inflammatory markers in healthy middle-aged and older adults: A systematic review and meta-analysis of randomized controlled trials. Front. Aging Neurosci. 2019, 11, 98. [CrossRef] [PubMed]

250. Cabral-Santos, C.; de Lima Junior, E.A.; Fernandes, I.M.D.C.; Pinto, R.Z.; Rosa-Neto, J.C.; Bishop, N.C.; Lira, F.S. Interleukin-10 responses from acute exercise in healthy subjects: A systematic review. J. Cell. Physiol 2019, 234, 9956-9965. [CrossRef]

251. Reshef, L.; Olswang, Y.; Cassuto, H.; Blum, B.; Croniger, C.M.; Kalhan, S.C.; Tilghman, S.M.; Hanson, R.W. Glyceroneogenesis and the triglyceride/fatty acid cycle. J. Biol. Chem. 2003, 278, 30413-30416. [CrossRef]

252. Krief, S.; Lönnqvist, F.; Raimbault, S.; Baude, B.; Van Spronsen, A.; Arner, P.; Strosberg, A.D.; Ricquier, D.; Emorine, L.J. Tissue distribution of beta 3-adrenergic receptor mRNA in man. J. Clin. Investig. 1993, 91, 344-349. [CrossRef]

253. Hopps, E.; Canino, B.; Caimi, G. Effects of exercise on inflammation markers in type 2 diabetic subjects. Acta Diabetol. 2011, 48, 183-189. [CrossRef] [PubMed]

254. Santos-Alvarez, J.; Goberna, R.; Sánchez-Margalet, V. Human leptin stimulates proliferation and activation of human circulating monocytes. Cell. Immunol. 1999, 194, 6-11. [CrossRef] [PubMed]

255. Kaser, S.; Kaser, A.; Sandhofer, A.; Ebenbichler, C.F.; Tilg, H.; Patsch, J.R. Resistin messenger-RNA expression is increased by proinflammatory cytokines in vitro. Biochem. Biophys. Res. Commun. 2003, 309, 286-290. [CrossRef] [PubMed] 
256. Díaz-Delfín, J.; Hondares, E.; Iglesias, R.; Giralt, M.; Caelles, C.; Villarroya, F. TNF- $\alpha$ represses $\beta$-Klotho expression and impairs FGF21 action in adipose cells: Involvement of JNK1 in the FGF21 pathway. Endocrinology 2012, 153, 4238-4245. [CrossRef]

257. Sakamoto, T.; Takahashi, N.; Sawaragi, Y.; Naknukool, S.; Yu, R.; Goto, T.; Kawada, T. Inflammation induced by RAW macrophages suppresses UCP1 mRNA induction via ERK activation in 10T1/2 adipocytes. Am. J. Physiol. Cell Physiol. 2013, 304, C729-C738. [CrossRef]

258. Goto, T.; Naknukool, S.; Yoshitake, R.; Hanafusa, Y.; Tokiwa, S.; Li, Y.; Sakamoto, T.; Nitta, T.; Kim, M.; Takahashi, N.; et al. Proinflammatory cytokine interleukin-1 $\beta$ suppresses cold-induced thermogenesis in adipocytes. Cytokine 2016, 77, 107-114. [CrossRef]

259. Trøseid, M.; Lappegård, K.T.; Claudi, T.; Damås, J.K.; Mørkrid, L.; Brendberg, R.; Mollnes, T.E. Exercise reduces plasma levels of the chemokines MCP-1 and IL-8 in subjects with the metabolic syndrome. Eur. Heart J. 2004, 25, 349-355. [CrossRef]

260. Alizadeh, H.; Safarzade, A. High intensity intermittent training induces anti-inflammatory cytokine responses and improves body composition in overweight adolescent boys. Horm. Mol. Biol. Clin. Investig. 2019, 39. [CrossRef]

261. Opal, S.M.; DePalo, V.A. Anti-inflammatory cytokines. Chest 2000, 117, 1162-1172. [CrossRef]

262. Nguyen, K.D.; Qiu, Y.; Cui, X.; Goh, Y.P.; Mwangi, J.; David, T.; Mukundan, L.; Brombacher, F.; Locksley, R.M.; Chawla, A. Alternatively activated macrophages produce catecholamines to sustain adaptive thermogenesis. Nature 2011, 480, 104-108. [CrossRef]

263. de Oliveira, M.F.A.; Talvani, A.; Rocha-Vieira, E. IL-33 in obesity: Where do we go from here? Inflamm. Res. 2019, 68, 185-194. [CrossRef] [PubMed]

264. Liu, Y.; Liu, S.X.; Cai, Y.; Xie, K.L.; Zhang, W.L.; Zheng, F. Effects of combined aerobic and resistance training on the glycolipid metabolism and inflammation levels in type 2 diabetes mellitus. J. Phys. Ther. Sci. 2015, 27, 2365-2371. [CrossRef]

265. Page, M.M.; Johnson, J.D. Mild suppression of hyperinsulinemia to treat obesity and insulin resistance. Trends Endocrinol. Metab. 2018, 29, 389-399. [CrossRef] [PubMed]

266. Templeman, N.M.; Skovsø, S.; Page, M.M.; Lim, G.E.; Johnson, J.D. A causal role for hyperinsulinemia in obesity. J. Endocrinol. 2017, 232, R173-R183. [CrossRef] [PubMed]

267. Erion, K.A.; Corkey, B.E. Hyperinsulinemia: A cause of obesity? Curr. Obes. Rep. 2017, 6, 178-186. [CrossRef]

268. Lustig, R.H. Which comes first? The obesity or the insulin? The behavior or the biochemistry? J. Pediatr. 2008, 152, 601-602. [CrossRef]

269. Mehran, A.E.; Templeman, N.M.; Brigidi, G.S.; Lim, G.E.; Chu, K.Y.; Hu, X.; Botezelli, J.D.; Asadi, A.; Hoffman, B.G.; Kieffer, T.J.; et al. Hyperinsulinemia drives diet-induced obesity independently of brain insulin production. Cell Metab. 2012, 16, 723-737. [CrossRef]

270. Boucher, J.; Mori, M.A.; Lee, K.Y.; Smyth, G.; Liew, C.W.; Macotela, Y.; Rourk, M.; Bluher, M.; Russell, S.J.; Kahn, C.R. Impaired thermogenesis and adipose tissue development in mice with fat-specific disruption of insulin and IGF-1 signalling. Nat. Commun. 2012, 3, 902. [CrossRef]

271. Katic, M.; Kennedy, A.R.; Leykin, I.; Norris, A.; McGettrick, A.; Gesta, S.; Russell, S.J.; Bluher, M.; Maratos-Flier, E.; Kahn, C.R. Mitochondrial gene expression and increased oxidative metabolism: Role in increased lifespan of fat-specific insulin receptor knock-out mice. Aging Cell 2007, 6, 827-839. [CrossRef] [PubMed]

272. Hron, B.M.; Ebbeling, C.B.; Feldman, H.A.; Ludwig, D.S. Relationship of insulin dynamics to body composition and resting energy expenditure following weight loss. Obesity (Silver Spring) 2015, 23, 2216-2222. [CrossRef] [PubMed]

273. Sampath Kumar, A.; Maiya, A.G.; Shastry, B.A.; Vaishali, K.; Ravishankar, N.; Hazari, A.; Gundmi, S.; Jadhav, R. Exercise and insulin resistance in type 2 diabetes mellitus: A systematic review and meta-analysis. Ann. Phys. Rehabil. Med. 2019, 62, 98-103. [CrossRef] [PubMed]

274. Zheng, S.L.; Li, Z.Y.; Song, J.; Liu, J.M.; Miao, C.Y. Metrnl: A secreted protein with new emerging functions. Acta Pharmacol. Sin. 2016, 37, 571-579. [CrossRef] [PubMed]

275. Almendro, V.; Fuster, G.; Busquets, S.; Ametller, E.; Figueras, M.; Argilés, J.M.; López-Soriano, F.J. Effects of IL-15 on rat brown adipose tissue: Uncoupling proteins and PPARs. Obesity (Silver Spring) 2008, 16, $285-289$. [CrossRef] [PubMed] 
276. Otero-Díaz, B.; Rodríguez-Flores, M.; Sánchez-Muñoz, V.; Monraz-Preciado, F.; Ordoñez-Ortega, S.; Becerril-Elias, V.; Baay-Guzmán, G.; Obando-Monge, R.; García-García, E.; Palacios-González, B.; et al. Exercise induces white adipose tissue browning across the weight spectrum in humans. Front. Physiol. 2018, 9, 1781. [CrossRef]

277. Zuriaga, M.A.; Fuster, J.J.; Gokce, N.; Walsh, K. Humans and mice display opposing patterns of "browning" gene expression in visceral and subcutaneous white adipose tissue depots. Front. Cardiovasc. Med. 2017, 4, 27. [CrossRef]

278. Chung, K.J.; Chatzigeorgiou, A.; Economopoulou, M.; Garcia-Martin, R.; Alexaki, V.I.; Mitroulis, I.; Nati, M.; Gebler, J.; Ziemssen, T.; Goelz, S.E.; et al. A self-sustained loop of inflammation-driven inhibition of beige adipogenesis in obesity. Nat. Immunol. 2017, 18, 654-664. [CrossRef]

279. DiPietro, L.; Stachenfeld, N.S. Exercise treatment of obesity. In Endotext [Internet]; Feingold, K.R., Anawalt, B., Boyce, A., Eds.; MDText.com, Inc.: South Dartmouth, MA, USA, 2000. Available online: https://www.ncbi. nlm.nih.gov/books/NBK278961/ (accessed on 9 March 2020).

280. Plomgaard, P.; Weigert, C. Do diabetes and obesity affect the metabolic response to exercise? Curr. Opin. Clin. Nutr. Metab. Care 2017, 20, 294-299. [CrossRef]

281. Zhang, H.J.; Zhang, X.F.; Ma, Z.M.; Pan, L.L.; Chen, Z.; Han, H.W.; Han, C.K.; Zhuang, X.J.; Lu, Y.; Li, X.J.; et al. Irisin is inversely associated with intrahepatic triglyceride contents in obese adults. J. Hepatol. 2013, 59, 557-562. [CrossRef]

282. Verheggen, R.J.; Maessen, M.F.; Green, D.J.; Hermus, A.R.; Hopman, M.T.; Thijssen, D.H. A systematic review and meta-analysis on the effects of exercise training versus hypocaloric diet: Distinct effects on body weight and visceral adipose tissue. Obes. Rev. 2016, 17, 664-690. [CrossRef]

283. Blundell, J.E.; Gibbons, C.; Caudwell, P.; Finlayson, G.; Hopkins, M. Appetite control and energy balance: Impact of exercise. Obes. Rev. 2015, 16 (Suppl. 1), 67-76. [CrossRef]

284. Swift, D.L.; Johannsen, N.M.; Lavie, C.J.; Earnest, C.P.; Church, T.S. The role of exercise and physical activity in weight loss and maintenance. Prog. Cardiovasc. Dis. 2014, 56, 441-447. [CrossRef]

285. He, Z.; Tian, Y.; Valenzuela, P.L.; Huang, C.; Zhao, J.; Hong, P.; Yin, S.; Lucia, A. Myokine/Adipokine response to "Aerobic" exercise: Is it just a matter of exercise load? Front. Physiol. 2019, 10, 691. [CrossRef] [PubMed]

286. Gaich, G.; Chien, J.Y.; Fu, H.; Glass, L.C.; Deeg, M.A.; Holland, W.L.; Kharitonenkov, A.; Bumol, T.; Schilske, H.K.; Moller, D.E. The effects of LY2405319, an FGF21 analog, in obese human subjects with type 2 diabetes. Cell Metab. 2013, 18, 333-340. [CrossRef] [PubMed]

287. Lin, Z.; Tian, H.; Lam, K.S.; Lin, S.; Hoo, R.C.; Konishi, M.; Itoh, N.; Wang, Y.; Bornstein, S.R.; Xu, A.; et al. Adiponectin mediates the metabolic effects of FGF21 on glucose homeostasis and insulin sensitivity in mice. Cell Metab. 2013, 17, 779-789. [CrossRef] [PubMed]

288. Alex, M.D. 20 YEARS OF LEPTIN: Leptin in common obesity and associated disorders of metabolism. J. Endocrinol. 2014, 223, T71-T81. [CrossRef]

(C) 2020 by the authors. Licensee MDPI, Basel, Switzerland. This article is an open access article distributed under the terms and conditions of the Creative Commons Attribution (CC BY) license (http://creativecommons.org/licenses/by/4.0/). 